Universidad de Lima

Escuela de Ingeniería

Carrera de Ingeniería de Sistemas

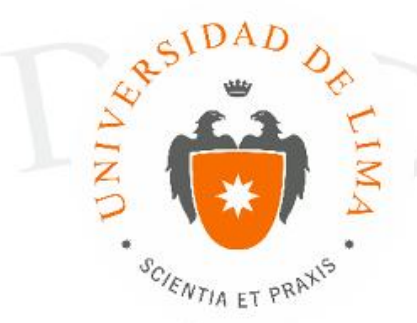

\title{
MODELO DE GESTION DE INCIDENTES, APLICANDO ITIL v3.0 EN UN ORGANISMO DEL ESTADO PERUANO
}

\author{
Tesis para optar el Título Profesional de Ingeniero de Sistemas
}

\section{Alexander Alberto Loayza Uyehara \\ Código 19952433}

\author{
Asesor \\ Mario David Pérez Narrea
}

Lima - Perú

Octubre de 2015 


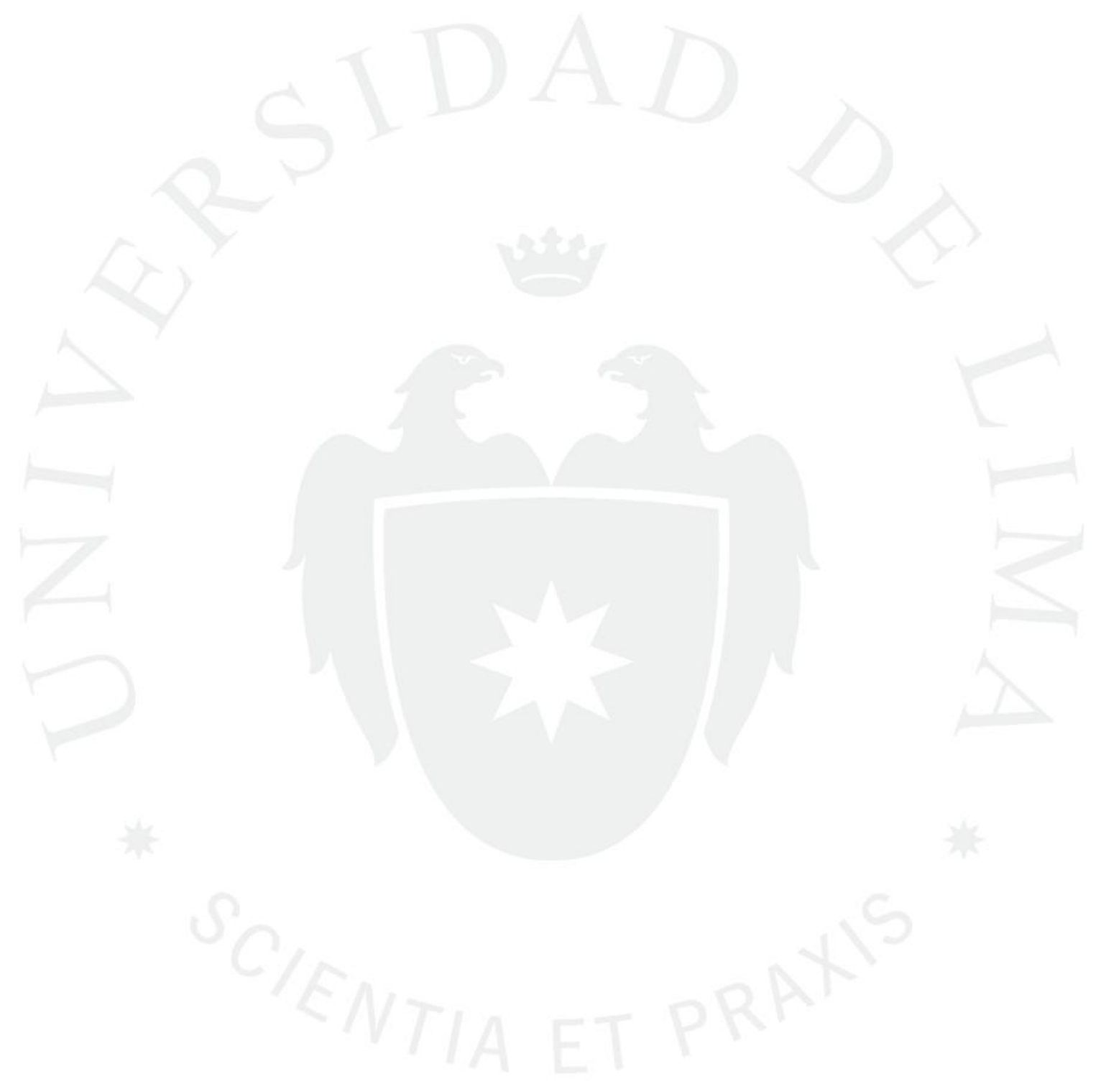




\section{MODELO DE GESTION DE INCIDENTES, APLICANDO ITIL v3.0 EN UN ORGANISMO DEL ESTADO PERUANO}




\section{Dedicatoria}

El presente trabajo de investigación se lo dedico a mis padres, por darme la oportunidad de estudiar y ser una mejor persona.

Se lo dedico a mi esposa Cristina y a mis hijos Claudia y Bruno, porque son la razón de mi vida.

A mi abuela Alicia que descansa en paz y que siempre quiso lo mejor para mí.

$\mathrm{Y}$ a todas las personas que de una $\mathrm{u}$ otra manera me han apoyado y demostrado su interés por mí. 


\section{Agradecimiento}

Agradecer a Dios, sobre todas las cosas y por todas las bendiciones que me ha dado en la vida.

Agradezco de manera especial a todos los profesores que me guiaron $y$ formaron profesionalmente.

Al director de la entidad gubernamental, Carlos Cabrera Delgado-Neira que me permitió dar inicio al presente trabajo de investigación.

A mi asesor, el profesor Mario David Pérez Narrea, por orientarme y apoyarme en la elaboración de mi tesis.

$\mathrm{Y}$ a todas esas personas que de una $\mathrm{u}$ otra manera me estuvieron apoyando y dando fuerzas para seguir adelante. 


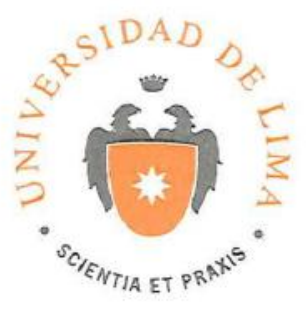

Autorización de Publicación

Tesis

$\mathrm{X} \quad$ Trabajo de Investigación
(Marcar según corresponda)

\section{Identificación del Autor}

\begin{tabular}{|l|l|}
\hline Apellidos, nombres: LOAYZA UYEHARA ALEXANDER ALBERTO \\
\hline Dirección: Solitario de Sayán 781 dpto. 401 San Miguel \\
\hline Teléfono: $\quad 999-555-860 \quad$ Correo electrónico: alexloayza@gmail.com \\
\hline
\end{tabular}

2. Identificación de la Tesis/Trabajo de Investigación

Bachiller $\mathrm{X} \quad$ Licenciado $\square \quad$ Magister $\square$

Facultad: SISTEMAS

Carrera: Ingeniería de Sistemas

Título o Grado al que opta: Ingeniero de Sistemas

Profesor asesor: Mario Pérez Narrea

Título:

MODELO DE GESTION DE INCIDENTES,APLICANDO ITIL V3.0 EN UN ORGANISMO DEL ESTADO PERUANO

\section{Autorización de Publicación}

A través de este medio autorizo a la Universidad de Lima publicar las versiones impresa y electrónica del presente trabajo en la Biblioteca y en el repositorio de la página web de la Universidad. Esta autorización se extiende a las páginas relacionadas o enlaces oficiales de la Universidad de Lima.

El autor reconoce la originalidad de su trabajo y mantiene la propiedad intelectual del contenido de la publicación. Además, es libre de editarla nuevamente en su forma presente o adaptarla.

El autor tiene conocimiento que, por disposición legal, copias del presente trabajo serán remitidas a la SUNEDU.

$$
\begin{aligned}
& \text { Lima, } 7 \text { de Marzo de } 2016 \\
& \text { Alexander leyza U.P. }
\end{aligned}
$$

Firma.

Apellidos, Nombres: Loayza Uyehara Alexander Alberto

DNI N: 10295147

* En caso de ser dos o más autores se deberá llenar un formato por cada uno. 


\section{RESUMEN}

El trabajo de investigación está orientado a proponer un Modelo de Gestión de Incidentes, aplicando las buenas prácticas de ITIL v3.0, con el propósito de mejorar la calidad de los servicios de tecnologías de la información (TI) ofrecidos por la entidad en estudio.

La aplicación del nuevo modelo de gestión de incidentes implicó la formalización del proceso de gestión de incidentes, de tal manera que se modificaron algunos procedimientos que se especifican en el presente trabajo. La aplicación del modelo propuesto estuvo respaldada por la alta gerencia que permitió organizar mejor al personal en el proceso de gestión de incidentes, permitiéndoles capacitarse y entender la aplicación del modelo propuesto.

De los resultados de la aplicación del modelo, se puede observar que la atención de incidentes y la satisfacción del usuario final mejoraron. La creación de una línea base de indicadores permitirá hacer los ajustes necesarios al modelo con el objetivo de buscar la mejora continua del modelo. 


\section{DESCRIPTORES TEMÁTICOS}

- Gestión de incidentes

- ITIL

- PIDE 


\section{TABLA DE CONTENIDO}

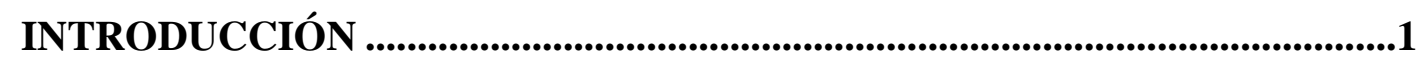

CAPÍTULO I: FORMULACIÓN DEL PROBLEMA .............................................2

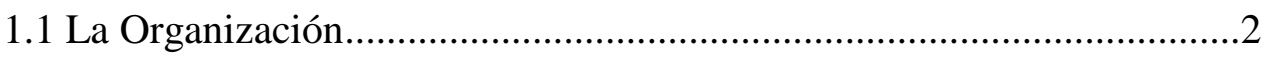

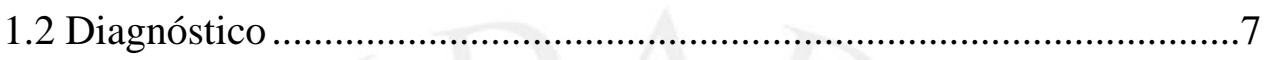

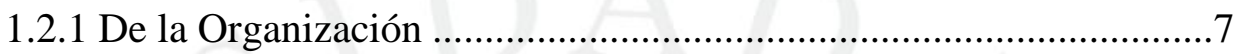

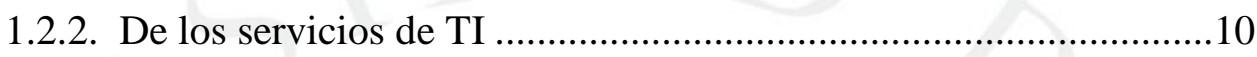

1.2.3. Del proceso de Atención de Incidentes..........................................11

1.3 Objetivo general y objetivos específicos ...........................................16

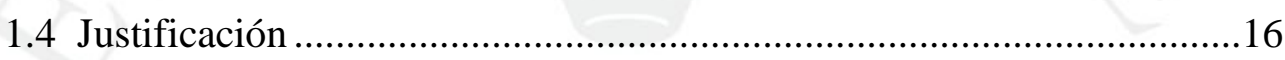

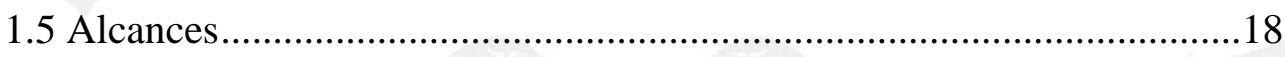

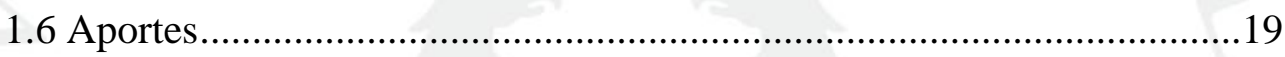

CAPÍTULO II: REVISION DE LITERATURA .................................................21

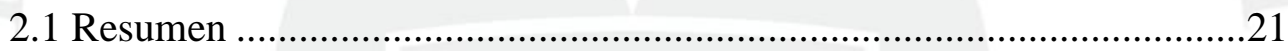

CAPÍTULO III: MARCO TEORICO ................................................................24

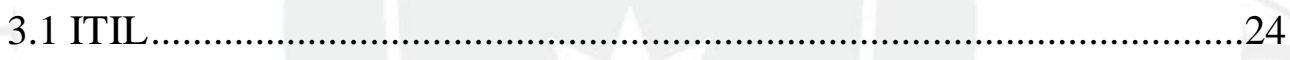

3.2 Proceso de Gestión de Incidentes ......................................................29

CAPITULO IV: ANÁLISIS DEL SISTEMA DE GESTIÓN.................................32

4.1. Sistema de Gestión de la Entidad Gubernamental.................................36

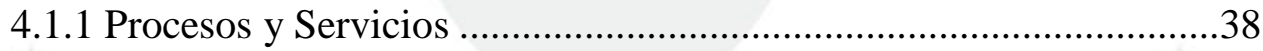

4.1.2 Análisis del Área de TI respecto al proceso de atención de incidentes . .45

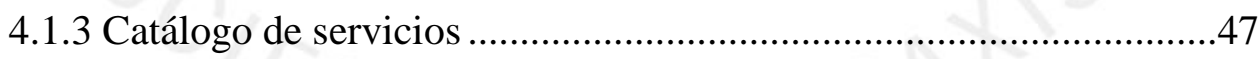

4.2 Estadísticas de gestión de incidentes ...................................................53

4.3 Diagnóstico de la gestión actual de incidentes .......................................60

CAPÍTULO V: DISEÑO E IMPLEMENTACIÓN DE LA PROPUESTA .......62

5.1 Estrategia del Servicio del Modelo Propuesto ........................................62

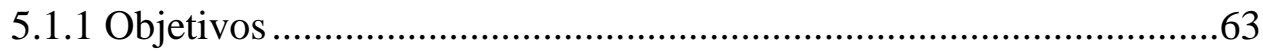

5.1.2 Estrategias a implementar ........................................................63

5.2 Diseño del Servicio del Modelo Propuesto ............................................66 
5.2.1 Identificación de Roles para la descripción de Roles . .66

5.2.2 Indicadores propuestos del modelo.............................................68

5.2.3 Criterios de cambio entre niveles de impacto .................................71

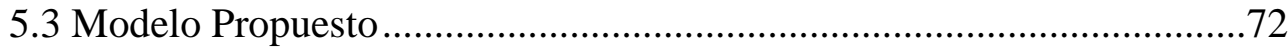

5.3.1 Relación del Modelo propuesto con otros procesos y funciones ......84

5.4 Consideraciones sobre la Implementación del Modelo propuesto ..........88

CAPÍTULO VI: RESULTADOS DE LA INVESTIGACION..............................90

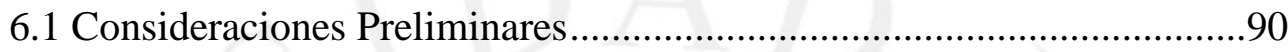

6.2 Resultados del modelo de Gestión de Incidentes .................................92

6.2.1 Total de Incidentes Registrados ................................................92

6.2.2 Incidentes repetidos solucionados con métodos conocidos ............93

6.2.3 Tiempos mínimos y máximos para resolver un incidente ...............94

6.2.4 Número de Incidentes agrupados por tipo de prioridad ...................95

6.2.5 Incidentes por mes de acuerdo a equipos de trabajo y prioridad ......96

6.2.6 Cantidad de Incidentes agrupados por Categoría............................99

6.2.7 Número de incidentes que desembocaron en problemas ..................100

6.3 Encuesta de Satisfacción...................................................................101

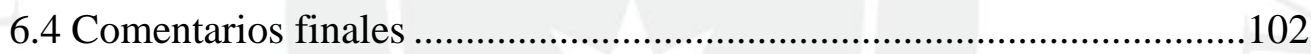

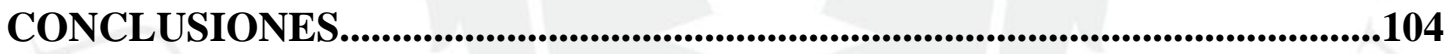

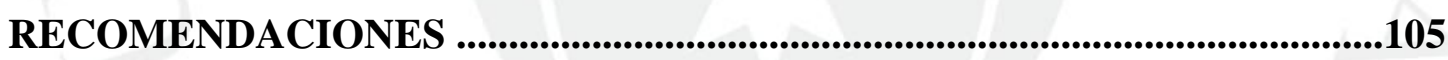

GLOSARIO DE TÉRMINOS.............................................................................106

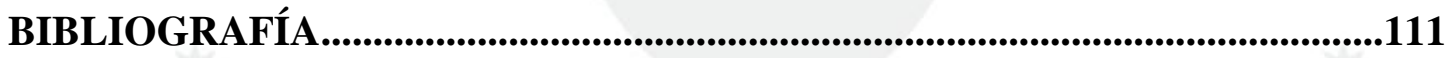

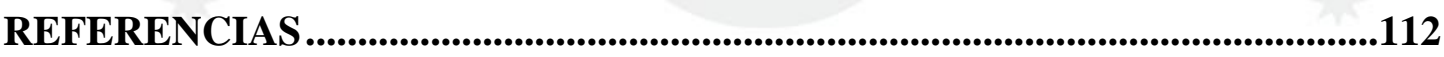




\section{ÍNDICE DE FIGURAS}

Figura 1.1 Organigrama Sectorial a la cual pertenece la Entidad en Estudio ...................6

Figura 1.2 Política nacional de Gobierno Electrónico ................................................. 8

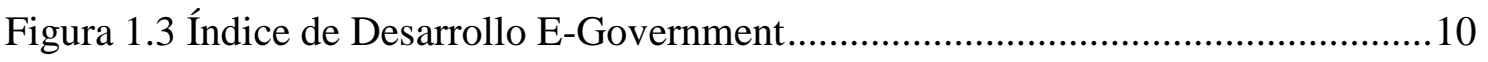

Figura 1. 4 Flujo de proceso: modelo actual de Gestión de Incidentes .......................... 13

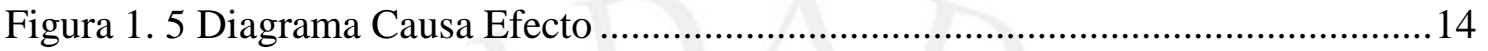

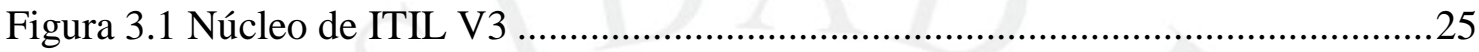

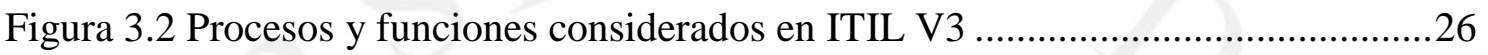

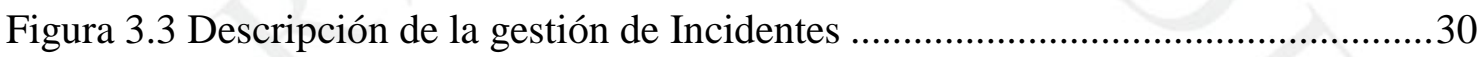

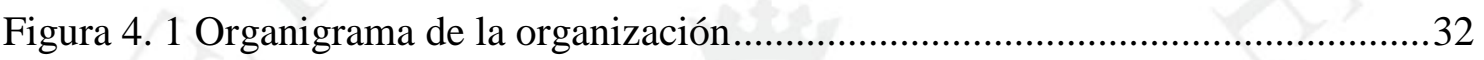

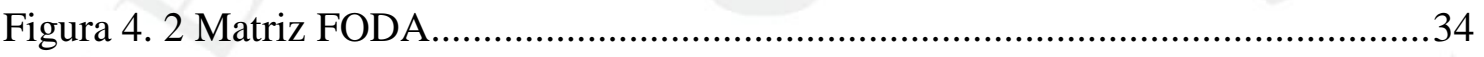

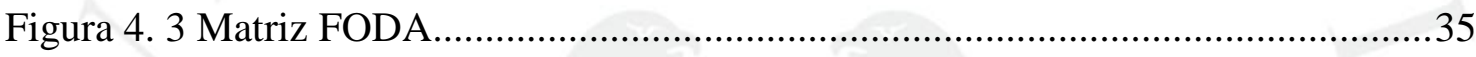

Figura 4. 4 Modelo de gestión de la Entidad Gubernamental........................................37

Figura 4. 5 Jerarquía de Documentos del Sistema de Gestión..........................................37

Figura 4. 6 Esquema de funcionamiento de la PIDE ....................................................43

Figura 4. 7 Mapa de Procesos de la Entidad Gubernamental ........................................44

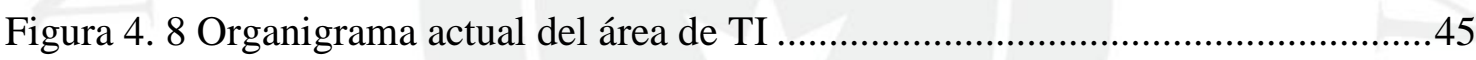

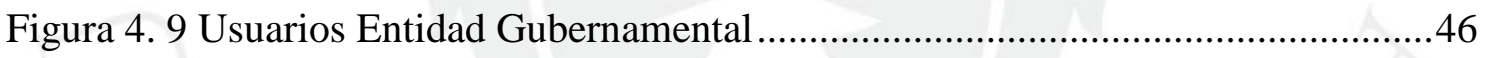

Figura 4. 10 Catálogo de servicios de la Entidad Gubernamental ..................................48

Figura 4. 11 Catálogo de servicios técnicos y activos de servicios ...............................51

Figura 4. 12 Servicios de TI - Modelo de madurez de gestión .......................................52

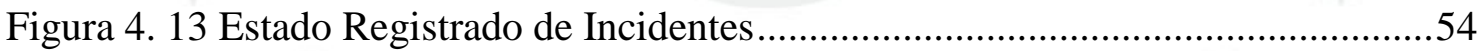

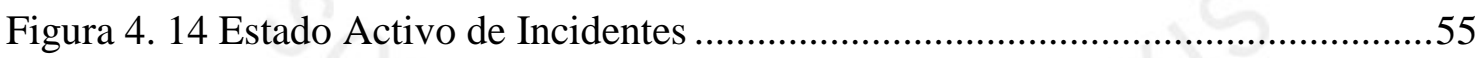

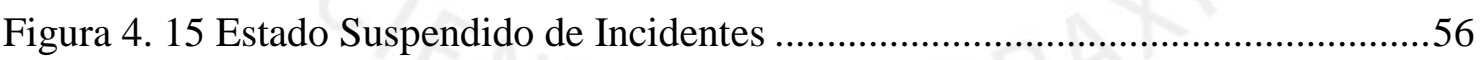

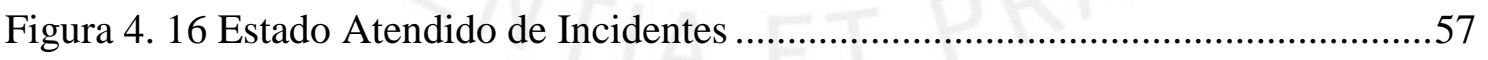

Figura 4. 17 Estado Cerrado de Incidentes ...................................................................58

Figura 4. 18 Histograma de Incidentes por Estado y mes............................................59

Figura 5. 1 Nuevo Organigrama para el área de TI (TO-BE) .........................................6

Figura 5. 2 Flujo de Proceso propuesto para la verificación diaria de servidores ...........74

Figura 5. 3 Flujo de Proceso propuesto para pruebas diarias de Servicios SMS ............75

Figura 5. 4 Flujo de Proceso propuesto para la verificación de usuarios bloqueados ....76 
Figura 5. 5 Modelo para la Gestión de Incidentes en la Entidad Gubernamental .77

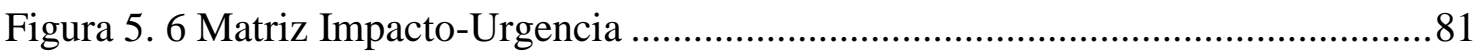

Figura 5. 7 Impacto del Modelo Propuesto con la función de mesa de servicios............84

Figura 5. 8 Estructura de Mesa de Servicio para la organización...................................8

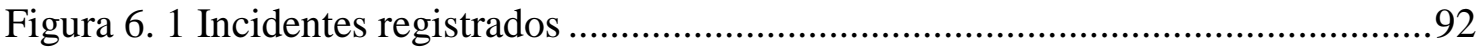

Figura 6. 2 Incidentes agrupados por algunos métodos utilizados ..............................93

Figura 6. 3 Incidentes agrupados por tipo de prioridad ..............................................95

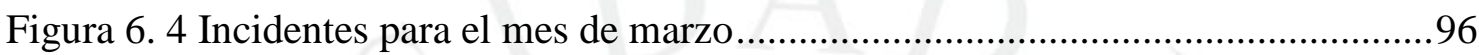

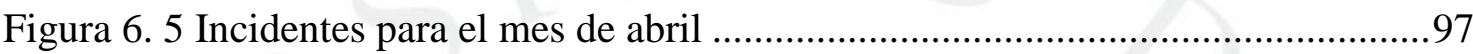

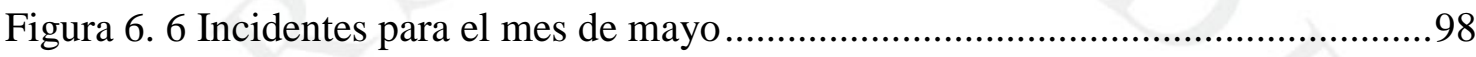

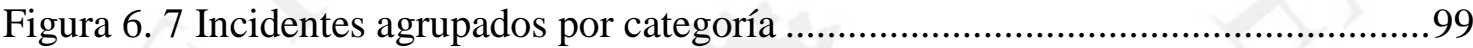

Figura 6. 8 Incidentes que desembocaron en problemas ........................................... 100

Figura 6. 9 Resultado de la encuesta realizada a los usuarios ..................................102 


\section{ÍNDICE DE TABLAS}

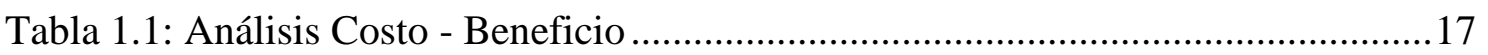

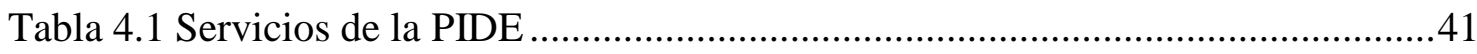

Tabla 4.2 Usuarios de la Entidad Gubernamental .......................................................47

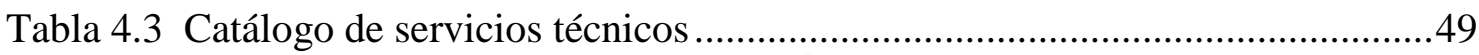

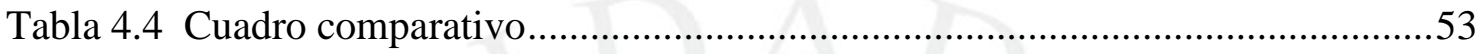

Tabla 4.5 Estado de Incidentes del último trimestre del año 2014...............................53

Tabla 5. 1: Propuesta de Capacitaciones.........................................................................65

Tabla 5. 2: Roles en la Gestión de Incidentes .................................................................67

Tabla 5. 3: Matriz RACI para la Gestión de Incidentes en la Entidad Gubernamental ..68

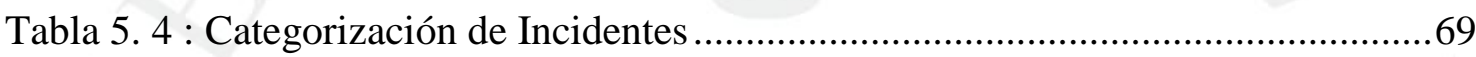

Tabla 5. 5: Descripción de los niveles impacto propuesto........................................... 70

Tabla 5. 6: Definición de tiempos de respuesta ............................................................ 71

Tabla 5. 7: Estados de Incidentes del Modelo Propuesto ...............................................83

Tabla 5. 8: Tipo de estructuras organizacionales para Mesa de Servicio .......................87

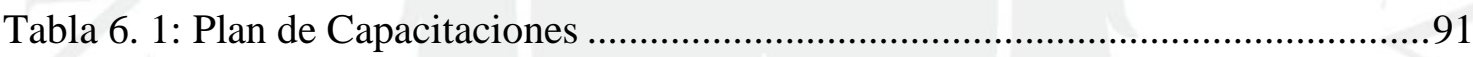

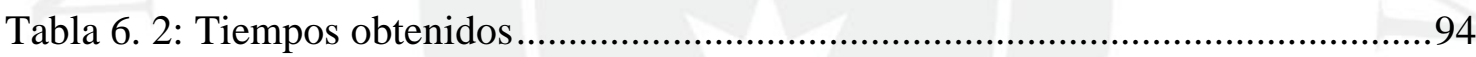

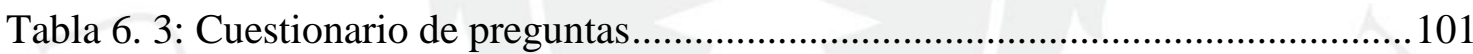




\section{ÍNDICE DE ANEXOS}

Anexo 1: Acuerdo de Servicios para la Atención de Incidentes.................................. 115

Anexo 2: Formato de Modelo en Excel ............................................................. 117

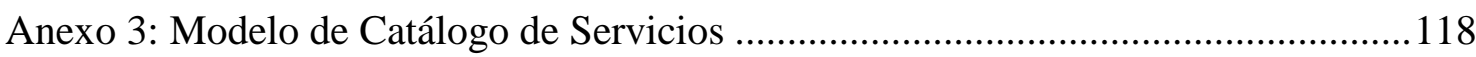

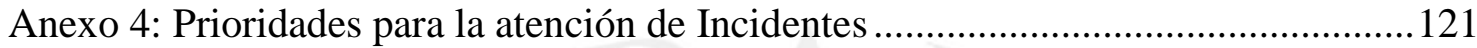

Anexo 5: Formato para la creación Acuerdos de Nivel Operativo (OLA) ....................122

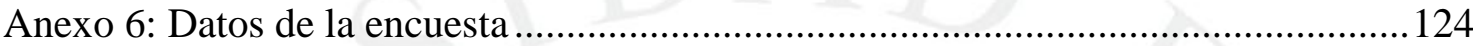




\section{INTRODUCCIÓN}

En el presente trabajo de investigación, se diseñará y analizará un modelo de gestión de incidentes, aplicando ITIL v3.0 para una entidad que brinda servicios de TI a las diversas entidades del estado. En este trabajo de investigación nos centraremos en las operaciones de soporte tecnológico más importantes, buscando maximizar la eficacia de los servicios de tecnologías de información con procesos de cambios consolidados, integrados y automatizados.

La entidad en estudio hace los esfuerzos para mantener el servicio que brinda en óptimas condiciones pero existen diversos factores que perjudican dichos esfuerzos como son: los factores externos (políticos en mayor grado), la alta rotación de personal, condiciones técnicas limitantes y la falta de mejores prácticas estandarizadas. Esto tiene como consecuencia que sea difícil reponer el servicio tan pronto como sea posible y minimizar el impacto desfavorable sobre las operaciones de la entidad. A través del modelo propuesto, se busca superar estos problemas y entregar un nivel óptimo de los servicios así como también una alta disponibilidad de los mismos. 


\section{CAPÍTULO I: FORMULACIÓN DEL PROBLEMA}

\subsection{La Organización}

El Gobierno Electrónico es la prestación de los servicios del estado al ciudadano a través del uso de las TIC, para mejorar la relación del Estado con el ciudadano y posibilitar una mejor prestación de los servicios. De esta manera se puede lograr un gobierno cercano y abierto; esto es, transparente, participativo, colaborativo e inclusivo, así como eficiente, de acceso fácil y rápido, interoperable, integrado y seguro.

La entidad en estudio es la Oficina Nacional de Gobierno Electrónico e Informático (ONGEI), órgano técnico especializado de la Presidencia del Consejo de Ministros, que es el ente rector del Sistema Nacional de Informática encargado de coordinar y supervisar la integración funcional de los sistemas informáticos del Estado Peruano, promover el desarrollo de sistemas de uso común, proponer la Estrategia Nacional de Gobierno Electrónico, coordinar y supervisar su implementación, así como coordinar y supervisar el desarrollo de los portales de las entidades de la Administración Pública. De ahora en adelante se le denominará la Entidad Gubernamental.

Entre sus actividades permanentes se encuentran las vinculadas a la normatividad informática, la seguridad de la información, el desarrollo de proyectos emblemáticos en Tecnologías de la Información y la Comunicación (TIC), brindar asesoría técnica e informática a las entidades públicas, así como, ofrecer capacitación y difusión en temas de Gobierno Electrónico y la modernización y descentralización del Estado.

"La organización, asimismo, se encarga de la administración de diversos portales del Estado, entre los que se encuentran el Portal del Estado Peruano (PEP), portal de mayor jerarquía a nivel de Estado, que se constituye en el sistema interactivo 
de información a los ciudadanos a través de Internet; el Portal de Servicios al Ciudadano y Empresas (PSCE), el Portal de la Comisión de Desarrollo de la Sociedad de la Información (CODESI), entre otros” (ONGEI, 2014).

Este organismo de estado, se encarga de normar, coordinar, integrar y promover el desarrollo de la actividad informática en la Administración Pública (DS No 066-2003-PCM, DS Nº67-2003-PCM).

\section{- Misión}

"Ser una organización descentralizada autónoma reconocida por su perfil innovador que promueve la ingeniería y la transformación del Estado para brindar mejores servicios a los ciudadanos y empresas a través del buen uso de las tecnologías de la información y de las comunicaciones”. (ONGEI, 2014)

\section{- Visión}

Ayudar a las entidades del Estado a mejorar sus resultados de gobierno electrónico, a través del desarrollo de directrices sobre el uso de TI, del fortalecimiento de la estrategia de gobierno electrónico, del alineamiento operativo y la optimización de procesos y de las alianzas con el sector empresarial, la academia e instituciones intergubernamentales de función similar al organismo de estado. Resultados que permitan generar valor a los administrados y desarrollar la sociedad de información y conocimiento en el Perú (ONGEI, 2014).

\section{- Funciones}

De acuerdo al Reglamento de Organización y Funciones de la Presidencia del Consejo de Ministros (PCM) sus funciones son:

a. Actuar como ente rector del Sistema Nacional de Informática para lo cual emite las directivas o lineamientos que permitan la aplicación de dicho Sistema. 
b. Proponer la Estrategia Nacional de Gobierno Electrónico, así como coordinar y supervisar su Implementación.

c. Desarrollar acciones orientadas a la consolidación y desarrollo del Sistema Nacional de informática y supervisar el cumplimiento de la normativa correspondiente.

d. Coordinar y supervisar la integración funcional de los sistemas informáticos del Estado y promover el desarrollo de sistemas y aplicaciones de uso común en las entidades de la Administración Pública.

e. Coordinar y supervisar el desarrollo de los portales de las entidades de la Administración Pública para facilitar la interrelación de las entidades entre sí y de éstas con el ciudadano, con el fin de establecer la ventanilla única de atención.

f. Administrar el Portal del Estado Peruano.

g. Proponer los lineamientos de la política de contrataciones electrónicas del Sistema Electrónico de Adquisiciones y Contrataciones del Estado - SEACE.

h. Brindar asistencia técnica a las entidades de la Administración Pública para la implementación de proyectos tecnológicos en materia de su competencia.

i. Formular propuestas para impulsar el proceso de desarrollo e innovación tecnológica para la mejora de la gestión pública y modernización del Estado promoviendo la integración tecnológica.

j. Aprobar los estándares tecnológicos para asegurar las medidas de seguridad de la información en las entidades de la Administración Pública.

k. Fomentar una instancia de encuentro con representantes de la Administración Pública y del Sector Privado, con el fin de coordinar y potenciar los distintos esfuerzos tendientes a optimizar un mejor aprovechamiento de las nuevas tecnologías aplicadas a la modernización de la gestión pública. 
1. Emitir opinión técnica respecto de las autógrafas, proyectos de Ley y proyectos normativos que la Alta Dirección someta a su consideración. Dicha opinión versará respecto de las competencias que le han sido asignadas.

m. Emitir opinión técnica en materia de su competencia.

n. Evaluar y proponer para aprobación la normativa para cautelar la confidencialidad, autenticidad e integridad de la información producida por los órganos del Sistema Nacional de Informática.

o. Evaluar y presentar para aprobación el Plan Operativo Anual, Presupuesto Analítico de Gastos y el Cuadro de Necesidades de Bienes y Servicios del órgano especializado del gobierno.

p. Proponer la contratación de personal para el órgano especializado del gobierno.

q. Guardar absoluta confidencialidad sobre las actividades, documentos e información relacionada con el ejercicio de su cargo.

r. Velar por la adecuada conservación y uso racional de los bienes a su cargo.

s. Desempeñar otras funciones afines que les sean asignadas por el Despacho Ministerial.

La Entidad Gubernamental presenta el siguiente organigrama sectorial mostrado en la figura 1.1 
Figura 1.1

Organigrama Sectorial a la cual pertenece la Entidad Gubernamental

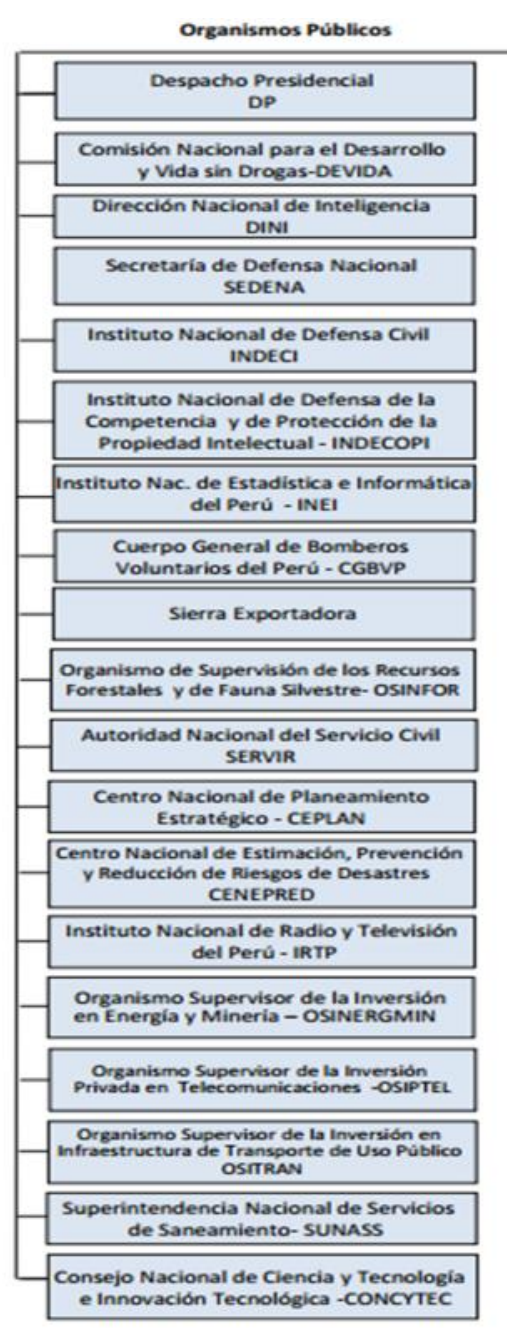

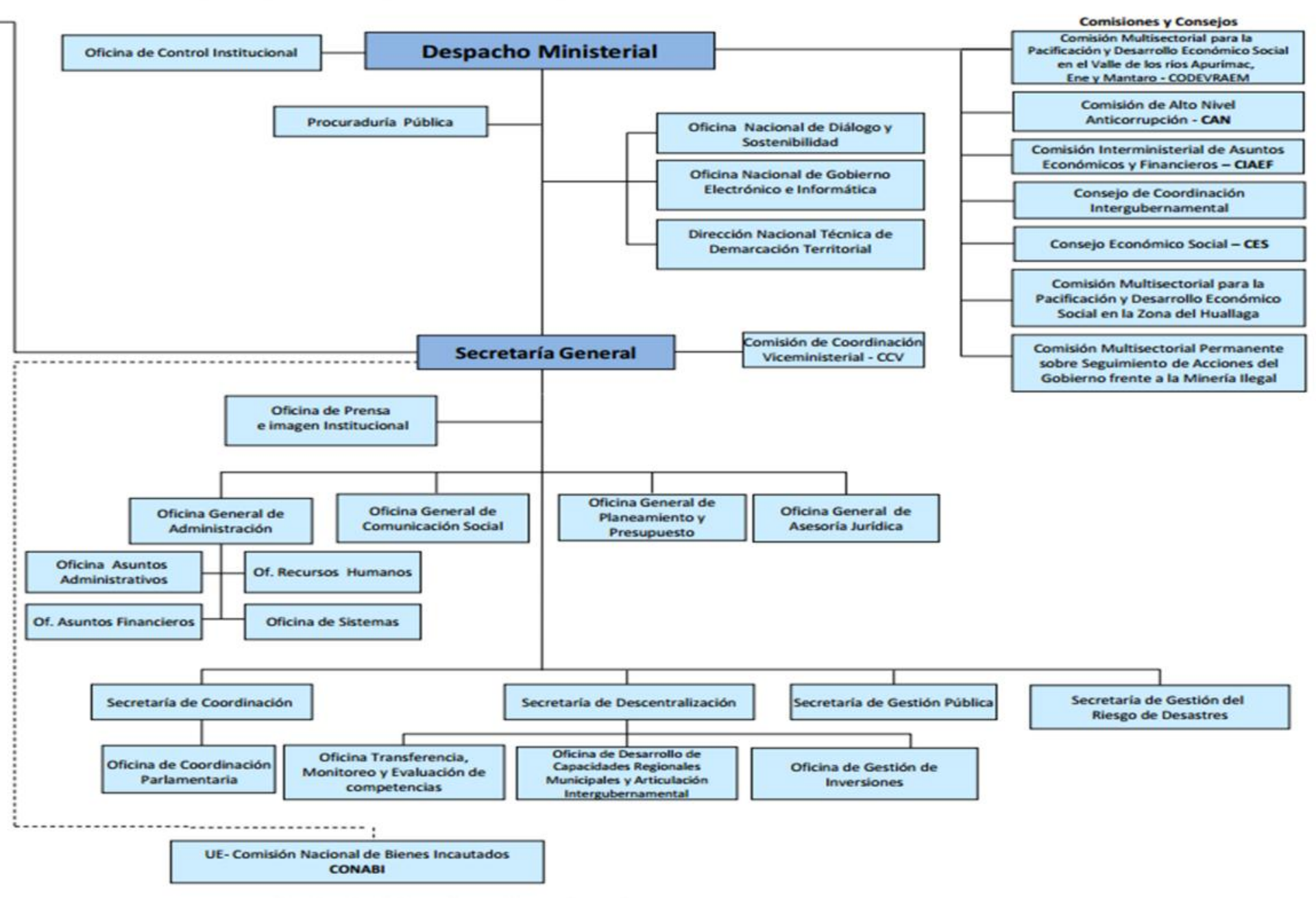

Fuente: www.pcm.gob.pe 


\subsection{Diagnóstico}

\subsubsection{De la Organización}

La Política Nacional de Gobierno Electrónico es el principal instrumento de gestión para el desarrollo y despliegue del gobierno electrónico a fin de mejorar la competitividad, el acercamiento del Estado a los ciudadanos, la participación ciudadana, la transparencia, la gestión pública y la seguridad de la información.

"La Política Nacional de Gobierno Electrónico se basa en lineamientos y objetivos de los principales planes nacionales como la Agenda Digital Peruana 2.0, Agenda de Competitividad 2012 -2013, el Plan Bicentenario: El Perú hacia el 2021 y la Política Nacional de Modernización de la Gestión Pública" (Manual de Gestión v1.0 2014:13-14).

La política del órgano especializado del gobierno también se alinea con la nueva tendencia internacional sobre gobierno abierto (Transparencia, Colaboración y Participación) que busca que sea promovida en todas las entidades del Estado. EL órgano especializado del gobierno como ente rector se encuentra afiliado a la Alianza para el Gobierno Abierto (Open Government Partnership) desde el año 2012.

Los objetivos de la política se describen en la figura 1.2. 
Figura 1.2

Política nacional de Gobierno Electrónico

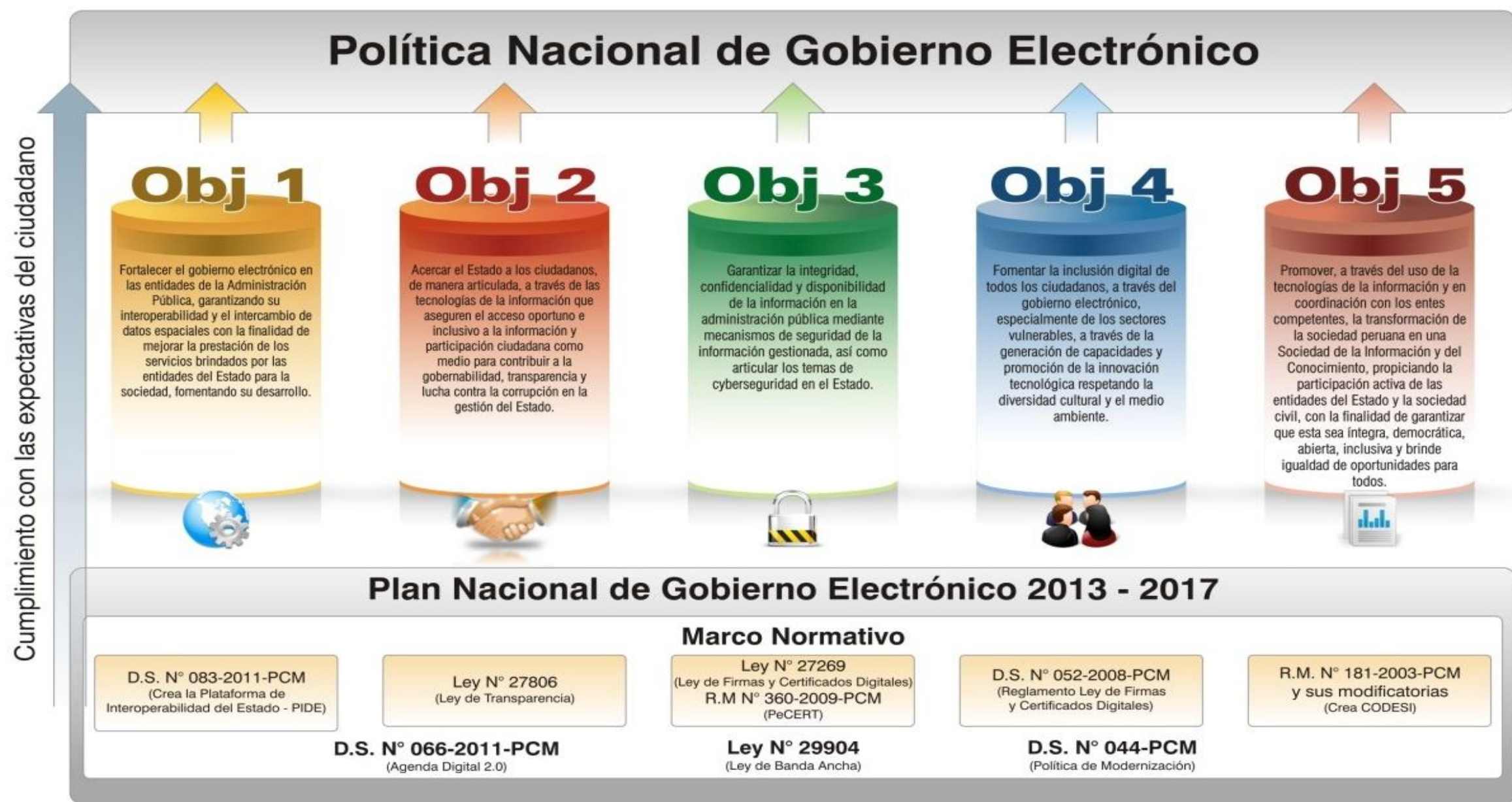

Fuente: Manual de Gestión Entidad Gubernamental v1.0 
Las Naciones Unidas a través de su División de Administración Pública y Gestión del Desarrollo (DPADM) realizan una clasificación de los países en materia de Gobierno Electrónico, cada país tiene suscrito tiene un ente que lo representa y de los cuales obtiene los indicadores, tomando como referencia 3 aspectos básicos:

- $\quad$ Índice de Servicio en Línea

- $\quad$ Índice de Infraestructura en Telecomunicaciones

- $\quad$ Índice de Capital Humano.

La Entidad Gubernamental como ente rector es clasificada de acuerdo a estos aspectos y según el ranking del 2014 se encuentra en el puesto 72 de la clasificación, ubicándose por debajo del nivel promedio de acuerdo a la figura 1.3. El órgano especializado del gobierno busca mejorar en estos aspectos como entidad, y parte de su mejora debe comenzar internamente. La Política Nacional de Gobierno Electrónico 2013-2017 busca alinearse a estos parámetros internacionales, para ello debe mejorar la entrega de sus servicios de TI a las entidades del estado y a la ciudadanía en general. 
Figura 1.3

Índice de Desarrollo E-Government

\begin{tabular}{|c|c|c|c|c|c|}
\hline Rank & Country & $E G D I$ & $\begin{array}{c}\text { Online Service } \\
\text { Component }\end{array}$ & $\begin{array}{c}\text { Telecomm. Infrastructure } \\
\text { Component }\end{array}$ & $\begin{array}{l}\text { Human Capital } \\
\text { Component }\end{array}$ \\
\hline 164 & Mozambique & 0.2384 & 0.3150 & 0.0545 & 0.3457 \\
\hline 175 & Myanmar & 0.1869 & 0.0236 & 0.0084 & 0.5288 \\
\hline 117 & Namibia & 0.3880 & 0.3228 & 0.2719 & 0.5693 \\
\hline 145 & Nauru & 0.2776 & 0.0551 & 0.2159 & 0.5617 \\
\hline 165 & Nepal & 0.2344 & 0.1575 & 0.1684 & 0.3774 \\
\hline 5 & Netherlands & 0.8897 & 0.9291 & 0.8175 & 0.9224 \\
\hline 9 & New Zealand & 0.8644 & 0.8425 & 0.7506 & 1.0000 \\
\hline 147 & Nicaragua & 0.2759 & 0.0945 & 0.1692 & 0.5639 \\
\hline 191 & Niger & 0.0946 & 0.1260 & 0.0385 & 0.1192 \\
\hline 141 & Nigeria & 0.2929 & 0.3071 & 0.1905 & 0.3811 \\
\hline 13 & Norway & 0.8357 & 0.7559 & 0.8133 & 0.9380 \\
\hline 48 & Oman & 0.6273 & 0.7323 & 0.4873 & 0.6624 \\
\hline 158 & Pakistan & 0.2580 & 0.3228 & 0.1174 & 0.3337 \\
\hline 108 & Palau & 0.4415 & 0.1654 & 0.3592 & 0.7999 \\
\hline 77 & Panama & 0.5747 & 0.3701 & 04571 & 07455 \\
\hline 188 & Papua New Guinea & 0.1203 & 0.0079 & 0.0530 & 0.3000 \\
\hline 122 & Paraguay & 0.3740 & 0.2283 & 0.2236 & 0.6700 \\
\hline 72 & Peru & 0.5435 & 0.6299 & 0.2718 & 0.7289 \\
\hline 95 & Philippines & 0.4768 & 0.4803 & 0.2451 & 0.7051 \\
\hline 42 & Poland & 0.6482 & 0.5433 & 0.5618 & 0.8396 \\
\hline 37 & Portugal & 0.6900 & 0.6378 & 0.6094 & 0.8227 \\
\hline
\end{tabular}

Fuente: Naciones Unidas CEPAL, 2014

\subsubsection{De los servicios de TI}

De acuerdo al análisis realizado en la Entidad Gubernamental se pudo identificar los siguientes puntos:

- Poca transparencia y lentitud en atender a ciudadanos, esto debido a la falta de un sistema de respaldo y atención de servicios adecuados, que permitan a las entidades del estado mantener un nivel de servicio óptimo en el uso de tecnología de información.

- Inadecuado soporte de hardware; según el análisis realizado, existen en la entidad equipos que necesitan ser cambiados para entregar mejores servicios a los usuarios internos y a las diversas entidades públicas.

- Falta de estrategia coherente del Estado. El cambio frecuente de Directores hace que las estrategias pierdan rumbo en el camino. En 10 años de creación han existido más de 10 directores.

- Insuficiencia de mecanismos de coordinación. 
- Falta de normas específicas en el uso de TI en el Estado, alineadas a estándares internacionales.

- Baja disponibilidad de TI.

- Poca integración de sistemas del estado.

- Falta de sensibilización y capacitación de funcionarios.

\subsubsection{Del proceso de Atención de Incidentes}

La atención de incidentes actualmente no cuenta con un proceso estandarizado de guía, lo cual hace que se presenten irregularidades en el ingreso de los mismos por los siguientes motivos:

- El incidente no siempre ingresa por donde debería ser el primer punto de contacto. Se han detectado muchos casos que son atendidos directamente por el equipo de soporte inclusive sin ser registrados.

- El incidente ingresa en muchos casos previamente por trámite documentario lo que hace que se genere retrasos en la atención generando insatisfacción en los usuarios. Es observado que este medio de ingreso sirve como medio de justificación a las entidades del estado para el incumplimiento normativo (POI, ENRIAP).

- Los roles y responsabilidades no están definidos adecuadamente originando que en muchos casos los equipos de trabajo realicen tareas que no les corresponde con respecto a la atención de incidentes.

- Duplicidad en el registro de incidentes, durante la investigación se detectó que un mismo incidente se registró varias veces, generando conflictos con el usuario, esto repercute en la imagen de la Entidad Gubernamental, además hace que las estadísticas no entreguen datos exactos. 
a) Ambiente Tecnológico

Los incidentes son registrados actualmente en archivo compartido de Excel como se muestra en el anexo 2, esto se debe a que el sistema anterior (Bitácora) no permite gestionar los nuevos incidentes para los nuevos servicios creados. A este archivo de registro, tienen acceso los 3 equipos de soporte (Mesa de ayuda, Soporte TI, Seguridad de la Información).

El actual sistema a medida no cuenta con mantenimiento, además de no contar los archivos fuente para su modificación. Este sistema se sigue utilizando exclusivamente para el registro de inventario, la infraestructura de TI y documentación sobre problemas de TI resueltos.

\section{b) Gestión de Incidentes}

Tiene por objetivo restablecer el servicio normal de la operación de los portales web, servicios SOA e infraestructura tecnológica lo más rápido posible. Debido al aumento de servicios más sofisticados, el modelo actual muestra deficiencias en la atención de incidentes. De acuerdo a la información recopilada en algunos casos los incidentes no son atendidos ni registrados por la mesa de ayuda, lo que hace que el control de los incidentes no sea el adecuado.

A continuación en la figura 1.4 se muestra el modelo actual para la gestión de incidentes en la Entidad Gubernamental. 
Figura 1. 4

Flujo de proceso: modelo actual de Gestión de Incidentes

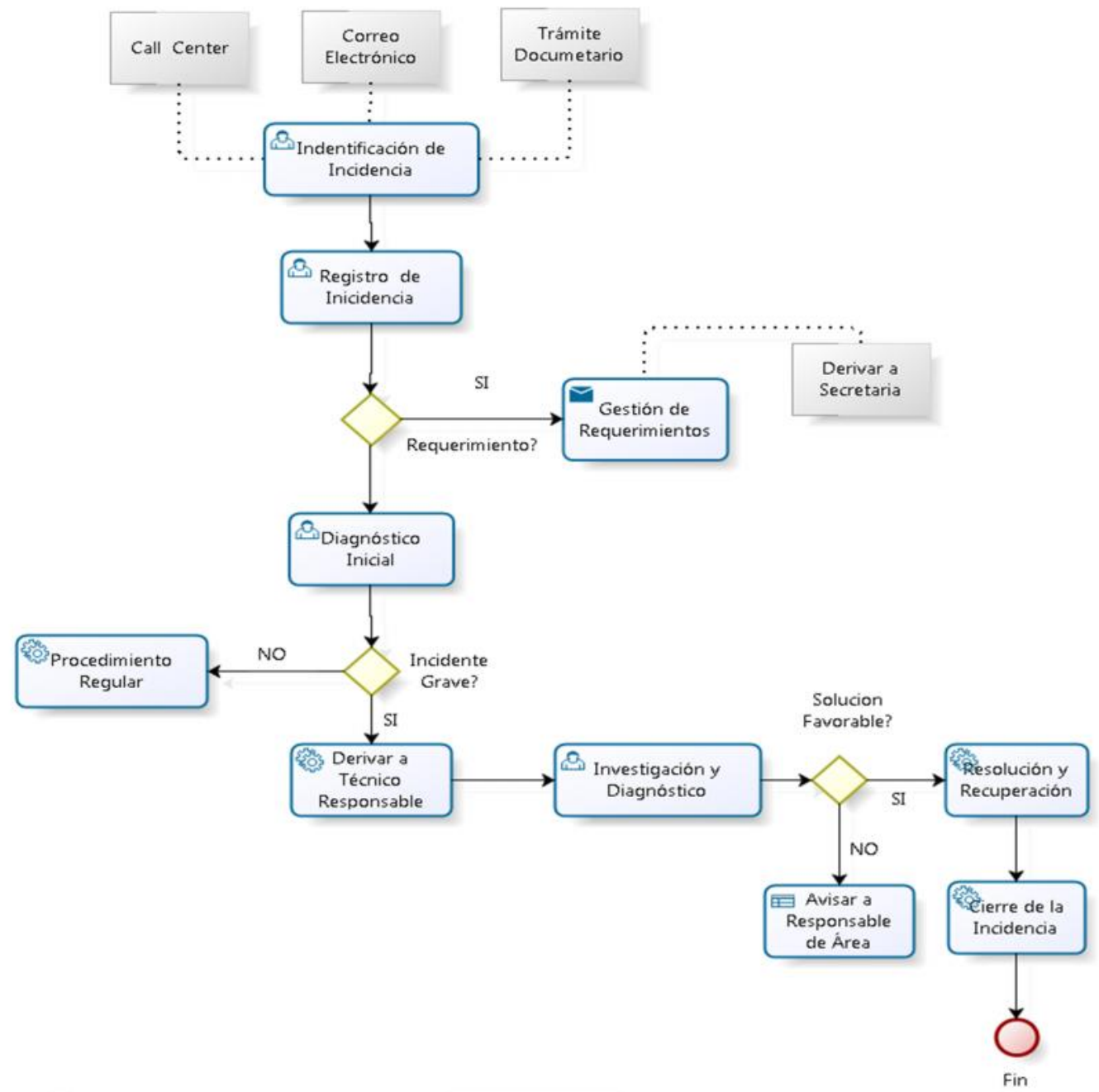

Fuente: Manual de Gestión Entidad Gubernamental v1.0 


\section{c) Problemática del proceso}

Durante el involucramiento con la entidad se pudo determinar que la falta de calidad en los servicios de TI entregados por la entidad gubernamental se debieron a diversos factores. A continuación en la figura 1.5 mostraremos esta definición.

Figura 1.5

Diagrama Causa-Efecto de la problemática del proceso de atención de incidentes

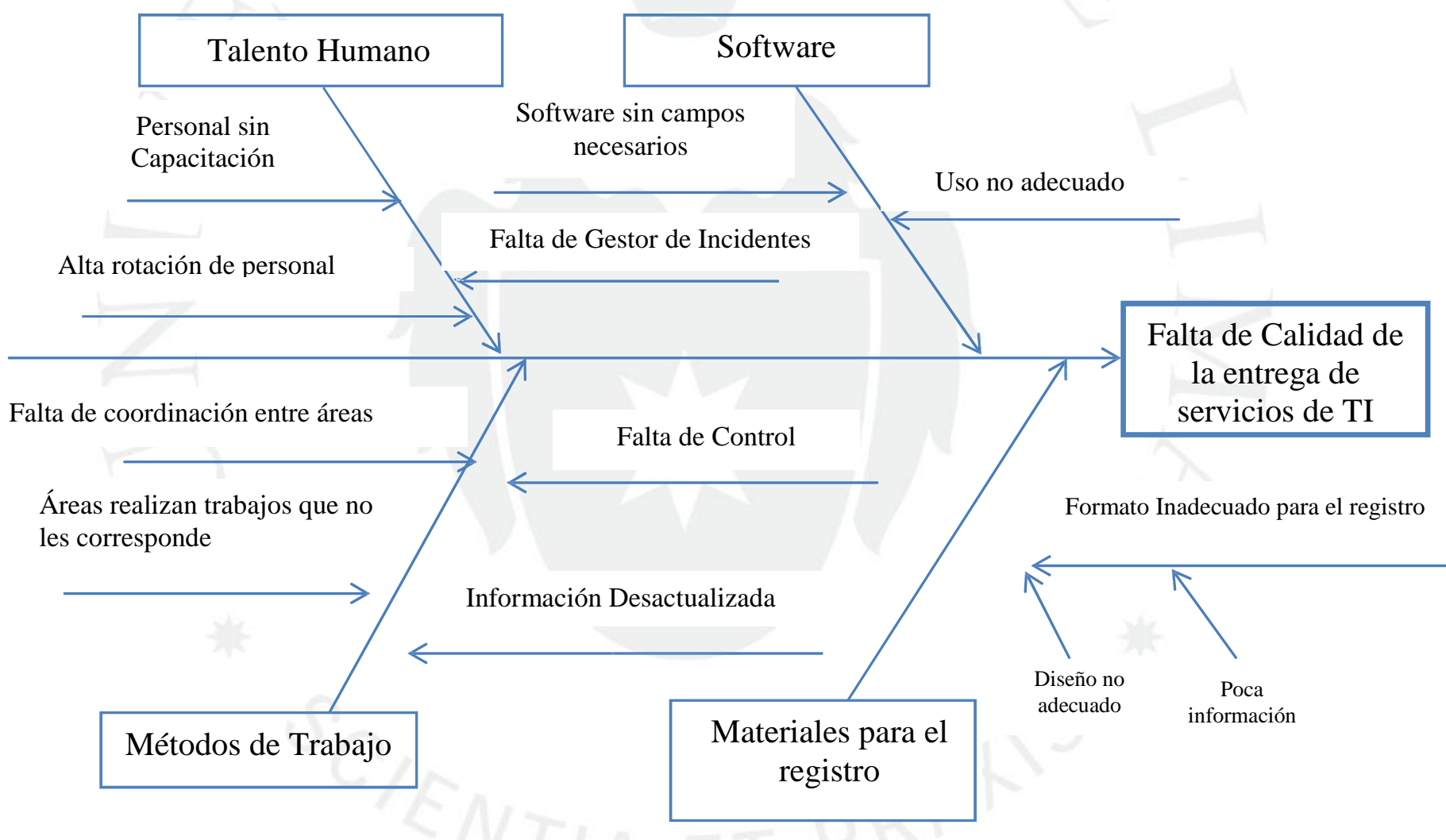

Fuente: Elaboración Propia.

Adicionalmente a estos problemas detectados en la entidad, se pudo identificar también que la función de mesa de servicios no estaba implementada de manera adecuada, pudiéndose detectar los siguientes problemas: 
i) Actualmente no se cuenta con un historial de incidentes de los servicios atendidos, publicados y puestos en marcha.

ii) No todos los servicios están amparados bajo la modalidad de SLA (Acuerdo de nivel de servicio).

iii) La entidad no cuenta con un plan de mejora (SIP) respecto a la gestión de incidentes.

iv) La entidad no cuenta con un acuerdo de nivel de operación (OLA) respecto a la gestión de incidentes.

v) No se rige por catálogo de servicios aunque esta exista.

vi) Canales de comunicación diversos que no permiten tener un solo punto de contacto.

Estos problemas detectados muestran también una deficiente gestión en la atención de los incidentes y de otros procesos que precisan ser mejorados; si bien es cierto que existe un modelo previo, este no se ajusta a las necesidades de la entidad. El presente trabajo se enfocará exclusivamente en uno de los puntos críticos para la entidad que es el proceso de Gestión de Incidentes.

En tal sentido el presente proyecto de investigación pretende formular un nuevo modelo de gestión de incidentes, basado en ITIL v3.0 que permita la inmediata restauración de servicios, manteniendo la continuidad de los servicios de los procesos de negocios en la Entidad Gubernamental. 


\subsection{Objetivo general y objetivos específicos}

\section{- Objetivo General}

Diseñar un nuevo modelo de Gestión de incidentes utilizando la Metodología ITIL V3.0, para la entidad gubernamental, de tal forma que se superen las deficiencias y la pérdida de calidad del servicio que actualmente presenta.

\section{- Objetivos Específicos}

- Desarrollar un modelo de gestión de incidentes, estructurado en módulos, utilizándola Metodología ITIL V3.0.

- Identificar el impacto en la mejora de la calidad de servicio de soporte a usuario por Incidentes, en la entidad gubernamental.

- Reducir el nivel de incumplimiento de los diversos SLA, elaborando los formatos de requerimientos de usuario.

\subsection{Justificación}

- El presente proyecto se justifica por la conveniencia de ajustar los procesos de gestión de incidentes a estándares mundialmente aceptados como ITIL v.3.0, que permitirá no solamente a la Entidad Gubernamental ofrecer un servicio idóneo a sus clientes, sino que servirá de modelo y referencia para cualquier proyecto similar en el sector público.

- El presente proyecto, se justifica por su impacto en la calidad de servicio, que brinde a los clientes internos de la entidad gubernamental, y a los clientes externos, que son las demás entidades del estado distribuidas a nivel nacional. El organismo brinda servicios en: asesoría técnica e informática, capacitación y difusión en temas de Gobierno Electrónico, la administración de diversos portales del Estado, etc. 
- Evaluación Económica:

- La Entidad Gubernamental depende del Plan y Presupuesto Anual aprobado por el MEF (Ministerio de Economía y Finanzas); este presupuesto tiene como finalidad hacer mejoras en temas de Gobierno Electrónico y debe ser sustentado.

- La no ejecución del gasto hará que el presupuesto del año siguiente disminuya, lo que perjudicará a la entidad en estudio en la ejecución de nuevos proyectos, siendo este un riesgo común en todas las entidades del estado. Los valores para cuantificar los montos serán expresados en dólares americanos.

- Los beneficios obtenidos se cuantifican con el ahorro por los conceptos a los que anualmente se incurre para cubrir las necesidades generadas por la deficiente atención a los usuarios.

- Los valores que se muestran para los beneficios son el promedio de gasto anual de los últimos 3 años (2012,2013 y 2014) por cada concepto.

Este análisis lo podemos apreciar en la tabla 1.1

Tabla 1.1 Análisis Costo - Beneficio

\begin{tabular}{|c|c|c|c|}
\hline \multicolumn{4}{|c|}{ Análisis Costo Beneficio } \\
\hline Detalle de Costo & Costo & Detalle de Beneficios & $\begin{array}{l}\text { Beneficios } \\
\text { Económicos }\end{array}$ \\
\hline Consultor Externo & $\$ 6800$ & $\begin{array}{l}\text { Incremento en el nivel de satisfacción } \\
\text { de los usuarios }\end{array}$ & $\$ 7800$ \\
\hline Personal Interno & $\$ 5000$ & $\begin{array}{l}\text { Incremento en el nivel cumplimiento } \\
\text { Normativo }\end{array}$ & $\$ 5000$ \\
\hline $\begin{array}{l}\text { Implementación de modelo } \\
\text { propuesto }\end{array}$ & $\$ 9000$ & $\begin{array}{l}\text { Mejora en la organización de equipos } \\
\text { de trabajo }\end{array}$ & $\$ 4500$ \\
\hline Capacitaciones & $\$ 1900$ & $\begin{array}{l}\text { Entrega de servicios de soporte más } \\
\text { confiable }\end{array}$ & $\$ 4000$ \\
\hline Total Costo & $\$ 22700$ & Total Beneficio & $\$ 21300$ \\
\hline
\end{tabular}

Fuente: Entidad Gubernamental Administración - Elaboración propia 
- La inversión se justifica ya que en un año y un mes se estaría recuperando la inversión. El modelo propuesto busca corregir las deficiencias identificadas en la atención de incidentes.

- Cabe indicar que el alcance inicial del proyecto es la de mejorar la gestión de incidentes de la entidad, a pesar de que existen otros procesos por mejorar. El presente trabajo de investigación entregará las pautas necesarias para mejorarlas y que impacten positivamente la entidad.

\subsection{Alcances}

- El presente trabajo de investigación pretende mejorar la gestión de incidentes de la Entidad Gubernamental, entregando un modelo que se adecue a la realidad de la entidad en estudio.

- El modelo propuesto de gestión de incidentes tendrá como usuarios a todas las entidades públicas del Estado que requieren utilizar los servicios de TI ofrecidos por la Entidad Gubernamental.

\section{a) Limitaciones}

- El éxito del modelo propuesto está condicionado por las particularidades de la Entidad Gubernamental también depende del compromiso de los responsables de turno para incorporar las mejoras en sus actividades diarias.

- Aunque el presente Modelo de Gestión de Incidentes para una entidad del estado puede ser aplicado en otras entidades del estado, este proyecto de investigación se centra en la aplicación de ITIL v3.0 en la Entidad Gubernamental. 


\section{b) Riesgos}

- El entorno político ofrece un riesgo latente puesto que las personas claves de la entidad pueden ser cambiadas, y como consecuencia de esto termine por afectar la implementación del modelo.

- El rechazo al cambio por parte del personal involucrado tanto operativo como gerencial.

\subsection{Aportes}

Los aportes asociados a la implementación del modelo de gestión de incidentes, aplicando ITIL v3.0 en un organismo del estado peruano son los siguientes:

\section{a) A nivel interno:}

- Implementar un modelo de gestión de incidentes, aplicando ITIL v3.0 en la entidad gubernamental.

- Garantizar la trazabilidad de información para los procesos de Gestión de Incidentes, desde su recepción hasta su atención.

- Elevar el nivel de calidad de servicio y satisfacción de los usuarios internos; expresados en menores tiempos de respuesta, menor cantidad de reclamos, etc.

- Inventario actualizado de activos (Software y Hardware) y procedimientos del área de TI e Infraestructura Tecnológica en la entidad de estudio.

\section{b) A nivel externo:}

- Ofrecer un servicio idóneo a sus clientes externos, con un porcentaje de satisfacción, superior al 95\%.

- Sentar las bases técnicas y funcionales a fin de mejorar los servicios de mesa de ayuda y a futuro se implemente un decreto a nivel nacional que 
norme y regule los servicios gestionados de TI, teniendo como base las mejores prácticas de la gestión de servicios ITIL.

- Ser modelo técnico y referencial para cualquier proyecto similar en el sector público. 


\section{CAPÍTULO II: REVISION DE LITERATURA}

\subsection{Resumen}

Las empresas que prestan servicios de TI tienen la necesidad de cumplir con las expectativas de sus usuarios, buscando tener siempre un esquema de disponibilidad y capacidad que les permita entregar valor.

Existe una amplia variedad de publicaciones sobre implementaciones ITIL en diversas instituciones, destacan entre ellas las siguientes:

Herrera(2013, p48) dice:

"Desde la perspectiva del negocio no se debería esperar a que un usuario sea afectado por un incidente de TI y recién se reporte a Helpdesk. Es por eso que las actividades principales son monitoreadas constantemente, de esta manera se podrán detectar posibles fallas con anticipación, y se podrán tener planes secundarios”.

En este trabajo de investigación se entrega una nueva perspectiva de cómo gestionar los incidentes de manera que se adecue a la necesidad de la empresa, aquí se muestra que el involucramiento del investigador es fundamental para determinar los factores críticos en la entrega adecuada de los servicios de TI, el investigador citado considera necesario el monitoreo temprano para la detección temprana de fallas.

Así mismo Gomez (2012, p81) dice:

"A través de la implementación de procesos ITIL, se desarrollan procedimientos estandarizados y fáciles de entender que apoyan la agilidad en la atención, logrando de esta forma visualizar el cumplimiento de objetivos corporativos"

En este trabajo de investigación se hace énfasis en la entrega de servicios de comienzo a fin, apoyándose en las buenas prácticas de ITIL. El autor de este trabajo 
hace énfasis en que a pesar de que pueden existir procesos de ITIL implementados, estos pueden ser mejorados de manera que sean uniformes y fáciles de entender.

Por otra parte Chávarry(2012, p202) dice como parte de sus conclusiones lo siguiente:

"La elaboración de un Acuerdo de Nivel de Servicio (SLA), permitió al Departamento Central de Computo comprometerse en brindar un mejor servicio a usuarios finales en ciertos aspectos establecidos".

En esta tesis se puede observar que se toma importancia en definir los niveles de acuerdo de servicio (SLA) para mejora la entrega de los servicios a los usuarios en la universidad en estudio. El autor también hace referencia a la necesidad de revisar un SLA las veces que sean necesarias para mejorar la entrega de los servicios.

Por otro lado Ariza \& Ramirez(2012, p9) afirman que:

“Actualmente las empresas que desean mejorar aspectos en los que han detectado fallas, y por las cuales sus ganancias no han sido las más favorables, recurrieron a la implementación de sistemas de gestión de calidad que les ha generado beneficios directos a su organización; pero no solo es implantarlo sino también mantenerlo y mejorarlo para seguir avanzando en el posicionamiento de la empresa”.

Este trabajo de investigación aplica las buenas prácticas de ITIL para mejorar la entrega de servicios buscando mejorar la percepción de los usuarios finales. A su vez resalta la importancia de mantener en el tiempo las implementaciones para que puedan aportar en el crecimiento de la empresa.

Finalmente se hizo referencia a una tesis que contempla el desarrollo de una herramienta a medida en la que De la Cruz \& Rosas (2012,p7 ) dicen:

"Se debe considerar que las TI requieren tener una administración adecuada que se componga de métricas definidas y así poder medir el verdadero desempeño y valor que están aportando a los fines del negocio. Existen diferentes estándares para implementar la gestión de las TI y la elección de uno de ellos depende de las necesidades de cada organización”. 
Esta tesis entrega una opción diferente en cuanto al uso de una herramienta de servicios gestionados basados en ITIL, dando alternativa de hacerlo a medida de acuerdo a las necesidades del negocio. La herramienta implementó algunos procesos siguiendo las buenas prácticas de ITIL v3.0.

Los trabajos mencionados en este capítulo fueron considerados por seguir las buenas prácticas de ITIL, adicionalmente se hace referencia también a los libros propios de ITIL (OGC) donde se contemplan las 5 fases de ITIL (Estrategia, Diseño, Transición, Operación y Mejora Continua). 


\section{CAPÍTULO III: MARCO TEORICO}

\subsection{ITIL}

Los autores de libros definen de diversas formas ITIL (Biblioteca de Infraestructura de Tecnologías de Información), pero todos convergen en el sentido de que es un marco de referencia de buenas prácticas en TI con el propósito de mejorar los servicios de TI ofrecidos por una empresa. A continuación se proporciona una definición de este marco de buenas prácticas.

"Es el marco y fuente de buenas prácticas en la gestión del servicio. ITIL es usado por organizaciones de todo el mundo para establecer y mejorar las capacidades en la gestión del servicio. ISO / IEC 20000 proporciona la guía oficial y el estándar universal para las organizaciones que buscan tener en su servicio las capacidades de gestión auditadas y certificadas. Mientras la ISO / IEC 20000 es una estándar lograda y mantenida, ITIL ofrece un cuerpo de conocimientos útiles para alcanzar el estándar", (OGC, 2008,p.3-7)

ITIL tiene los siguientes componentes:

- $\quad$ El Núcleo de ITIL - guía de mejores prácticas aplicables a todos los tipos de organizaciones que prestan servicios a una empresa. Ver figura 3.1

- Publicaciones Complementarias ITIL - Un conjunto complementario de publicaciones con orientación específicos para sectores de la industria, los tipos de organización, modelos operativos y arquitecturas tecnológicas. 
Figura 3.1

Núcleo de ITIL V3

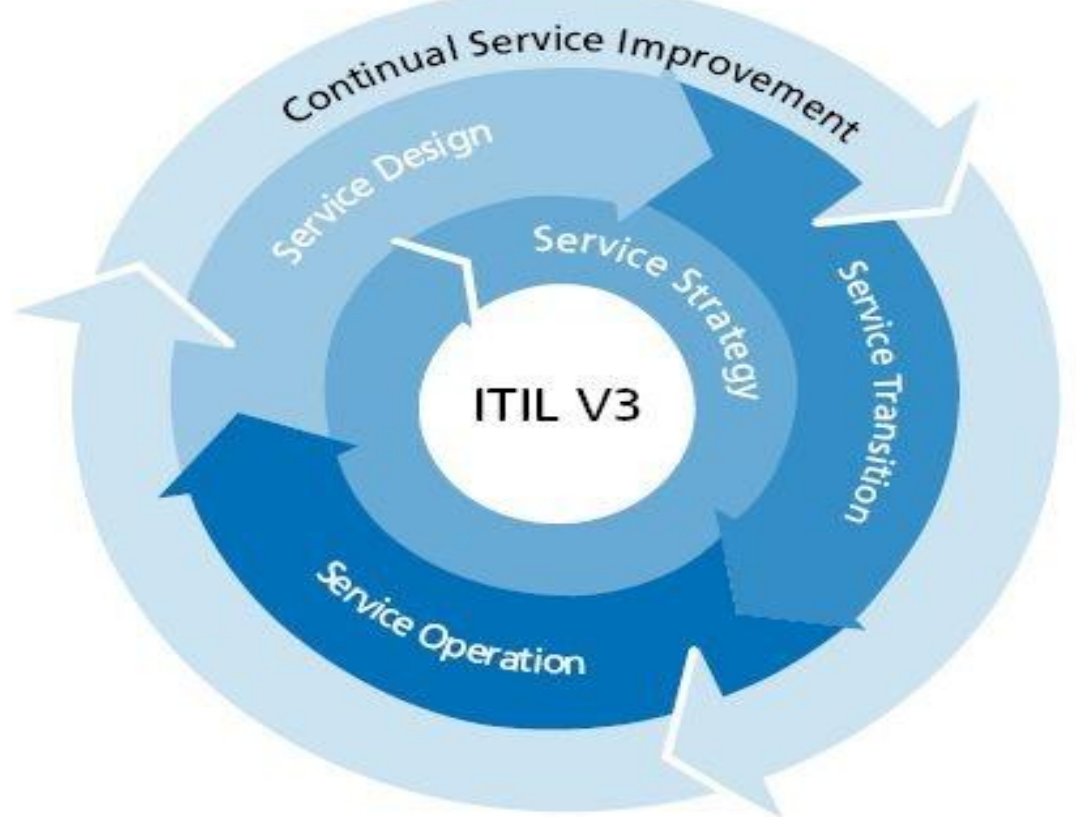

Fuente: ITIL V.3: Continual Service Improvement Autor: OGC - Publisher: TSO

El Núcleo de ITIL se compone de cinco publicaciones. Cada uno proporciona la guía necesaria para un enfoque integrado como es requerido por el estándar oficial ISO / IEC 20000:

- Estrategia del Servicio

- Diseño del Servicio

- Transición del Servicio

- Operación del Servicio

- Mejora Continua del Servicio

Como se mencionó en las descripciones anteriores sobre las fases de ITIL se hace referencia también a los procesos y funciones involucrados en ITIL tal como se muestra en la Figura 3.2. 
Figura 3.2

Procesos y funciones considerados en ITIL V3

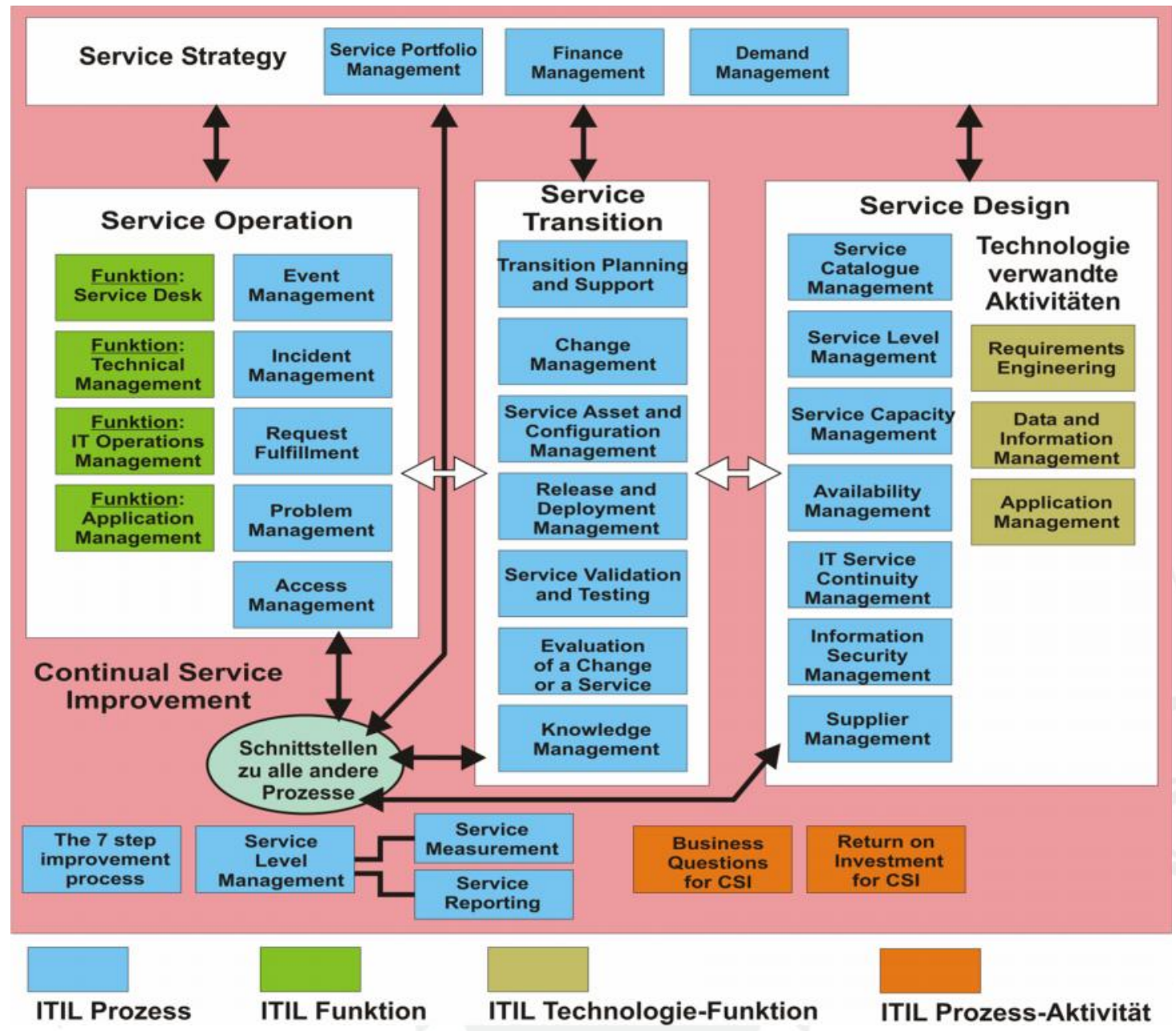

Fuente: Estrategia del Servicio basada en ITIL®V3 - Guía de Gestión Jan van Bon, Arjen de Jong, Axel Kolthof

\section{Estrategia del Servicio}

Es la fase que tiene como finalidad definir qué servicios se entregarán, a los usuarios de una entidad; cabe señalar que esta fase gestiona los servicios de manera que puedan convertirse en un activo que entregue valor. A continuación se hace referencia a la siguiente definición: 
"La Estrategia del Servicio proporciona orientación sobre cómo diseñar, desarrollar y poner en práctica la gestión de servicios no sólo como una capacidad organizativa, sino como un activo estratégico”. (OCG, 2011,p.8-11).

\section{Diseño del Servicio}

Esta fase de ITIL tiene como finalidad diseñar nuevos servicios que se puedan incorporar posteriormente al catálogo de servicios. El diseño del servicio permite definir las necesidades de los clientes y sus requerimientos, además de definir si es que se cuenta con los recurso y capacidades para entregar los servicios adecuadamente. Aquí se considera que los servicios existentes podrán ser revisados para mejorarlos de acuerdo a las necesidades de la empresa. A continuación se proporciona una definición.

“El Servicio de Diseño proporciona una guía para el diseño y desarrollo de los servicios y procesos de gestión de servicios. Abarca los principios de diseño y métodos para convertir los objetivos estratégicos en catálogo de servicios y servicios activos"'(OGC, 2008,p. 6-7).

Entre las funciones y procesos que comprende esta fase se encuentran : la Gestión del Catálogo de Servicios, Gestión de Niveles de Servicio, Gestión de la Capacidad, Gestión de la Disponibilidad, Gestión de la Continuidad de los Servicios TI, Gestión de la Seguridad de la Información y la Gestión de Proveedores. De estos procesos se pondrá mayor énfasis en la Gestión de Catálogo de Servicios.

\section{Transición del Servicio}

Esta fase tiene como objetivo ser facilitador de los servicios definidos en la fase previa para que puedan transformarse en productos que entreguen valor a los usuarios. El proceso de cambio es supervisado en esta fase con el fin de entregar a los clientes servicios alineados a su núcleo de negocio. La idea de esta fase es 
disminuir los riesgos que genera el cambio, buscando reducir el impacto. A continuación se enuncia el concepto :

"La Transición del Servicio proporciona una guía para el desarrollo y la mejora de las capacidades para la transición de los servicios nuevos y modificados en operaciones." (ITIL Service Transition, págs. 1-11).

Aquí se verán las siguientes funciones y servicios: Planificación y soporte a la Transición, Gestión de Cambios, Gestión de la Configuración y Activos del Servicio, Gestión de Entregas y Despliegues, Validación y pruebas, Evaluación y Gestión del Conocimiento. En el presente trabajo se involucrará al proceso de Gestión de Cambios.

\section{Operación del Servicio}

Esta fase tiene como objetivos principales coordinar e implementar las actividades y procesos que son necesarios para la entrega y la gestión de TI para prestar y dar soporte según los niveles de calidad acordados. Es en esta fase donde se entregan los servicios creados, además de entregar la retroalimentación necesaria para hacer los ajustes que sean necesarias para una adecuada entrega.

"La guía encarna prácticas en la gestión de la Operación del Servicio. Ella incluye orientación sobre el logro de la eficacia y eficiencia en la prestación y apoyo de los servicios a fin de garantizar el valor para el cliente y el servicio al proveedor". (ITIL Service Operation, págs. 7-10).

Esta fase comprende varios procesos, entre los cuales se encuentran: Gestión de Eventos, Gestión de Incidentes, Petición de Servicios TI, Gestión de Problemas y Gestión de Acceso a los Servicios TI. Esta fase tiene los procesos claves para el presente trabajo de investigación, para lo cual se dará más énfasis en la gestión de incidentes y la gestión de problemas. 


\section{Mejora Continua del Servicio (CSI)}

Esta fase tiene como objetivo analizar cada una de las fases anteriores y hacer las respectivas recomendaciones para la mejora de cada una de las fases anteriores.

Debe asegurarse que se utilicen los métodos adecuados para que sean soportadas las actividades de mejora continua. Esta fase debe estar presente siempre en todo el ciclo de ITIL, entregando indicadores que permitan hacer las mejoras del caso. Una de sus funciones es la de revisar los niveles de acuerdo de servicio (SLA) para hacer los ajustes necesarios para que se cumplan los compromisos acordados. En la figura 2.1 se puede observar la forma en que esta fase cubre todas las etapas.

"Esta guía es fundamental en la creación y el mantenimiento de valor para clientes a través de un mejor diseño, implantación y operación de los servicios". (ITIL , Mejora Continua del Servicio, págs. 3-11).

La mejora continua está presente todas las fases de ITIL, y tiene como procesos: El Proceso de Mejora y los Informes de Servicios TI.

\subsection{Proceso de Gestión de Incidentes}

La gestión de incidentes tiene como objetivo resolver, de la manera más rápida y eficaz posible, cualquier incidente que cause una interrupción en el servicio. El presente trabajo de investigación implementa las mejores prácticas de este proceso en la Entidad Gubernamental en estudio.

"La versión 3 de ITIL establece una diferencia entre "Incidentes" (interrupciones del servicio) y "Solicitudes de Servicio" (consultas estándares de los usuarios, como por ejemplo sobre la reposición de contraseñas, etc.). (WIKI, 2013). 
Figura 3.3

Descripción de la gestión de Incidentes

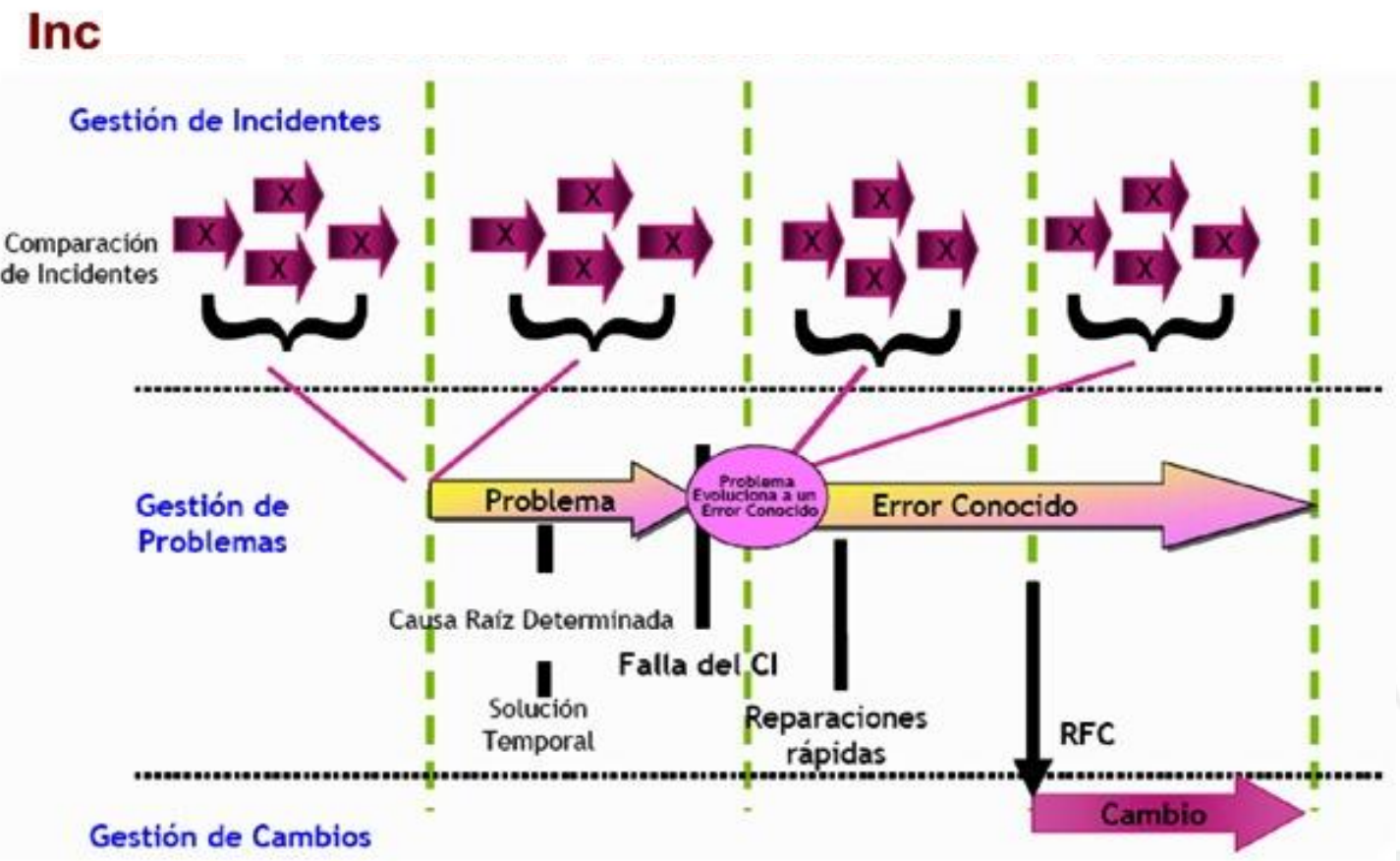

Fuente: Estrategia del Servicio basada en ITIL®V3 - Guía de Gestión van Bon, de Jong, Kolthof

\section{Objetivos de la Gestión de Incidentes}

Los objetivos principales de la Gestión de Incidentes son:

$\checkmark$ Detección y registro del incidente.

$\checkmark$ Clasificación y soporte inicial.

$\checkmark$ Investigación y diagnóstico.

$\checkmark$ Solución y restablecimiento del servicio.

$\checkmark$ Cierre del incidente.

$\checkmark$ Monitorización, seguimiento y comunicación del incidente. 
El proceso de gestión de incidentes tiene una estrecha relación con la función mesa de servicios, siendo una parte fundamental para una correcta entrega de servicios de TI.

\section{Beneficios esenciales de una adecuada Gestión de Incidentes}

Una adecuada gestión de incidentes permitirá restablecer los servicios en el menor tiempo posible de acuerdo a los tiempos de respuesta acordados.

Los principales beneficios que se pueden apreciar, y que es compartido por diversos autores se pueden resumir en la publicación de la siguiente empresa Osiatis (osiatis.es, 2013) que expresa lo siguiente:

$\checkmark \quad$ Mejorar la productividad de los usuarios.

$\checkmark$ Cumplimiento de los niveles de servicio acordados en el SLA. Mayor control de los procesos y monitorización del servicio.

$\checkmark$ Optimización de los recursos disponibles.

$\checkmark$ Una CMDB más precisa, pues se registran los incidentes en relación con los elementos de configuración.

Y principalmente: mejora la satisfacción general de clientes y usuarios.

A su vez los distintos conceptos utilizados en el trabajo de investigación, se encuentran en el glosario de términos. 


\section{CAPITULO IV: ANÁLISIS DEL SISTEMA DE GESTIÓN}

Durante el desarrollo de este trabajo de investigación, la Entidad Gubernamental estuvo atravesando por un proceso de fortalecimiento a través del cual buscaba resolver los principales problemas de la organización tales como el esquema de organización reactiva con procesos no formales que no permite concentrar ni priorizar los esfuerzos en materia de gobierno electrónico, la rotación de directivos y funcionarios que afecta la continuidad de las iniciativas al interior de la organización y en la administración pública, los escasos recursos y competencias para atender la demanda, entre otros. En la figura 4.1 podemos observar el organigrama actual de la entidad.

Figura 4.1

Organigrama de la organización

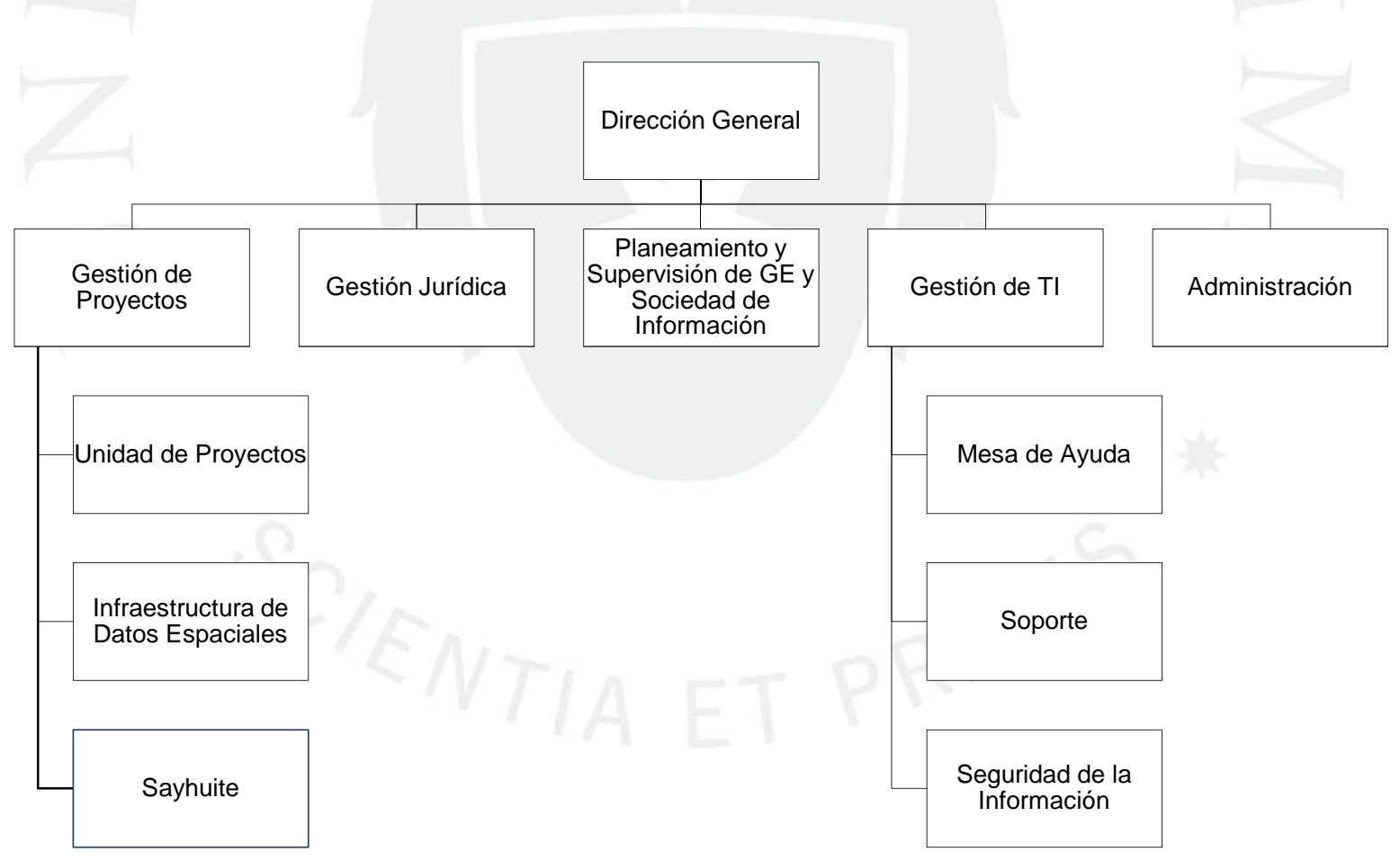

Fuente: Entidad Gubernamental en estudio 
El análisis completo de fortalezas, oportunidades, debilidades y amenazas se describe en las figuras 4.2 y 4.3 que se muestra a continuación. 
Figura 4. 2

\section{Matriz FODA}

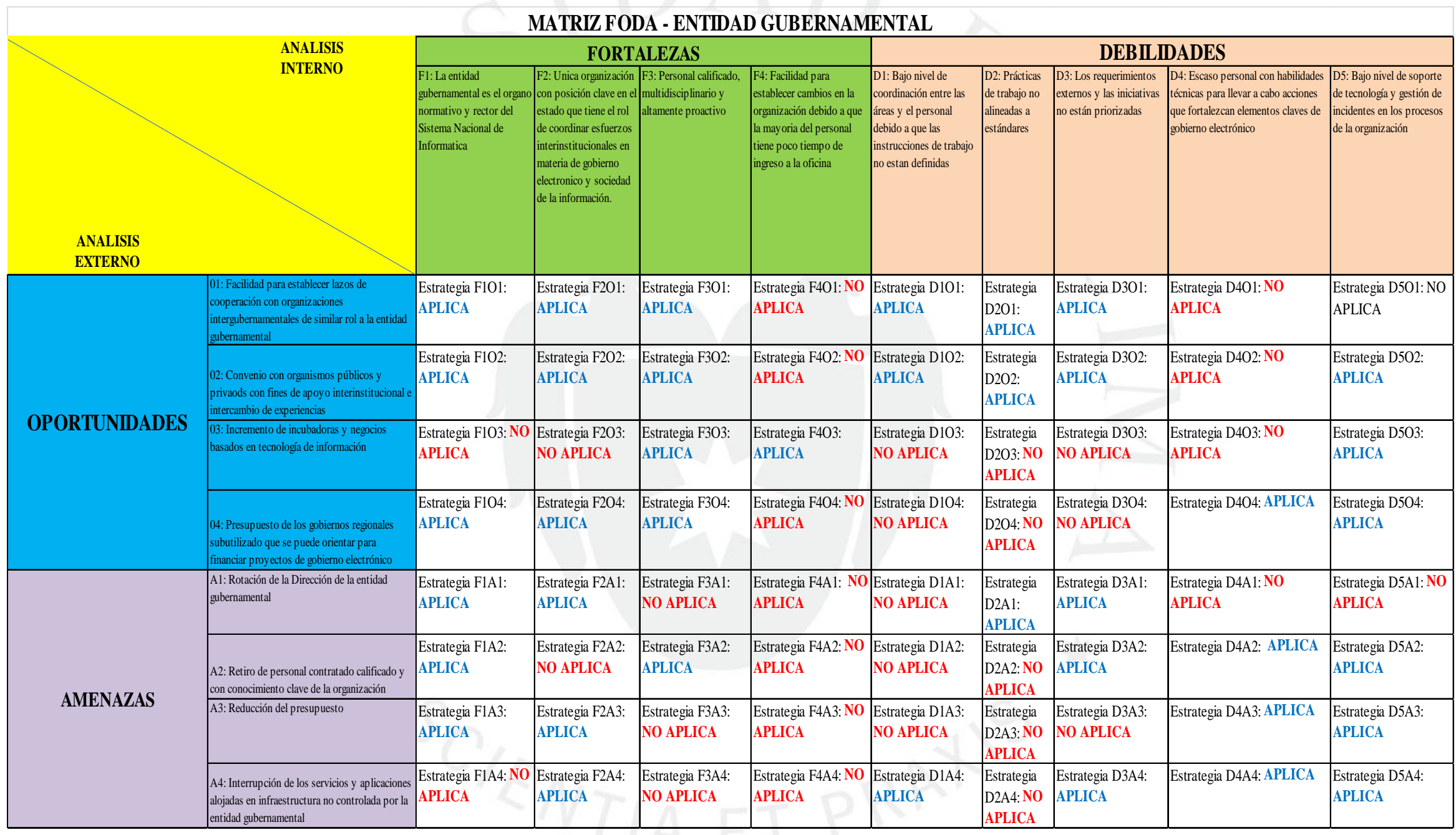

Fuente: Elaboración propia 
Figura 4. 3

Matriz FODA

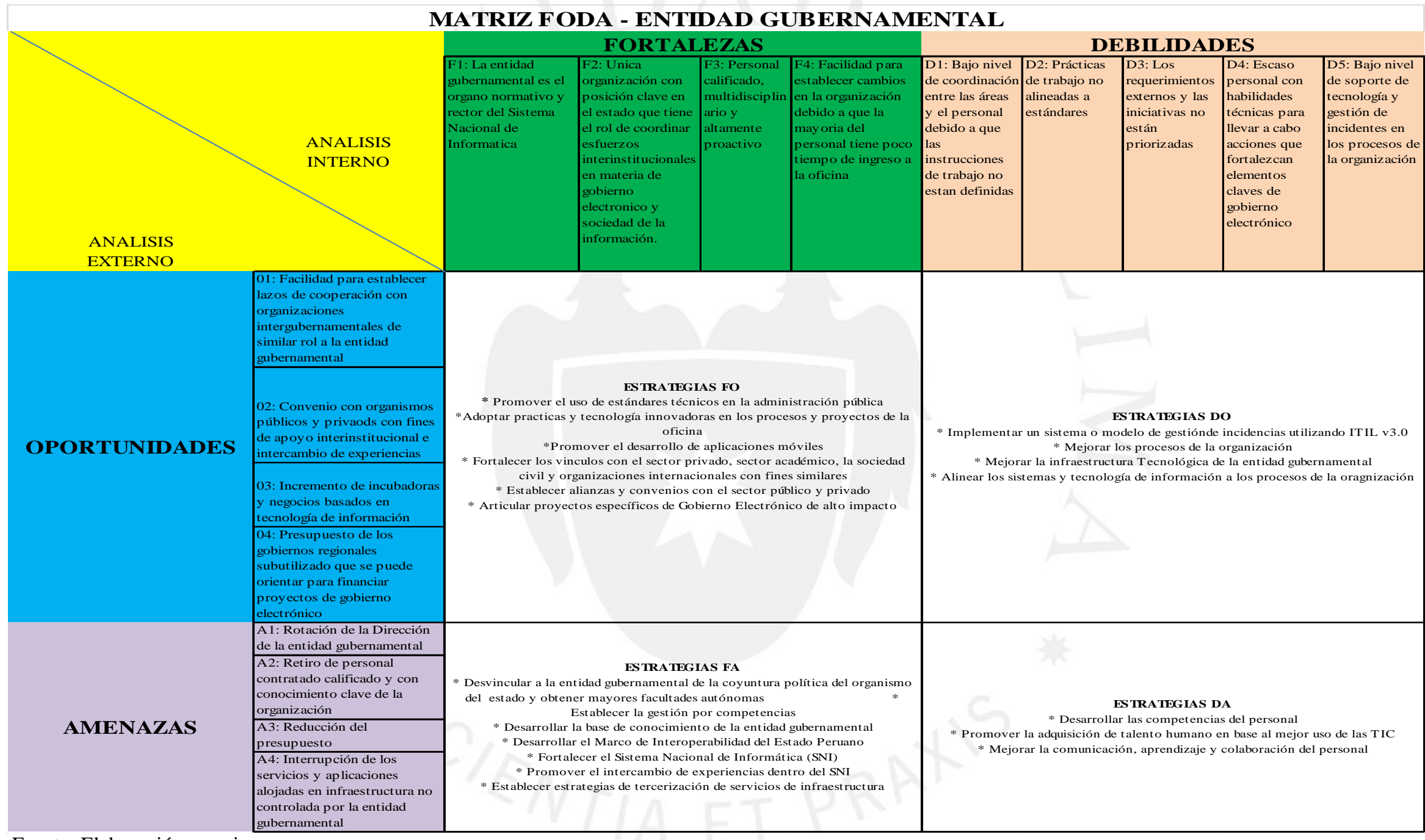

Fuente: Elaboración propia 


\subsection{Sistema de Gestión de la Entidad Gubernamental}

Este sistema ofrece un enfoque metodológico para dirigir y controlar la organización respecto al cumplimiento de los objetivos de gestión y la mejora de su desempeño. Su ámbito de aplicación incluye a los colaboradores, procesos y recursos de la Entidad Gubernamental y su implementación toma como referencia el modelo de sistema de gestión de la calidad de la ISO 9001.

El Sistema de Gestión de la Entidad Gubernamental es un instrumento de gestión que promueve el fortalecimiento de la gestión a través del cumplimiento de los requisitos de los diferentes sistemas de gestión que la administración pública exige en el marco de la modernización del Estado.

\section{a) Modelo de Gestión}

El Modelo de Gestión permite implementar y mejorar el Sistema de Gestión de la Entidad Gubernamental, a través del cual se dé cumplimiento integral a los requisitos establecidos en las normas y políticas vigentes que en materia de desempeño institucional y modernización del estado ha promovido el Gobierno. Este modelo, como se indica en la figura 4.4, comprende varios elementos: 
Figura 4. 4

Modelo de gestión de la Entidad Gubernamental

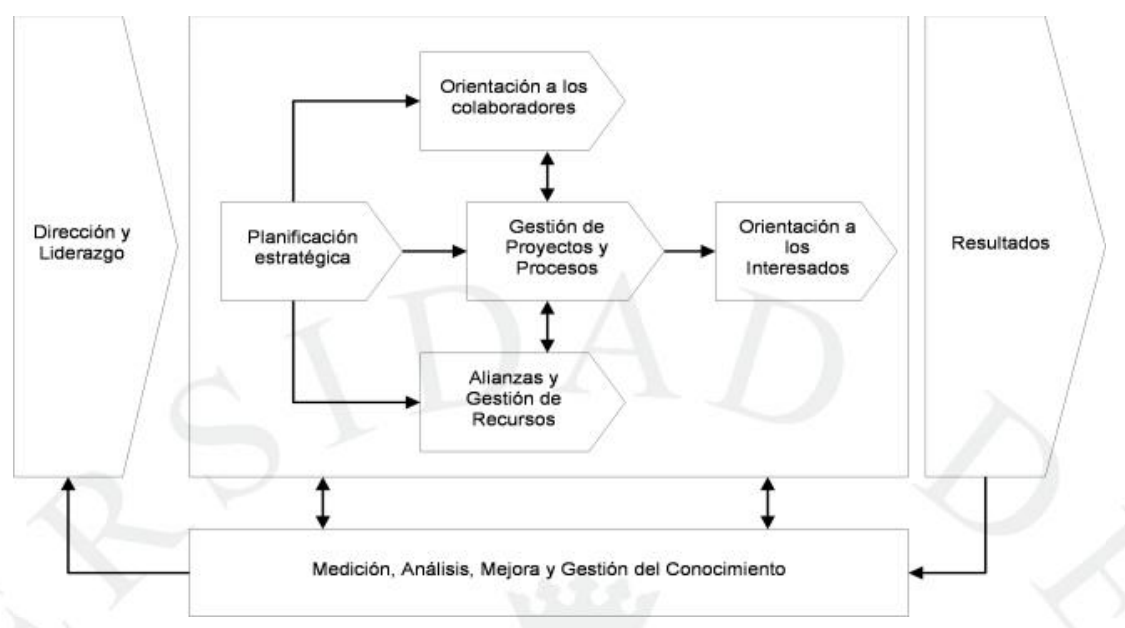

Fuente: Manual de Gestión ONGEI v1.0

\section{b) Documentación del Sistema de Gestión}

Los documentos del sistema de gestión son controlados de acuerdo al procedimiento SGO-PRO-001 Elaboración y Control de Documentos, que comprende la elaboración, revisión, aprobación, distribución, mantenimiento y uso de los documentos del Sistema de Gestión de Entidad Gubernamental. La jerarquía de tales documentos se indica en la figura 4.5.

Figura 4. 5

Jerarquía de Documentos del Sistema de Gestión

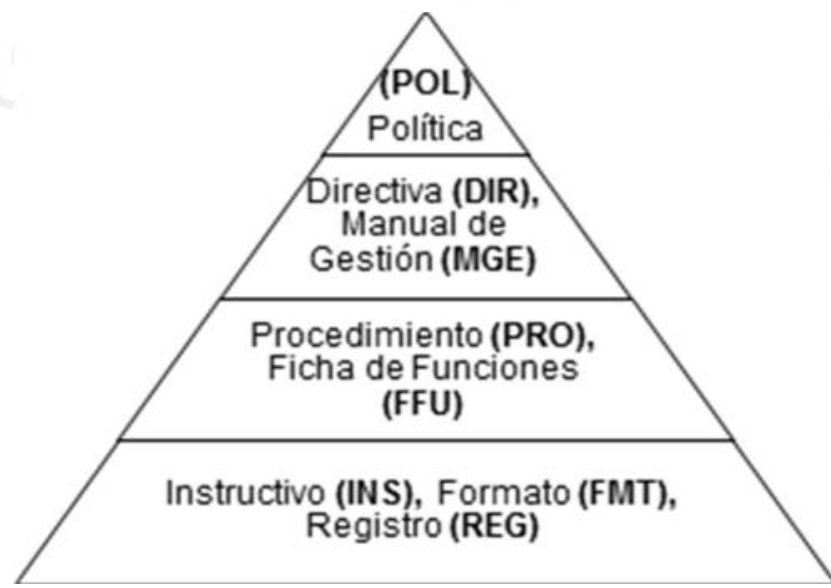

Fuente: Manual de Gestión ONGEI v1.0 


\subsubsection{Procesos y Servicios}

a) Servicios de TI entregados por la Entidad Gubernamental

- $\quad$ Plataforma de Interoperabilidad del Estado -PIDE.

- $\quad$ Interoperación de servicios.

- $\quad$ Publicación de Servicios PIDE.

Consumo de Servicios PIDE.

Servicios de mensaje de texto - SMS.

Se muestra el esquema en la figura 4.6

- $\quad$ Sayhuite

Apoyo de TI para Monitoreo de la Inversión Pública (SNIP) apoyados en la georreferenciación.

Creación de indicadores para una intervención articulada del Estado.

- Infraestructura de Datos Espaciales del Perú - IDEP

- Datos espaciales.

- $\quad$ Gestión de datos geofererenciados.

- Yachaywasi Digital

- $\quad$ Programas de inclusión digital en educación.

- Regulación Técnico-Normativo sobre Gobierno Electrónico

Políticas y directrices de gobierno electrónico y del SIN.

Programas y planes de gobierno electrónico.

Prospección y apropiación de tecnología. 
- Lineamientos para la adopción de estándares y mejores prácticas.

- $\quad$ Metodologías y guías de gestión de TI.

- $\quad$ Plan Operativo Informático - POI.

Encuesta Nacional de Recursos Informáticos en la Administración Pública - ENRIAP

\section{- $\quad$ Portales del Estado Peruano}

Portal de Transparencia del Estado Peruano.

Portal de Servicios al Ciudadano y Empresas.

Portal web para municipios.

Registro Unificado de Entidades del Estado Peruano -RUEEP.

- Coordinadora de Emergencias de Redes Teleinformáticas de

\section{Perú - PeCERT}

Atención de Incidentes de seguridad informática.

Atención de Incidentes relacionados a reportes de vulnerabilidad y ataques a los servicios establecidos (portal, web, correo)

Solución de consultas técnicas sobre aplicación de políticas de seguridad informática.

Registro de solicitudes y/o requerimientos de tareas de seguridad informática a desarrollarse vía proyectos de mejora.

\section{- Asesoría Legal}

Atención de consultas, opinión técnica y normativa sobre gobierno electrónico. 
- $\quad$ Asesoría y apoyo consultivo (técnico, legal y de gestión).

- $\quad$ Participación en mesas de trabajo.

- Capacitación de funcionarios del SIN y funcionarios No TI

Articulación de iniciativas transversales.

Difusión y concientización de políticas de TI.

Capacitación de funcionarios (Sistema Nacional Informático y funcionarios No TI).

La Plataforma de Interoperabilidad del Estado, está a disposición de las entidades públicas, integrantes del Sistema Nacional de Informática, que implementen servicios públicos en línea por medios electrónicos y/o el intercambio electrónico de datos, que requieran de la participación de una o más entidades del Estado.

Cabe resaltar que varios de estos servicios de TI usan servicios atómicos de la plataforma PIDE para poder generar nuevos servicios.

"El acceso a los servicios públicos por medios electrónicos a través de la Plataforma de Interoperabilidad del Estado - PIDE, no demandará costo adicional al administrado o ciudadano" (Manual de Gestión Entidad Gubernamental v1.0 2014:33). En la tabla 4.1 la relación de los servicios soportados por la plataforma. 
Tabla 4.1

Servicios de la PIDE

\begin{tabular}{|c|c|c|c|c|}
\hline $\mathrm{N}^{\mathrm{o}}$ & $\begin{array}{l}\text { SERVICIOS WEB } \\
\text { (UDDI) }\end{array}$ & DESCRIPCION & $\begin{array}{l}\text { ENTIDAD } \\
\text { RESPONSABLE }\end{array}$ & $\begin{array}{l}\text { NIVEL DE } \\
\text { ACCESO }\end{array}$ \\
\hline 1. & $\begin{array}{l}\text { Código Único de } \\
\text { Operación - CUO }\end{array}$ & $\begin{array}{l}\text { Es un código de } 10 \text { dígitos que permite } \\
\text { tener la trazabilidad de los servicios } \\
\text { públicos interoperables, a nivel de } \\
\text { entidades públicas. }\end{array}$ & PCM & $\begin{array}{l}\text { ENTIDADES } \\
\text { PÚBLICAS }\end{array}$ \\
\hline 2. & Consulta de DNI & $\begin{array}{l}\text { Permite tener los apellidos y nombres de } \\
\text { los ciudadanos, dado el número de DNI. }\end{array}$ & RENIEC & $\begin{array}{l}\text { ENTIDADES } \\
\text { PÚBLICAS }\end{array}$ \\
\hline 3. & $\begin{array}{l}\text { Servicio de Mensajes } \\
\text { de Texto - SMS }\end{array}$ & $\begin{array}{l}\text { Permite enviar mensajes SMS en forma } \\
\text { automatizada a un grupo de números de } \\
\text { teléfonos móviles, desde un sistema de } \\
\text { información. }\end{array}$ & PCM & $\begin{array}{l}\text { ENTIDADES } \\
\text { PÚBLICAS }\end{array}$ \\
\hline 4. & Consulta de RUC & $\begin{array}{l}\text { Dado el número de RUC, se obtiene el } \\
\text { nombre del contribuyente, estado, } \\
\text { dirección y otros datos. }\end{array}$ & SUNAT & $\begin{array}{l}\text { DATOS } \\
\text { ABIERTOS }\end{array}$ \\
\hline 5. & Generación de RUC & $\begin{array}{l}\text { Es un servicio web elaborado para el } \\
\text { Servicio de Constitución de Empresas } \\
\text { en Línea, dado el envío de SUNARP, de } \\
\text { los datos de la nueva empresa, genera el } \\
\text { RUC en menos de } 8 \text { segundos, } \\
\text { comparado a las } 3 \text { horas promedio por } \\
\text { trámite tradicional. }\end{array}$ & SUNAT & $\begin{array}{l}\text { ENTIDADES } \\
\text { PÚBLICAS } \\
\text { (EXCLUSIV } \\
\text { O) }\end{array}$ \\
\hline 6. & \begin{tabular}{lll|} 
Envió de & Partes & de \\
Embargos & de \\
Inmuebles & &
\end{tabular} & $\begin{array}{l}\text { Servicio que permite el envío de } \\
\text { documentos electrónicos entre SUNAT } \\
\text { (embargos inmuebles) y SUNARP. }\end{array}$ & SUNAT & $\begin{array}{l}\text { ENTIDADES } \\
\text { PÚBLICAS }\end{array}$ \\
\hline 7. & \begin{tabular}{|l|} 
Consulta de Placas \\
Vehiculares, \\
conductores \\
infractores (MTC).
\end{tabular} & $\begin{array}{l}\text { Permite consultar licencias de } \\
\text { conductor, papeletas y Sanciones. }\end{array}$ & MTC & $\begin{array}{l}\text { DATOS } \\
\text { ABIERTOS }\end{array}$ \\
\hline 8. & \begin{tabular}{|l|}
$\begin{array}{l}\text { Convertidor de } \\
\text { Monedas }\end{array}$ \\
\end{tabular} & $\begin{array}{l}\text { Dado un tipo de moneda origen y un } \\
\text { destino se obtiene el tipo de cambio. }\end{array}$ & PCM & $\begin{array}{l}\text { DATOS } \\
\text { ABIERTOS }\end{array}$ \\
\hline 9. & Clima de ciudades & $\begin{array}{l}\text { Dado el nombre de País y ciudad, se } \\
\text { obtiene datos del clima en línea. }\end{array}$ & PCM & $\begin{array}{l}\text { DATOS } \\
\text { ABIERTOS }\end{array}$ \\
\hline 10. & $\begin{array}{l}\text { Funcionarios de } \\
\text { Entidades Publicas }\end{array}$ & $\begin{array}{l}\text { Mediante el RUC como campo clave } \\
\text { muestra la lista de funcionarios } \\
\text { incluyendo cargos, resolución de } \\
\text { designación, teléfono y correo } \\
\text { institucional. }\end{array}$ & PCM & $\begin{array}{l}\text { DATOS } \\
\text { ABIERTOS }\end{array}$ \\
\hline 11. & $\begin{array}{l}\text { Catálogo de } \\
\text { Servicios en Línea }\end{array}$ & $\begin{array}{l}\text { El servicio muestra por medio del ruc de } \\
\text { entidad, el listado de Servicios en línea } \\
\text { de la misma, registrados en el Portal de } \\
\text { Servicios al Ciudadano y Empresas - } \\
\text { PSCE }\end{array}$ & PCM & $\begin{array}{l}\text { DATOS } \\
\text { ABIERTOS }\end{array}$ \\
\hline 12. & $\begin{array}{l}\text { Envío de Partes } \\
\text { Notariales } \\
\text { Electrónico, consulta } \\
\text { de partidas registrales }\end{array}$ & $\begin{array}{l}\text { Servicio que permite el envío de } \\
\text { documentos electrónicos entre Colegio } \\
\text { de Notarios de Lima (Constitución de } \\
\text { Empresas) , SUNAT (embargos) y } \\
\text { SUNARP }\end{array}$ & SUNARP & $\begin{array}{l}\text { ENTIDADES } \\
\text { PÚBLICAS } \\
\text { (EXCLUSIV } \\
\text { O) }\end{array}$ \\
\hline 13. & Ejecutoras por año & $\begin{array}{l}\text { Consulta SNIP por unidades ejecutoras } \\
\text { por año, usado en el aplicativo Sayhuite }\end{array}$ & MEF & $\begin{array}{l}\text { DATOS } \\
\text { ABIERTOS }\end{array}$ \\
\hline 14. & Fuentes por año & $\begin{array}{lllll}\text { Consulta } & \text { SNIP } & \text { por } & \text { fuentes } \\
\text { presupuestales } & \text { por } & \text { año, usado en } & \text { el }\end{array}$ & MEF & $\begin{array}{l}\text { ENTIDADES } \\
\text { PÚBLICAS } \\
\end{array}$ \\
\hline
\end{tabular}




\begin{tabular}{|c|c|c|c|c|}
\hline $\mathrm{N}^{\mathrm{o}}$ & $\begin{array}{l}\text { SERVICIOS WEB } \\
\text { (UDDI) }\end{array}$ & DESCRIPCION & $\begin{array}{l}\text { ENTIDAD } \\
\text { RESPONSABLE }\end{array}$ & $\begin{array}{l}\text { NIVEL DE } \\
\text { ACCESO }\end{array}$ \\
\hline & & aplicativo Sayhuite. & & \\
\hline 15. & Proyectos por año & $\begin{array}{l}\text { Consulta de proyectos por año, usado en } \\
\text { el aplicativo Sayhuite. }\end{array}$ & MEF & $\begin{array}{l}\text { ENTIDADES } \\
\text { PÚBLICAS }\end{array}$ \\
\hline 16. & Rubros por año & $\begin{array}{l}\text { Consulta de rubros por año del SNIP, } \\
\text { usado en el aplicativo Sayhuite. }\end{array}$ & $\mathrm{MEF}$ & $\begin{array}{l}\text { ENTIDADES } \\
\text { PÚBLICAS }\end{array}$ \\
\hline 17. & Sectores por año & $\begin{array}{l}\text { Consulta de proyectos por sectores y } \\
\text { año, usado en el aplicativo Sayhuite. }\end{array}$ & MEF & $\begin{array}{l}\text { ENTIDADES } \\
\text { PÚBLICAS }\end{array}$ \\
\hline 18. & $\begin{array}{l}\text { Gasto PIP por año y } \\
\text { nivel de gobierno }\end{array}$ & $\begin{array}{l}\text { Consulta de gastos sobre Proyectos de } \\
\text { Inversión, por niveles de gobierno, } \\
\text { usado en el aplicativo Sayhuite. }\end{array}$ & $\mathrm{MEF}$ & $\begin{array}{l}\text { ENTIDADES } \\
\text { PÚBLICAS }\end{array}$ \\
\hline 19. & SNIP por código & $\begin{array}{l}\text { Consulta de proyectos de Inversión } \\
\text { Pública por Código, usado en el } \\
\text { aplicativo Sayhuite. }\end{array}$ & MEF & $\begin{array}{l}\text { ENTIDADES } \\
\text { PÚBLICAS }\end{array}$ \\
\hline 20. & \begin{tabular}{|l|} 
Licencia de \\
Funcionamiento \\
Municipal en Línea / \\
Trámite
\end{tabular} & $\begin{array}{l}\text { Integración del Sistema de Trámite } \\
\text { Documentario de la Municipalidad con } \\
\text { Sistema de Licencia de Funcionamiento } \\
\text { Municipal en Línea - PCM. }\end{array}$ & PCM/MEF-CND & $\begin{array}{l}\text { ENTIDADES } \\
\text { PÚBLICAS }\end{array}$ \\
\hline 21. & \begin{tabular}{|l|} 
Licencia de \\
Funcionamiento \\
Municipal en Línea / \\
Pago de Servicio
\end{tabular} & $\begin{array}{l}\text { Integración del Sistema de Caja (Pago) } \\
\text { de la Municipalidad con el Sistema de } \\
\text { Licencia de Funcionamiento Municipal } \\
\text { en Línea- PCM. }\end{array}$ & PCM/MEF-CNC & $\begin{array}{l}\text { ENTIDADES } \\
\text { PÚBLICAS }\end{array}$ \\
\hline 22. & $\begin{array}{l}\text { Integración del } \\
\text { Sistema de Licencia } \\
\text { de Funcionamiento } \\
\text { de la Municipalidad } \\
\text { con el Sistema de } \\
\text { Licencia } \\
\text { Funcionamiento } \\
\text { Municipal en Línea } \\
\text { de PCM }\end{array}$ & $\begin{array}{l}\text { Integración del Sistema de Licencia de } \\
\text { Funcionamiento de la Municipalidad } \\
\text { con el Sistema de Licencia de } \\
\text { Funcionamiento Municipal en Línea de } \\
\text { PCM. }\end{array}$ & PCM/MEF-CNC & $\begin{array}{l}\text { ENTIDADES } \\
\text { PÚBLICAS }\end{array}$ \\
\hline 23. & $\begin{array}{l}\text { Relación } \\
\text { Comisarías }\end{array}$ & $\begin{array}{l}\text { Permite obtener el nombre, la dirección } \\
\text { y los teléfonos de todas las comisarías } \\
\text { de Lima y Callao. }\end{array}$ & MININTER & $\begin{array}{l}\text { DATOS } \\
\text { ABIERTOS }\end{array}$ \\
\hline 24. & $\begin{array}{l}\text { Establecimientos } \\
\text { Médicos }\end{array}$ & $\begin{array}{l}\text { Permite obtener el nombre, la dirección } \\
\text { y los teléfonos de todos los } \\
\text { establecimientos médicos de Lima y } \\
\text { Callao }\end{array}$ & MINSA & $\begin{array}{l}\text { DATOS } \\
\text { ABIERTO }\end{array}$ \\
\hline
\end{tabular}

Fuente: Elaboración Propia 
Figura 4. 6

Esquema de funcionamiento de la PIDE

\section{Plataforma de Interoperabilidad del Estado PIDE}

$\checkmark$ Encamina los datos entre Aplicaciones.

$\checkmark$ Utiliza estándares para el intercambio de datos.

$\checkmark$ Transformación de formatos de los datos entre la institución consumidora y el proveedor de la información. 


\section{b) Mapa de Procesos}

El mapa de procesos o modelo de operación por procesos de la Entidad Gubernamental se encuentra estructurado tal como se indica en la figura 4.7. Este modelo refleja los procesos (de nivel 0) que serán implementados gradualmente, para facilitar el análisis y la identificación de oportunidades de mejora. Estos procesos pueden descomponerse en procesos de bajo nivel. La descripción de cada uno de ellos se realiza a través de procedimientos a cargo de los Dueños de Procesos. Este mapa de procesos permite tener una mejor visión de la entidad en estudio.

Figura 4. 7

Mapa de Procesos de la Entidad Gubernamental

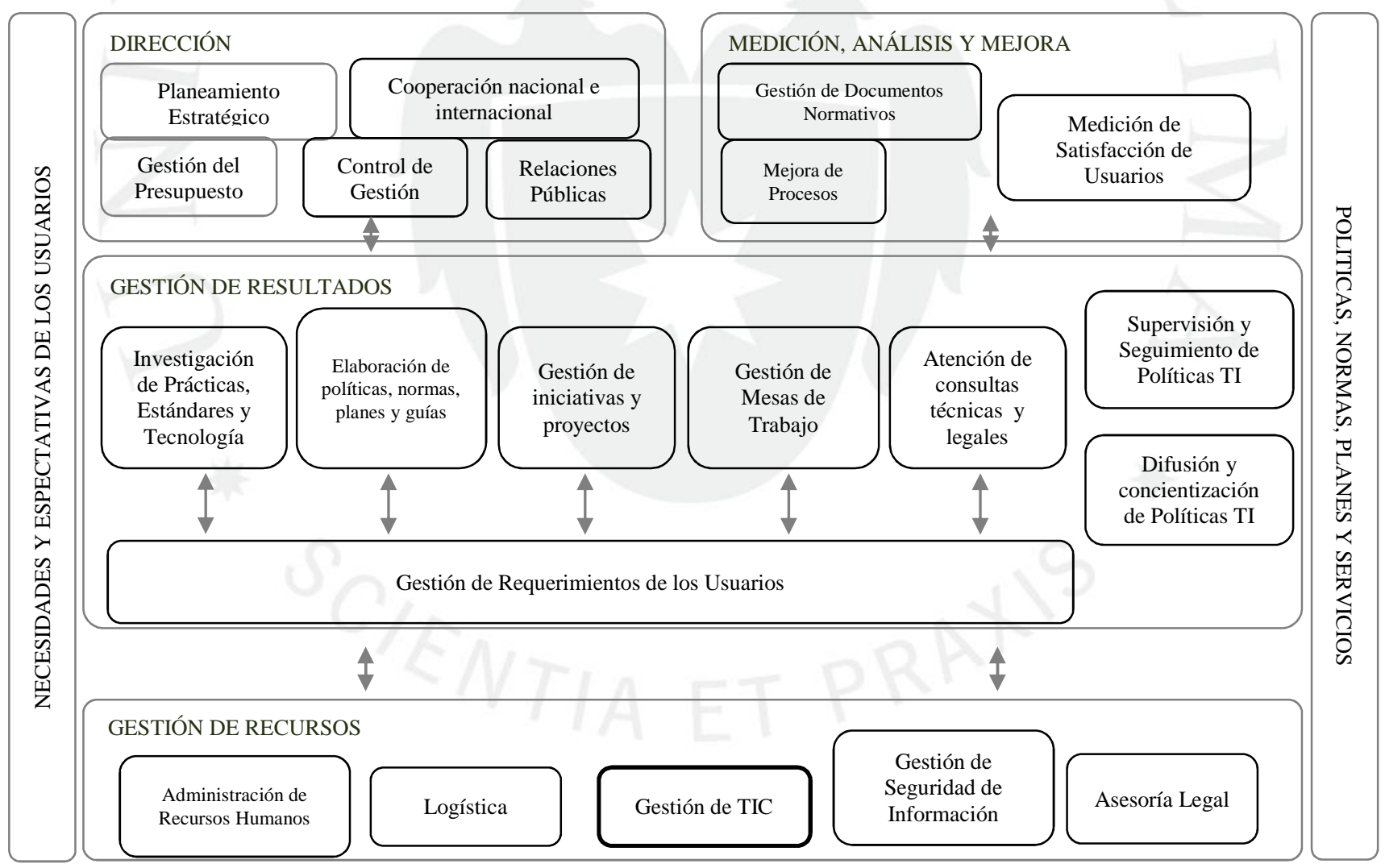

Fuente: $\quad$ Manual de Gestión ONGEI v1.0 


\subsubsection{Análisis del Área de TI respecto al proceso de atención de incidentes}

El área de Gestión de TI cumple un rol importante en la atención de incidentes, su estructura no ha sido cambiada desde la creación de la Entidad Gubernamental. El área por la cantidad de servicios que atiende debe seguir una línea de buenas prácticas que le permita entregar satisfactoriamente los servicios de TI a los usuarios del estado. Se muestra la estructura del área en la figura 4.8.

Figura 4.8

Organigrama actual del área de TI

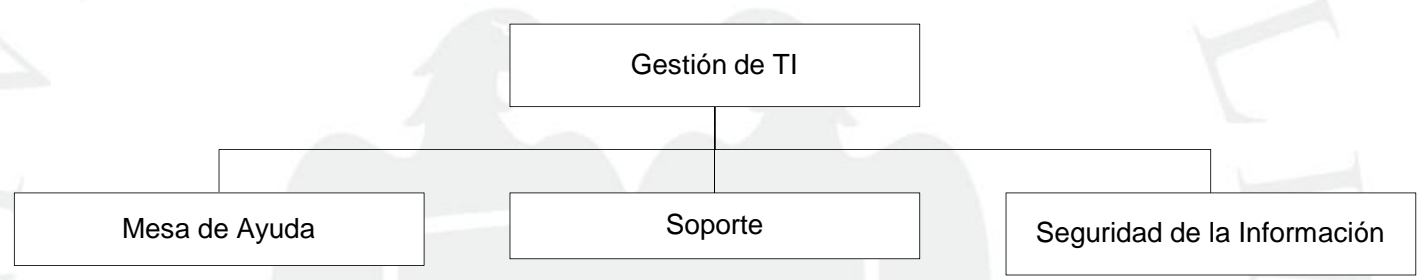

Fuente: Entidad Gubernamental (AS-IS)

\section{Usuarios de la Entidad Gubernamental}

La entidad en estudio tiene como clientes o usuarios de los servicios a las entidades públicas del estado peruano y se clasifican de acuerdo al diagrama de la figura 4.9 
Figura 4. 9

\section{Usuarios Entidad Gubernamental}

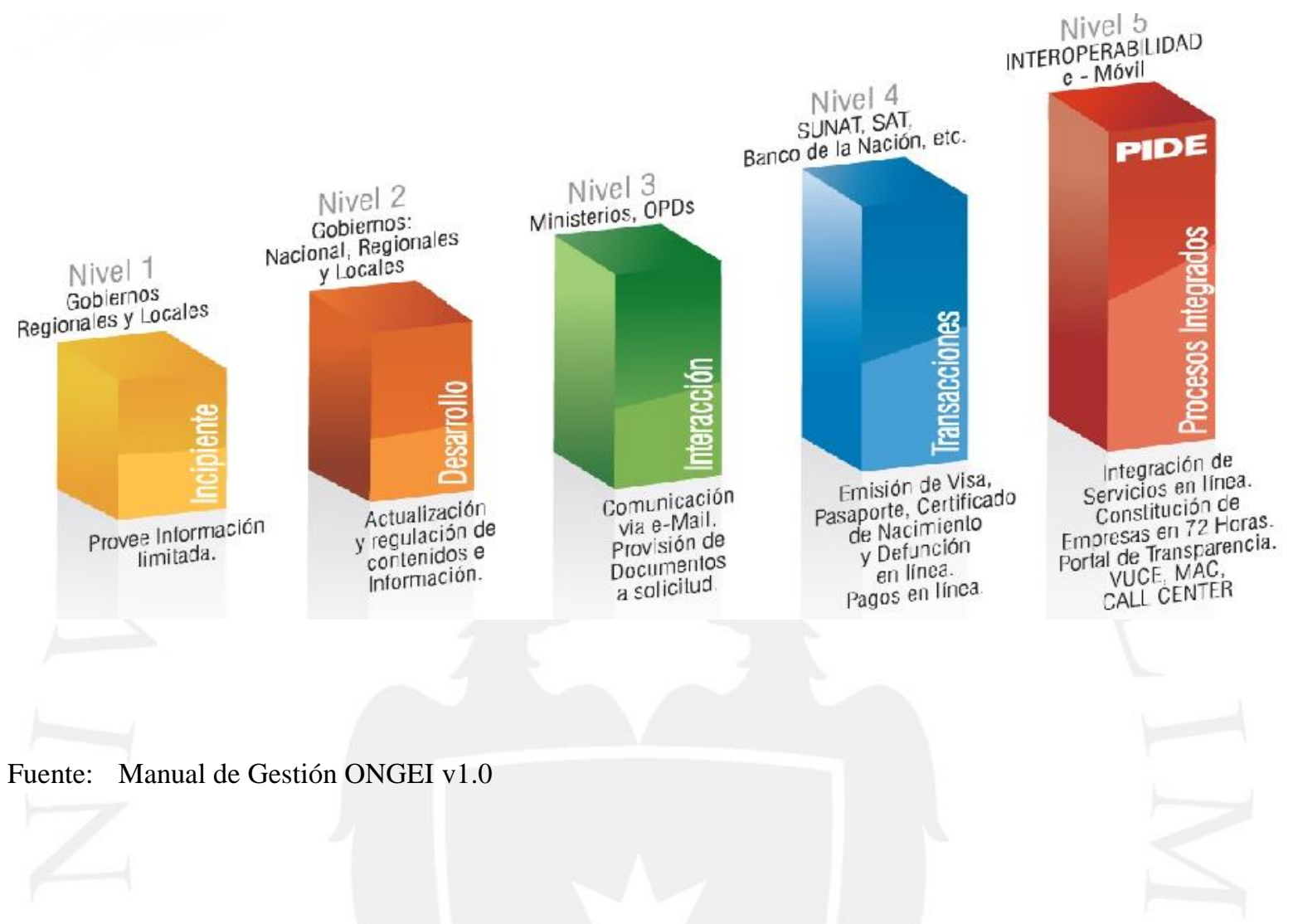

El gráfico indica cómo han evolucionado los servicios de TI y a su vez como las diferentes entidades se han ido clasificando de acuerdo al nivel de complejidad de los servicios que utilizan. A continuación se muestra a las entidades usuarias según su clasificación en la tabla 4.2. 
Tabla 4.2

Usuarios de la Entidad Gubernamental

\begin{tabular}{|l|c|}
\hline Entidades según clasificación & $\begin{array}{l}\text { Usuarios de Entidad } \\
\text { Gubernamental }\end{array}$ \\
\hline Poder Ejecutivo & 146 \\
\hline Poder Legislativo & 1 \\
\hline Poder Judicial & 2 \\
\hline Organismos Autónomos & 56 \\
\hline Gobiernos Locales & 1852 \\
\hline Gobiernos Regionales & 28 \\
\hline Total de Usuarios & $\mathbf{2 0 8 5}$ \\
\hline
\end{tabular}

Fuente: http://www.peru.gob.pe/directorio

\subsubsection{Catálogo de servicios}

El Catálogo de Servicios permite a las entidades del estado seleccionar un servicio acorde a sus necesidades, así como, conocer las funciones y responsabilidades de la organización de TI respecto al servicio.

La Entidad Gubernamental ha ido ampliando sus servicios en los ultimos años, creando servicios mas complejos e integrados, como se muestra en la figura $\mathrm{N}^{\circ} 4.10$ (Catalogo de Servicios). El incremento en los servicios de TI ha ocasionado que tengan que redefinirse algunos procesos internos para poder cumplir con los requerimientos de las entidades del estado peruano.

\section{a) Servicios Estratégicos Identificados}

- Plataforma de Interoperabilidad del Estado (PIDE).

- Sayhuite.

- Infraestructura de Datos espaciales (IDEP).

- Yachaywasi Digital.

- Regulación Técnico-normativo sobre Gobierno Electrónico.

- Portales del Estado Peruano. 
- Pe-Cert.

- Asesoría Legal.

- Capacitación de funcionarios del SIN y funcionarios No TI.

Figura 4. 10

Catálogo de servicios de la Entidad Gubernamental

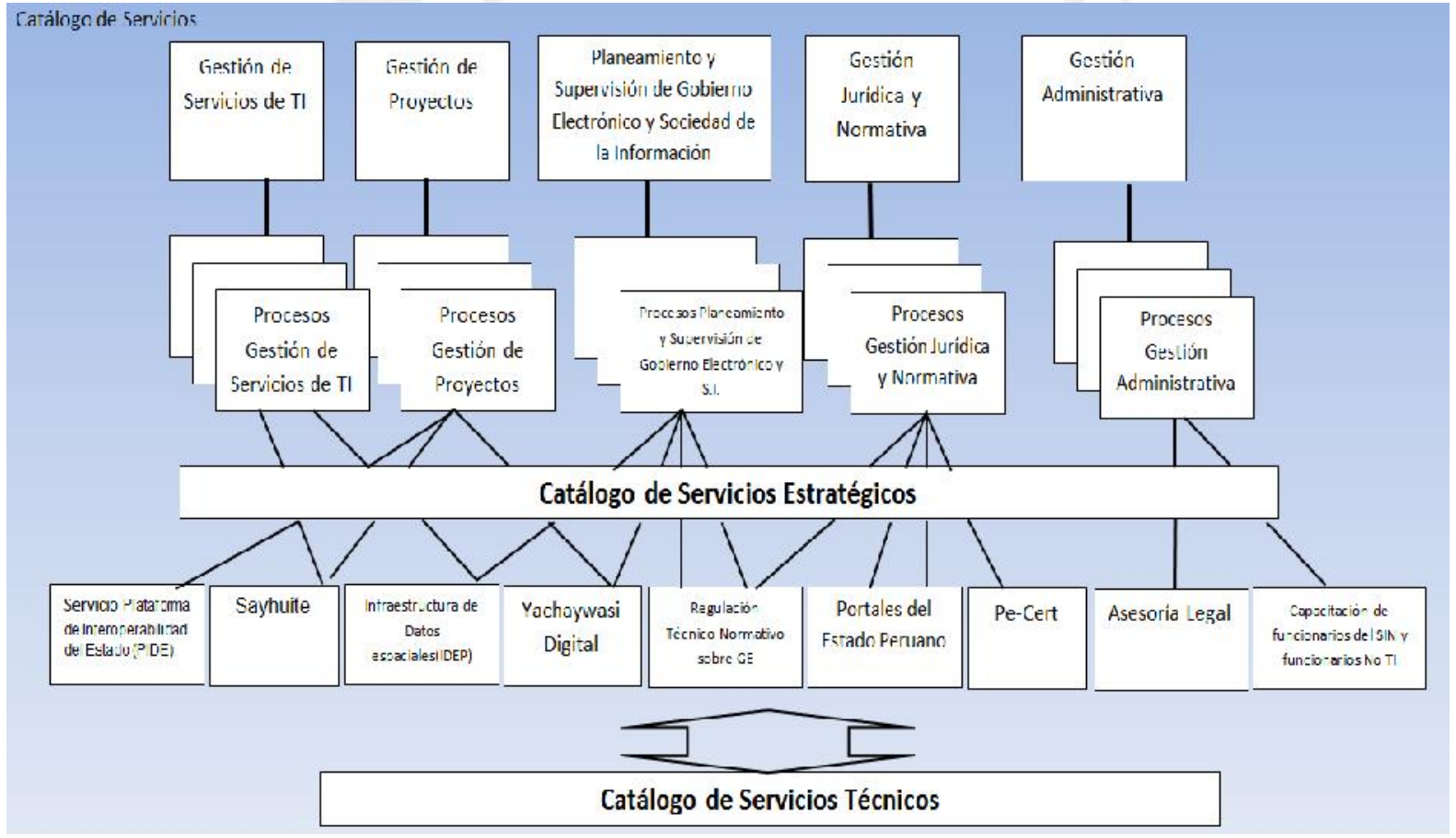

Fuente: Entidad Gubernamental en estudio

\section{b) Catálogo de Servicios Técnico}

El catalogo de servicios técnico muestra como están soportados los servicios estratégicos de la Entidad Gubernamental. En el presente trabajo de investigación no se mencionarán nombres especificos de los proveedores de servicios y detalles en cuanto a la capacidad operativa para no infringir temas de confidencialidad de la entidad en estudio.

Varios servicios se han adicionado al portafolio de servicios asi como también se han dado de baja algunos servicios por temas de 
cumplimiento normativo. El aumento de requerimientos por parte de las entidades del estado ha ocasionado que se tenga que hacer ajustes tanto en temas normativos como técnicos para poder entregar servicios de TI adecuados a las entidades del estado. Ver tabla 4.3

Tabla 4.3

Catálogo de servicios técnicos

\begin{tabular}{|c|c|}
\hline Servicios de TI & Descripción de Servicio TI \\
\hline Consumo PIDE & $\begin{array}{l}\text { Servicio que brinda acceso a las entidades del } \\
\text { estado a consumir los diversos de la } \\
\text { plataforma PIDE (Consultar DNI, RUC, } \\
\text { Servicios SUNARP, etc.) }\end{array}$ \\
\hline Publicación PIDE & $\begin{array}{l}\text { Servicio que permite a las entidades publicar } \\
\text { los web services para que sean consumidas } \\
\text { por otras entidades del estado. }\end{array}$ \\
\hline $\begin{array}{ll}\text { Servicio } & \text { de } \\
\text { Mensajeria SMS }\end{array}$ & $\begin{array}{l}\text { Servicio que entrega una cuota a las entidades } \\
\text { del estado para enviar mensajes de texto a } \\
\text { celulares de sus clientes. }\end{array}$ \\
\hline Servicio Streaming & $\begin{array}{l}\text { Servicio que entrega servicios de } \\
\text { videoconferencia a las entidades del estado, } \\
\text { aquí se configuran y programan los eventos } \\
\text { para las entidades. }\end{array}$ \\
\hline $\begin{array}{l}\text { Servicio de Registro } \\
\text { Normativo }\end{array}$ & $\begin{array}{l}\text { Servicio que permite a las entidades registrar } \\
\text { sus obligaciones normativas ( ENRIAP, POI, } \\
\text { Programas y Planes etc.) }\end{array}$ \\
\hline $\begin{array}{l}\text { Servicio de Control } \\
\text { de Accesos }\end{array}$ & $\begin{array}{l}\text { Este Servicio permite acceder a los servicios } \\
\text { puntales de acuerdo a los roles asignados para } \\
\text { el usuario. }\end{array}$ \\
\hline Servicio de Consulta & $\begin{array}{l}\text { Este servicio entrega accesos de acuerdo a los } \\
\text { modulos asignados de acuerdo a rol y } \\
\text { competencia de la entidad. }\end{array}$ \\
\hline $\begin{array}{l}\text { Servicio de } \\
\text { Seguridad Avanzada }\end{array}$ & $\begin{array}{l}\text { Este servicio entrega soluciones diversas a los } \\
\text { usuarios tales como: } \\
\text { - Emisión de Boletines de Seguridad } \\
\text { Personalizados. } \\
\text { - Servicio de Ranking de Pentesters. }\end{array}$ \\
\hline
\end{tabular}




\begin{tabular}{|l|l|}
\hline Servicios de TI & Descripción de Servicio TI \\
\hline & $\begin{array}{l}\text { - Servicio de Analisis Forense y Búsqueda de } \\
\text { Evidencias IT. } \\
\text { - Capacitación Online a técnicos TI } \\
\text { - Servicio de Ethical Hacking/Pentesting a } \\
\text { Demanda. } \\
\text { - Monitoreo de Servicios }\end{array}$ \\
\hline $\begin{array}{l}\text { Servicio de Registro } \\
\text { de Proyectos IDEP }\end{array}$ & $\begin{array}{l}\text { Servicio que permite a los usuarios registrar } \\
\text { los proyecto referentes a Georeferenciación. }\end{array}$ \\
\hline Servicio de Portales & $\begin{array}{l}\text { Servicio de administración de portales, que } \\
\text { permite administrar los diversos portales que } \\
\text { se entregan las entidades del estado.Aqui se } \\
\text { encuentra gestionados los portales del estado } \\
\text { peruano, portal de transparencia y diversos } \\
\text { portales de la PCM. }\end{array}$ \\
\hline
\end{tabular}

Fuente: Manual de Gestión ONGEI v1.0 
Figura 4. 11

Catálogo de servicios técnicos y activos de servicios

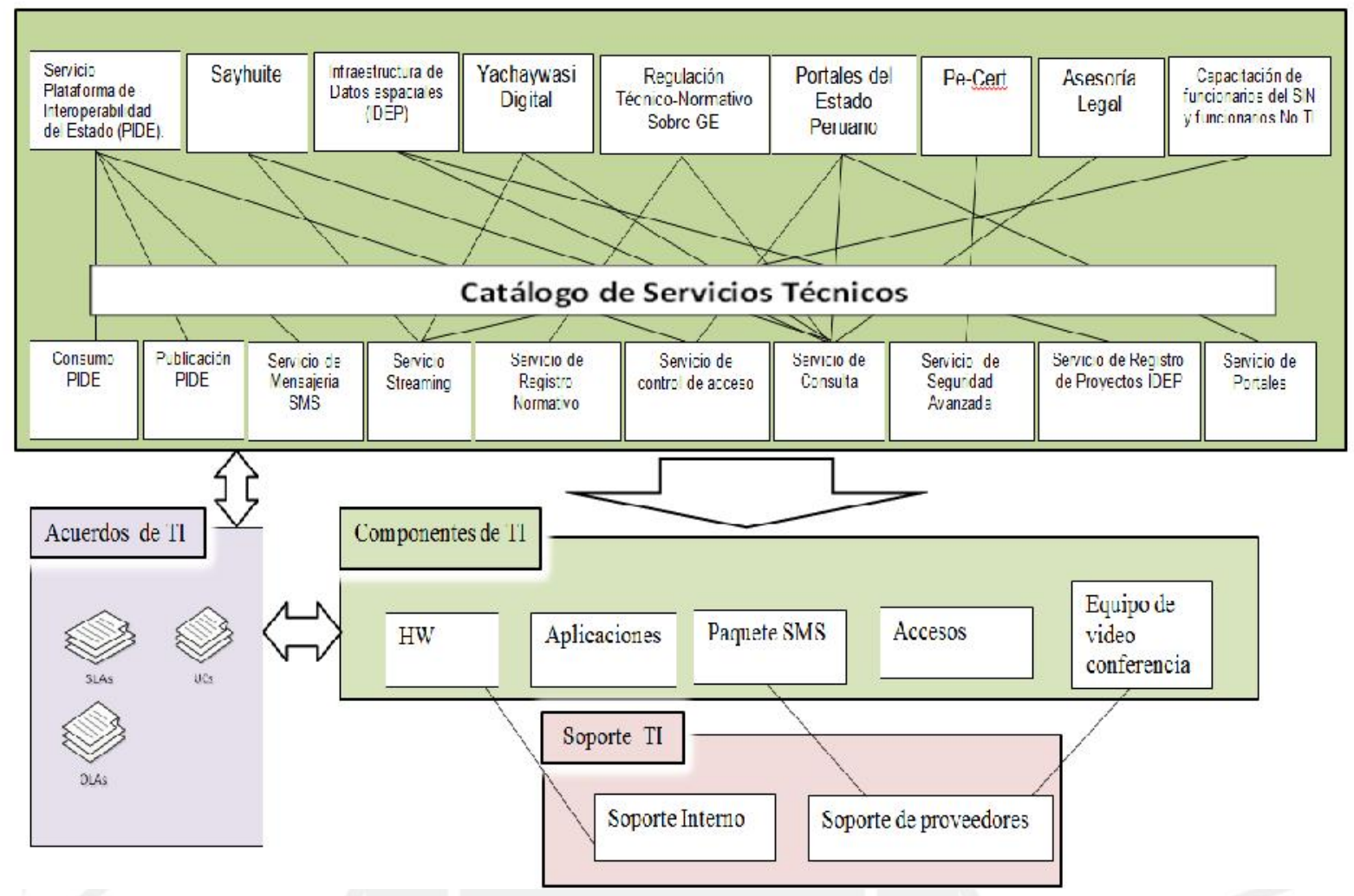

Fuente: Manual de Gestión ONGEI v1.0

La figura 4.11 muestra cómo interactúan los servicios técnicos con los componentes de TI, acuerdos de TI y soporte TI. De acuerdo a las entrevistas realizadas durante la investigación se pudo verificar que el SLA relacionado con la atención de incidentes debe ser modificado. Respecto a los niveles de acuerdo operativo (OLAs) no se encontró documentación.

\section{e) Análisis Comparativo con ITIL}

De acuerdo a la clasificación de niveles de ITIL v3.0, la Entidad Gubernamental se encuentra en el Nivel 0, concordando con las características que se muestra en la Figura 4.12. Durante las entrevistas realizadas a los diversos equipos de trabajo se pudo observar que los 
diversos intentos de aplicar las buenas prácticas de ITIL no han tenido la continuidad necesaria que la entidad requiere.

Figura 4. 12

Servicios de TI - Modelo de madurez de gestión

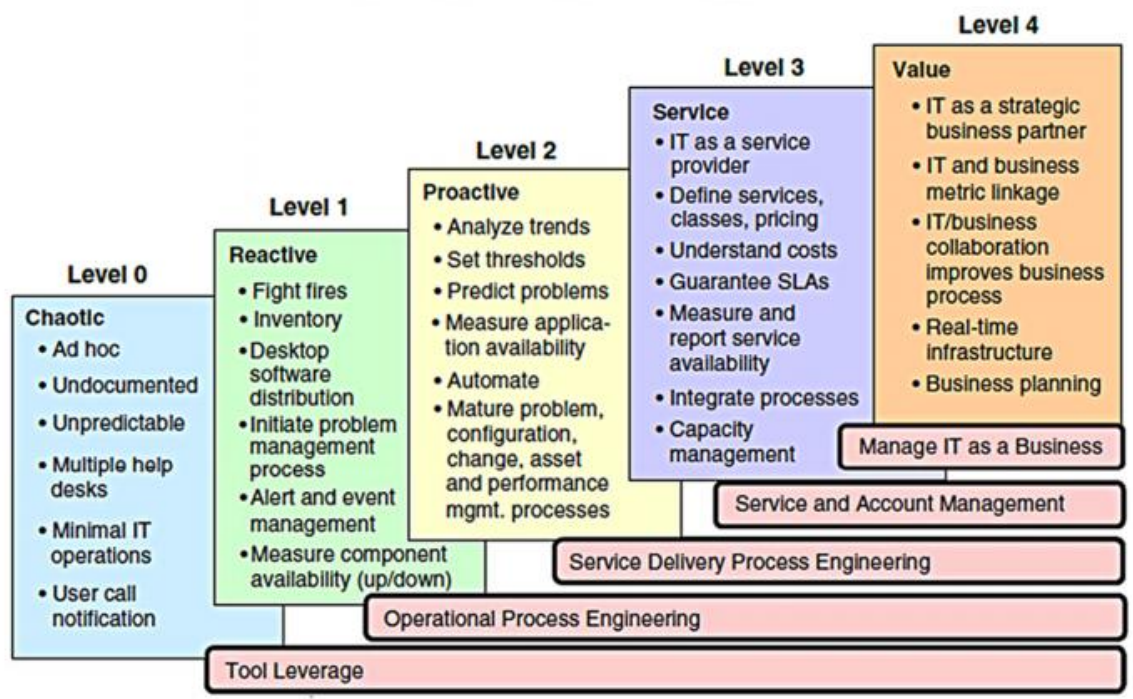

Fuente: Technology and Investment, http://dx.doi.org/10.4236/ti.2013.43022

Luego de ver el nivel de madurez de la entidad se procedió a verificar los elementos con los que cuenta la entidad para de esta manera poder determinar que procesos deben ser mejorados. A continuación se muestra en la tabla 4.4 la verificación realizada. 
Tabla 4.4

Cuadro comparativo

\begin{tabular}{|c|c|c|c|c|}
\hline & \multirow[b]{2}{*}{ Elementos } & \multicolumn{2}{|c|}{ Entidad } & \multirow{2}{*}{ Observación } \\
\hline & & $\begin{array}{l}\mathbf{S} \\
\mathbf{I}\end{array}$ & $\begin{array}{l}\mathbf{N} \\
\mathbf{O}\end{array}$ & \\
\hline \multirow{5}{*}{$\stackrel{\sim}{E}$} & $\begin{array}{l}\text { Estructura } \\
\text { Organizacional ITIL }\end{array}$ & $\mathrm{X}$ & & $\begin{array}{l}\text { Falta de madurez en la organización y } \\
\text { redefinir procesos. }\end{array}$ \\
\hline & Catálogo de Servicios & $\mathrm{X}$ & & $\begin{array}{l}\text { No está actualizado, es necesario } \\
\text { modificar el modelo o crear otro. }\end{array}$ \\
\hline & $\begin{array}{l}\text { Acuerdo de Nivel de } \\
\text { Servicios(SLA) }\end{array}$ & $\mathrm{X}$ & & No está actualizado, falta redefinir. \\
\hline & $\begin{array}{l}\text { Acuerdos de nivel de } \\
\text { Operación(OLA) }\end{array}$ & & $\mathrm{X}$ & $\begin{array}{l}\text { No está definido. Se necesita } \\
\text { establecer acuerdos internos. }\end{array}$ \\
\hline & Gestión de Incidentes & $X$ & & $\begin{array}{l}\text { No hay una buena administración de } \\
\text { Incidentes. Es necesario implementar } \\
\text { un nuevo modelo. }\end{array}$ \\
\hline
\end{tabular}

Fuente: Elaboración propia

El análisis realizado muestra que a pesar de tener una estructura organizacional ITIL, la entidad se encuentra en el nivel 0 de madurez como se mencionó anteriormente.

\subsection{Estadísticas de gestión de incidentes}

A continuación se muestran las estadísticas proporcionadas por el equipo de Mesa de ayuda, estos resultados son del estado actual (AS-IS).

El estado incidentes del último trimestre del 2014 se observa en al siguiente tabla 4.5: 
Tabla 4.5

Estado de Incidentes del último trimestre del año 2014.

\begin{tabular}{|l|c|c|c|c|c|}
\hline \multirow{2}{*}{ MES } & \multicolumn{5}{|c|}{ ESTADO DE INCIDENTES } \\
\cline { 2 - 6 } & Registrado & Activo & Suspendido & Atendido & Cerrado \\
\hline Octubre & 1256 & 55 & 360 & 841 & 750 \\
\hline Noviembre & 948 & 28 & 317 & 603 & 574 \\
\hline Diciembre & 1051 & 47 & 270 & 734 & 624 \\
\hline
\end{tabular}

Fuente: Entidad Gubernamental - Equipo de Mesa de ayuda

Estado Registrado: Estado de un incidente al momento en que es creado y registrado. Ver figura 4.13

Figura 4. 13

Estado Registrado de Incidentes

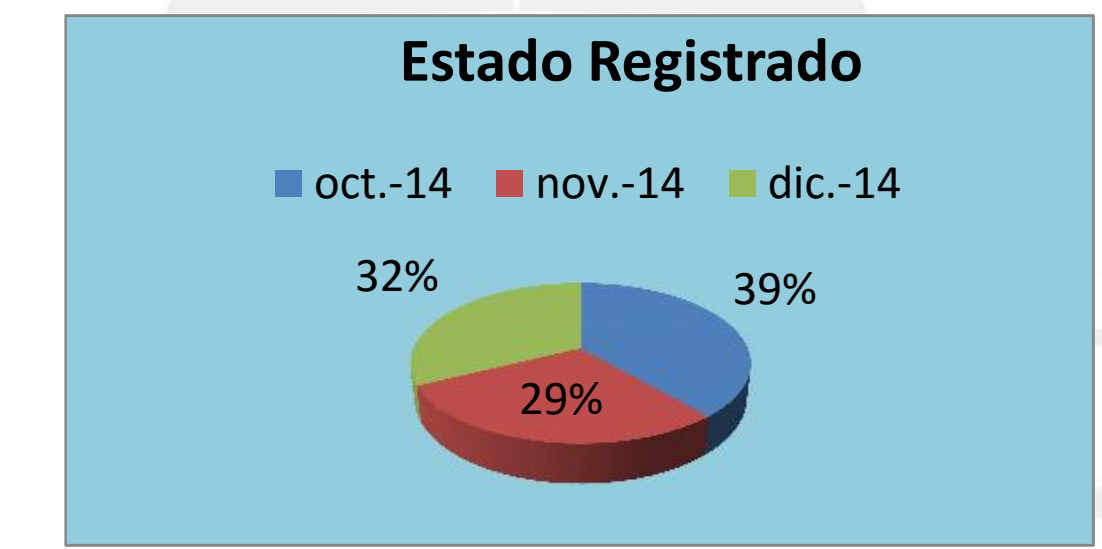

Fuente: Elaboración propia

De acuerdo a la información provista por el equipo de Mesa de ayuda, se pudo observar que los registros realizados fueron realizados personas de diversos equipos de trabajo, presentando en muchos casos duplicidad de registro por lo que la información mostrada servirá solo como referencia inicial.

Estado Activo: Indica que el incidente se encuentra en el portal de servicio, que ha sido derivado y que está siendo resuelto. Ver figura 4.14 
Figura 4. 14

Estado Activo de Incidentes

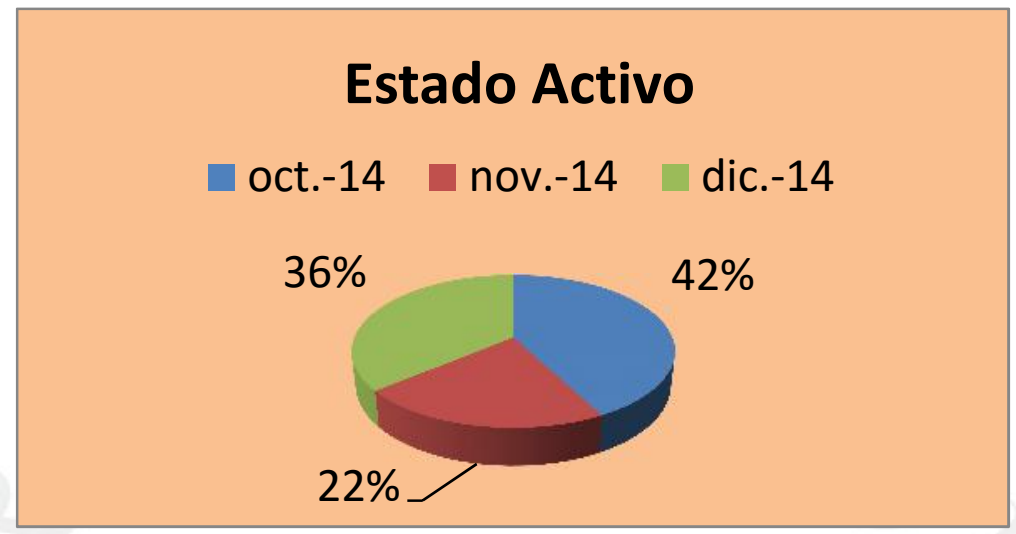

Fuente: Elaboración propia

Esta información muestra la cantidad de incidentes activas durante los meses de octubre , noviembre y diciembre del año 2014, según el equipo de Mesa de ayuda muchos de los incidentes derivados se resolvieron directamente con la entidad usuaria sin devolver al equipo de Mesa de ayuda la resolución del incidente, entendiendo que las estadística entregadas por ellos es referencial.

Estado Suspendido: Incidente que fue registrado, que pudo haber sido derivado o no, pero que ha sido suspendido (generalmente por el propio usuario solicitante). Ver figura 4.15 
Figura 4. 15

Estado Suspendido de Incidentes

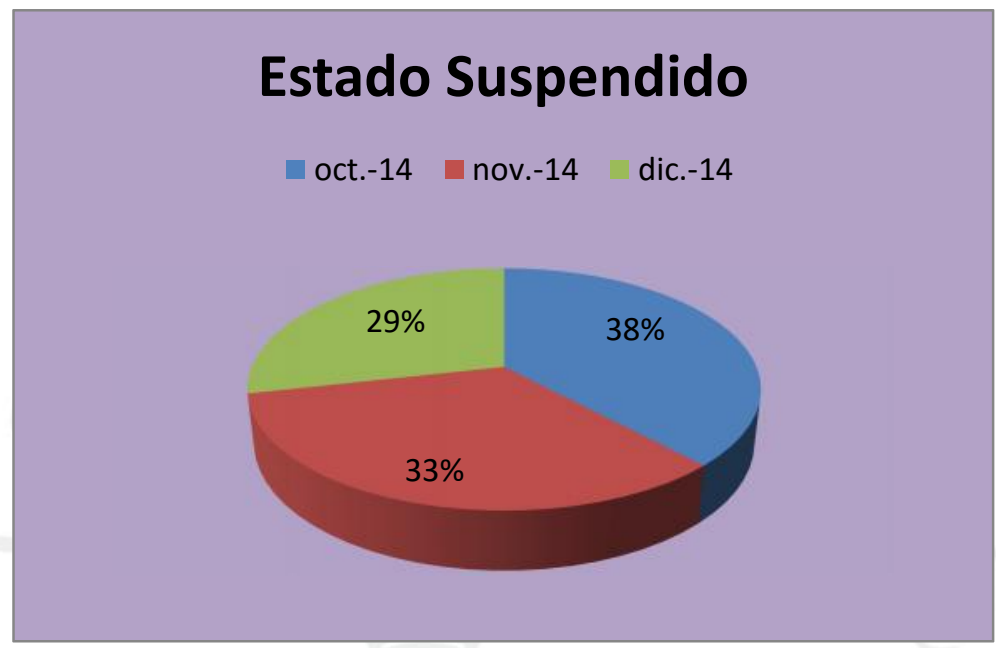

Fuente: Elaboración propia

Los incidentes suspendidos que se muestran en el gráfico son los reportados por el equipo de Mesa de ayuda, de acuerdo a la información el incidente pasó a suspenderse por diversos motivos como en el caso de duplicidad de registros cada vez que fue fueron detectados en su momento así como también por una mal registro del incidente que no correspondía al área de TI. 
Estado Atendido: Incidente, registrado, que fue activo y que ya está resuelto, esperando conformidad de usuario. Ver figura 4.16

Figura 4. 16

Estado Atendido de Incidentes

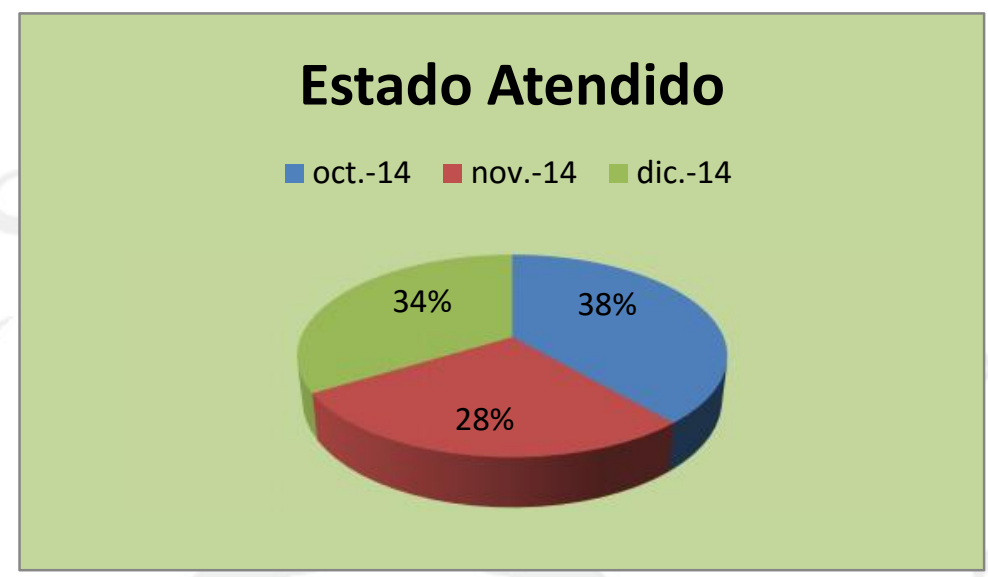

Fuente: Elaboración propia

Este estado corresponde según la definición entregada por el equipo de Mesa de ayuda a los incidentes resueltos, quedando pendiente conformidad por parte del usuario final. Esta estadística creada por el equipo de Mesa sirve para llevar el control respecto a la retroalimentación con el usuario. 
Estado Cerrado: Incidente atendido y que el usuario ya dio su conformidad y ha sido verificado. Ver figura 4.17

Figura 4. 17

Estado Cerrado de Incidentes

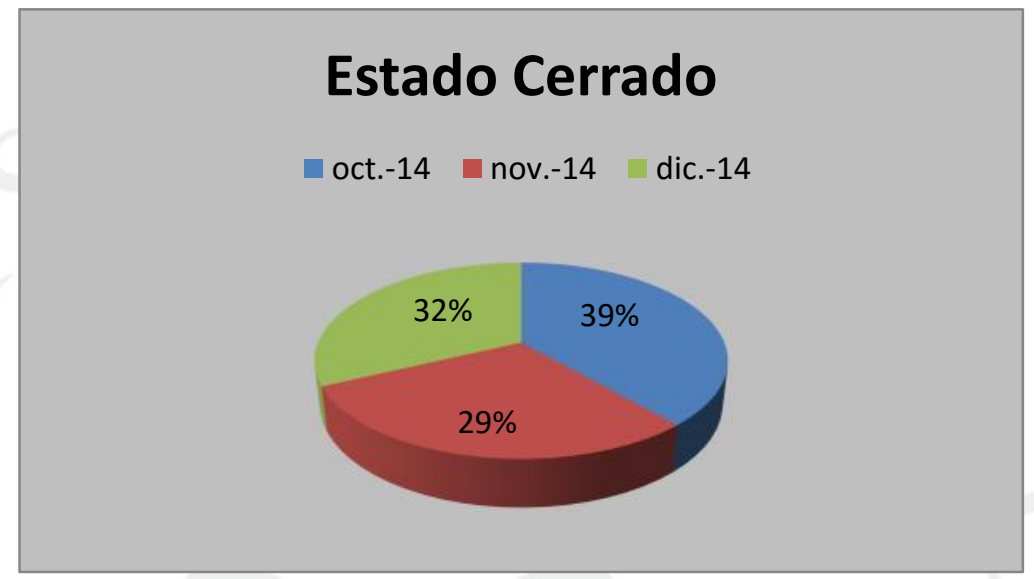

Fuente: Elaboración propia

Los incidentes cerrados en ese trimestre son los que completaron todas las etapas correspondientes de atención, cabe señalar que muchos de los incidentes cerrados fueron realizados por otros equipos de trabajo distintos al de Mesa de Ayuda. 
Figura 4. 18

Histograma de Incidentes por Estado y mes

\section{Entidad de Gobierno - Estadísticas de Incidentes por Estado y mes}

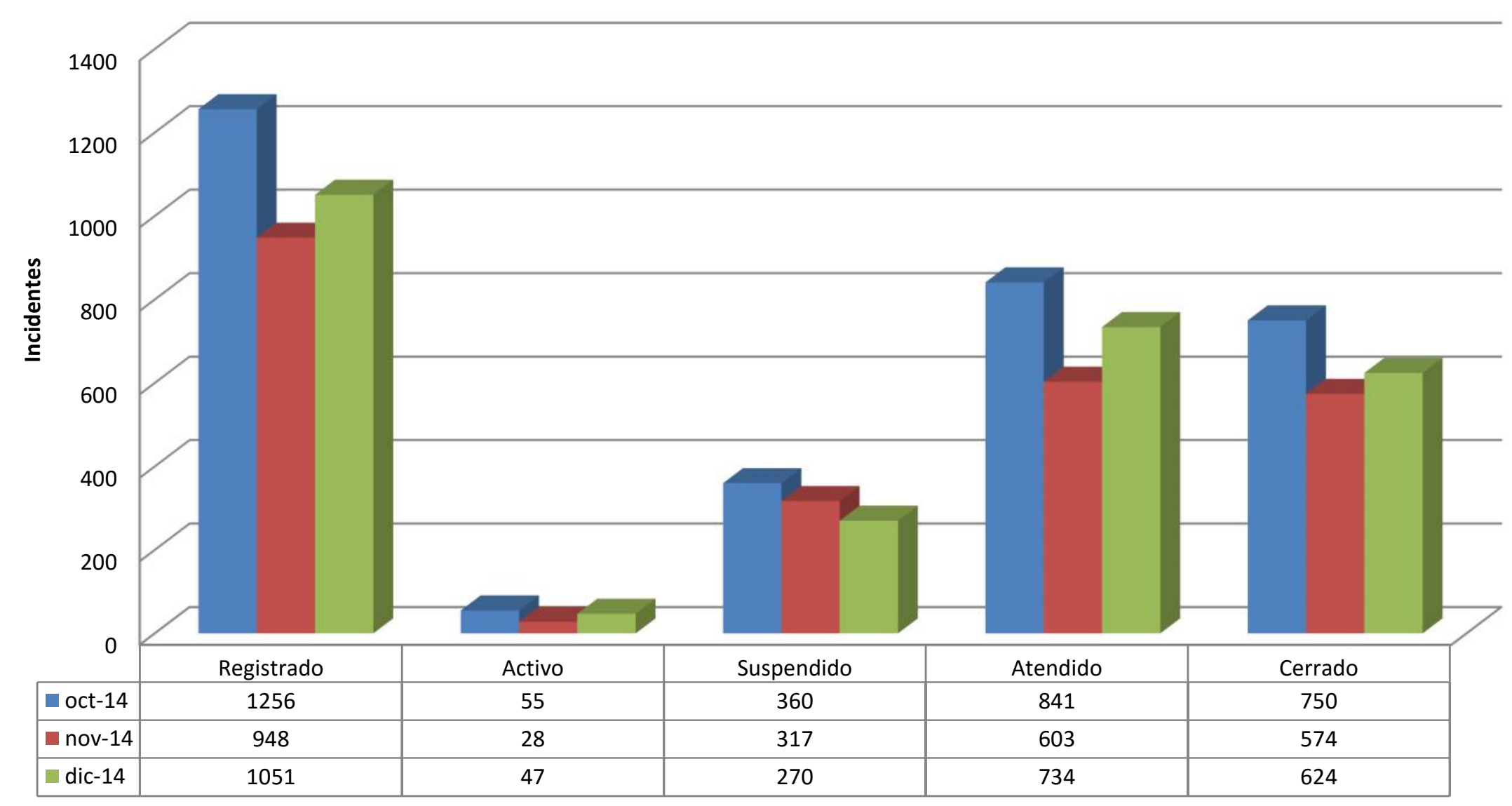

Fuente: Elaboración propia 
Debido a que no se tiene un formato adecuado de registro, actualmente no se pueden medir tiempos y estados de los incidentes, la información mostrada en la tabla $\mathrm{N}^{\circ} 4.5$ fue elaborada con apoyo del personal de mesa de ayuda.

El gráfico muestra la información de los diversos estados para el manejo de incidentes de la entidad gubernamental. Esta información entregada por el equipo de Mesa de ayuda muestra un panorama general que permite ver que existe un manejo poco adecuado en la atención de registros de incidentes, su escalamiento, comunicación con el usuario y la falta de coordinación entre equipos de trabajo del área, siendo estos los aspectos más saltantes de lo observado durante las recopilación de esta información.

\subsection{Diagnóstico de la gestión actual de incidentes}

- No hay una política definida de registro y atención de incidentes.

- El registro actual es una limitante para obtener indicadores más puntuales.

- Existe un alto de nivel incumplimiento por parte las entidades del estado en temas relacionados a POI, ENRIAP y algunos otros servicios obligatorios, debido a vacíos en los SLAs (Niveles de acuerdo de Servicio).

- Se necesita establecer procedimientos claros y sustentar la necesidad de mantenerlos, independientemente si existen cambios de jefes, directivos y/o gente de confianza de políticos de turno.

- El modelo actual no soporta eficientemente los incidentes generados para los nuevos servicios que actualmente entrega la Entidad Gubernamental.

- De acuerdo a lo observado el registro de incidentes es realizado por los diversos equipos de trabajo (equipo de mesa de ayuda, Soporte y Seguridad de TI) lo que ocasiona muchas veces duplicidad de esfuerzos y poca certeza en el registro de información. 
- De acuerdo al registro actual no se pude determinar si los incidentes registraron fueron de alto o bajo impacto y cuántos de estos fueron recurrentes y se convirtieron en problemas. 


\section{CAPÍTULO V: DISEÑO E IMPLEMENTACIÓN DE LA PROPUESTA}

El modelo propuesto, se basa en el núcleo de ITIL v3.0 y estará soportado en las buenas prácticas de ITIL, aplicado a la Gestión de Incidentes.

La propuesta involucra cambios tecnológicos y de organización, para lo cual el apoyo que presta el máximo responsable de la entidad es fundamental para aplicar el modelo propuesto.

La implementación y pruebas al modelo se realizarán con la herramienta adquirida por la entidad, la cual permitirá aplicar parte del modelo de Gestión de Incidentes propuesto y obtener indicadores que permitan analizar los resultados de la propuesta.

Durante la implementación se presentaron cambios en la Presidencia de Consejo de Ministros (PCM) que afectaron a la entidad en estudio, teniendo que involucrar nuevas personas en la puesta en marcha del modelo de Gestión de Incidentes; a pesar de los cambios, estos inconvenientes fueron superados con satisfacción gracias a que el nuevo personal se involucró adecuadamente.

Cabe señalar que en principio el modelo se aplicará en modo piloto en la Entidad Gubernamental para evaluar el posible impacto organizacional en el mismo, para que posteriormente el área de TI pase a la fase de reorganización.

\subsection{Estrategia del Servicio del Modelo Propuesto}

Esta fase sirve para que el modelo propuesto se ajuste a la visión estratégica y política de la Entidad Gubernamental. 


\subsubsection{Objetivos}

1. Entregar un modelo estructurado que permita la recepción, clasificación y registro de incidentes enviados por las entidades gubernamentales, con la finalidad de gestionarlos de una manera eficiente y con un mayor grado de calidad en la atención. Parte de esta propuesta conlleva a redefinir el Catálogo de Servicios (Anexo 3)

2. Generación automática de notificaciones vía correo al usuario al momento de registrar un incidente, notificado por él.

3. Crear las condiciones para que la trazabilidad de los incidentes sea la adecuada y permita tener informados a los usuarios sobre el estado de sus requerimientos

4. Reducir el nivel de incumplimiento de los diversos SLAs. Para esto se hace necesaria la modificación de los mismos. Ver Anexo 1.

5. Crear una línea base de indicadores para medir la madurez del modelo propuesto.

6. Proponer un modelo de Acuerdo de Nivel Operativo (OLA) que permita tener un mejor control de los tiempos de respuesta por cada servicio involucrado. Ver Anexo 5.

\subsubsection{Estrategias a implementar}

1. Hacer que el equipo de Mesa de ayuda sea el único punto de contacto con los usuarios, con el fin de establecer el orden adecuado de atención de los incidentes durante todas las etapas que correspondan a cada incidente y que el usuario pueda tener la trazabilidad requerida a través de un único punto de contacto.

2. Diseñar un modelo de Gestión de Incidentes, acorde a la organización y a los objetivos propuestos 
3. Contar con una base de datos de conocimientos, para brindar una atención rápida a los usuarios solicitantes dentro del soporte de primera línea.

4. Crear un nuevo modelo de catálogo de servicios que permita delimitar las funciones y compromisos de la mesa de ayuda con respecto a los servicios de TI que se brindan y que estos se adapten a las necesidades que presenten los usuarios de la Entidad Gubernamental. El modelo propuesto del nuevo catálogo se muestra en el anexo 3.

5. Crear un plan de capacitación para los involucrados en ITIL v3, que les permita adecuarse a los cambios del modelo propuesto. Es necesario también capacitar al personal de mesa de ayuda en el manejo de situaciones cuando se atiende a las entidades del estado. Se propone aprovechar los convenios con entidades gubernamentales relacionados al tema.

El plan de capacitación se muestra a continuación en la tabla 5.1: 
Tabla 5.1

Propuesta de Capacitaciones

\begin{tabular}{|c|c|c|}
\hline \multicolumn{3}{|c|}{ Plan de Capacitación } \\
\hline Curso & Objetivos & Personal \\
\hline ITIL Foundation v3.0 & $\begin{array}{l}\text { - } \text { Obtener conocimientos } \\
\text { sobre las buenas prácticas } \\
\text { de ITIL v3.0 }\end{array}$ & $\begin{array}{ll}\text { - } & \text { Equipos de } \\
& \text { Soporte } \\
\text { - } & \text { Equipo de Mesa } \\
& \text { de ayuda } \\
\text { - } & \text { Equipo de } \\
& \text { Seguridad } \\
& \text { Informática. } \\
\text { - Jefe de área }\end{array}$ \\
\hline $\begin{array}{l}\text { Laboratorio de Gestión } \\
\text { de Incidentes. }\end{array}$ & 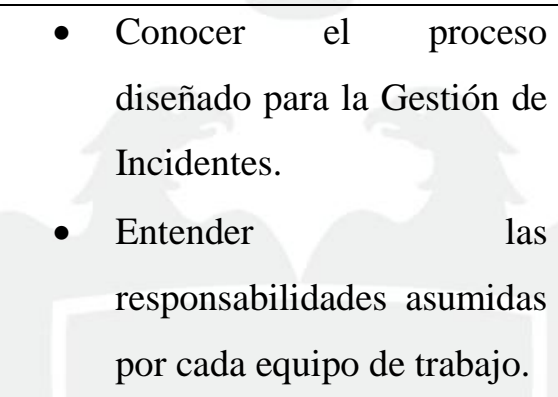 & $\begin{array}{ll}\text { - } & \text { Equipos de } \\
\text { Soporte } \\
\text { - } \\
\text { Equipo de Mesa } \\
\text { de ayuda } \\
\text { - } \\
\text { Equipo de } \\
\text { Seguridad } \\
\text { Informática. }\end{array}$ \\
\hline $\begin{array}{l}\text { Técnicas de Atención } \\
\text { a Usuarios }\end{array}$ & $\begin{array}{l}\text { - Desarrollar habilidades } \\
\text { comunicativas y de manejo } \\
\text { de tiempos que mejoren la } \\
\text { calidad de atención. }\end{array}$ & $\begin{array}{l}\text { Equipo de Mesa } \\
\text { de ayuda }\end{array}$ \\
\hline
\end{tabular}

Fuente: Elaboración propia

6. Proponer una nueva organización para el área de Gestión de TI, que permita llevar un mejor control de los incidentes.

Esta nueva organización propone implementar el área de Control, el cual estará liderado por el Gestor de Servicios de TI, este nuevo esquema permite tener a una persona con el perfil requerido para cubrir temas relevantes del área y darle el apoyo necesario al jefe de área de turno. Hay que tener presente que la rotación de jefes de área hace que muchos compromisos y responsabilidades de la Entidad Gubernamental se detengan. 
El cambio se muestra en la siguiente figura 5.1:

Figura 5. 1

Nuevo Organigrama para el área de TI (TO-BE)

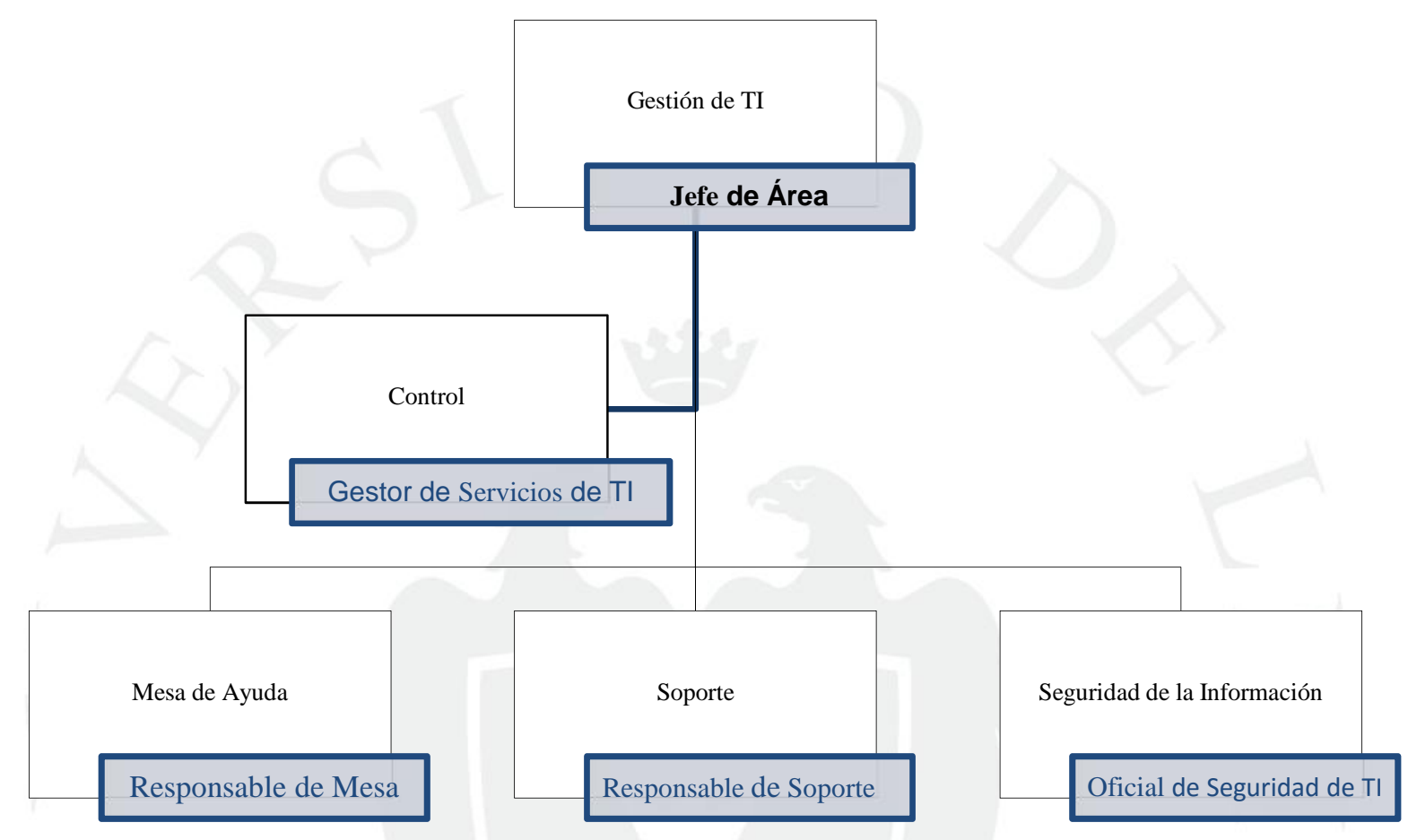

Fuente: Elaboración Propia

\subsection{Diseño del Servicio del Modelo Propuesto}

En esta fase se busca diseñar un modelo de gestión de incidentes basado en ITIL v3.0, e incorporar los nuevos servicios que mejoren la situación actual del organismo público en estudio.

\subsubsection{Identificación de Roles para la descripción de Roles}

A continuación en la tabla 5.2 se definen los roles propuestos para la Entidad Gubernamental. 
Tabla 5.2

Roles en la Gestión de Incidentes

\begin{tabular}{|l|l|}
\hline \multicolumn{1}{|c|}{ Roles } & \multicolumn{1}{|c|}{ Descripción } \\
\hline Usuario & $\begin{array}{l}\text { Entidades del Estado que usan servicios de TI de } \\
\text { la Entidad Gubernamental. }\end{array}$ \\
\hline Gestor de Incidentes & $\begin{array}{l}\text { Será definido como el Dueño del proceso y } \\
\text { encargado del buen funcionamiento del proceso y } \\
\text { la obtención de las métricas del proceso. Este rol } \\
\text { será asumido por el responsable de mesa de } \\
\text { ayuda. }\end{array}$ \\
\hline $\begin{array}{l}\text { Soporte 1er nivel (Nivel } \\
\text { Primario) }\end{array}$ & $\begin{array}{l}\text { Personas de primer contacto que reciben los } \\
\text { incidentes (HelpDesk). }\end{array}$ \\
\hline $\begin{array}{l}\text { Soporte de Siguiente Nivel } \\
\text { N nivel) }\end{array}$ & $\begin{array}{l}\text { Personal que resuelve los incidentes no resueltos } \\
\text { en el nivel primario, puede ser proveedor, } \\
\text { fabricante o experto de la Entidad } \\
\text { Gubernamental. Los niveles son de 2do o 3er } \\
\text { dependiendo del incidente. }\end{array}$ \\
\hline Gestor de Servicios de TI & $\begin{array}{l}\text { Será el responsable de la gestión de los servicios } \\
\text { en la Entidad Gubernamental durante todo el ciclo } \\
\text { de vida de estos. }\end{array}$ \\
\hline
\end{tabular}

Fuente: Entidad Gubernamental - Elaboración propia

\section{a) Matriz RACI}

La definición de esta matriz, permitirá aclarar roles operativos, responsabilidades y relaciones para la Gestión de Incidentes de la Entidad Gubernamental. Esto ayudará a:

- Definir las actividades por cada rol

- Definir y acordar responsabilidades.

- Mejorar la comunicación.

- Evitar el doble esfuerzo, además de evitar la cultura de "la culpa".

- Conseguir que se mejore la atención de incidentes dentro de los plazos establecidos y correctamente solucionados.

A continuación en la tabla 5.3 mostramos la matriz RACI para la entidad. 
Tabla 5.3

Matriz RACI para la Gestión de Incidentes en la Entidad Gubernamental

\begin{tabular}{|c|c|c|c|c|c|c|}
\hline \multirow[b]{2}{*}{ Actividades } & \multicolumn{6}{|l|}{ Roles } \\
\hline & $\begin{array}{l}\text { Usuario } \\
\text { de TI }\end{array}$ & $\begin{array}{ll}\text { Soporte de } \\
\text { Primer } & \\
\text { nivel } & \\
\text { Mesa } & \text { de } \\
\text { ayuda } & \end{array}$ & $\begin{array}{l}\text { Soporte } \\
\text { Técnico } \\
\text { de Nivel } \\
\mathrm{N}\end{array}$ & \begin{tabular}{|l|} 
Responsabl \\
e de Área
\end{tabular} & $\begin{array}{l}\text { Gestor de } \\
\text { Incidentes }\end{array}$ & $\begin{array}{ll}\text { Gestor } & \text { de } \\
\text { Servicios } & \text { de } \\
\text { TI } & \end{array}$ \\
\hline Identificación & $\mathrm{C}$ & $\mathrm{R}$ & & & A & $\mathrm{I} / \mathrm{C}$ \\
\hline $\begin{array}{l}\text { Registro, Clasificación } \\
\text { y Soporte Inicial del } \\
\text { Incidente }\end{array}$ & C & $\mathrm{R}$ & I & & A & $\mathrm{I} / \mathrm{C}$ \\
\hline $\begin{array}{l}\text { Investigación } \\
\text { Diagnóstico }\end{array}$ & $\mathrm{C}$ & $\mathrm{I} / \mathrm{R}$ & $\mathrm{R}$ & I & A & $\mathrm{I} / \mathrm{C}$ \\
\hline $\begin{array}{l}\text { Solución, } \\
\text { Recuperación }\end{array}$ & I & $\mathrm{I} / \mathrm{R}$ & $\mathrm{R}$ & & A & $\mathrm{I} / \mathrm{C}$ \\
\hline Cierre & $\mathrm{C}$ & $\mathrm{R}$ & & & A & $\mathrm{I} / \mathrm{C}$ \\
\hline
\end{tabular}

Fuente: Elaboración propia

\subsubsection{Indicadores propuestos del modelo}

Es necesario definir algunos indicadores que permitan medir el nivel de madurez que vaya adquiriendo el modelo, a continuación se muestra un listado de indicadores propuestos:

1. Tiempo mínimo de atención de un incidente en un mes

2. Tiempo máximo de atención de un incidente en un mes

3. Porcentaje de reducción de incidentes

4. Número total de incidentes comunes.

5. Total de incidentes agrupados por tipo de prioridad.

6. Incidentes derivados a equipos de trabajo clasificados por tipo de prioridad.

7. Cantidad de incidentes agrupados por categoría.

8. Cantidad de incidentes repetidos solucionados con métodos conocidos. 
9. Número incidentes que desembocaron en problemas

Las métricas mostraran valores que nos permitirán analizar como el modelo propuesto está impactando en la Entidad Gubernamental. Se busca con estas métricas iniciales encontrar una línea base de indicadores que permitan identificar los ajustes a realizar.

\section{Categorización de Incidentes:}

Tabla 5.4

Categorización de Incidentes

\begin{tabular}{|l|l|l|l|}
\hline Categoría & Nivel 1 & Nivel 2 & Nivel 3 (*) \\
\hline Accesos & $\mathrm{x}$ & & \\
\hline Consultas & $\mathrm{x}$ & & \\
\hline Hardware & & $\mathrm{x}$ & \\
\hline Software & & $\mathrm{x}$ & \\
\hline Comunicaciones & & $\mathrm{x}$ & \\
\hline Equipos & & $\mathrm{x}$ & \\
\hline Aplicaciones & $\mathrm{x}$ & \multicolumn{2}{|l|}{} \\
\hline
\end{tabular}

Fuente: Elaboración propia 


\section{Niveles de Escalamiento por niveles de impacto:}

\section{Tabla 5.5}

\section{Descripción de los niveles impacto propuesto}
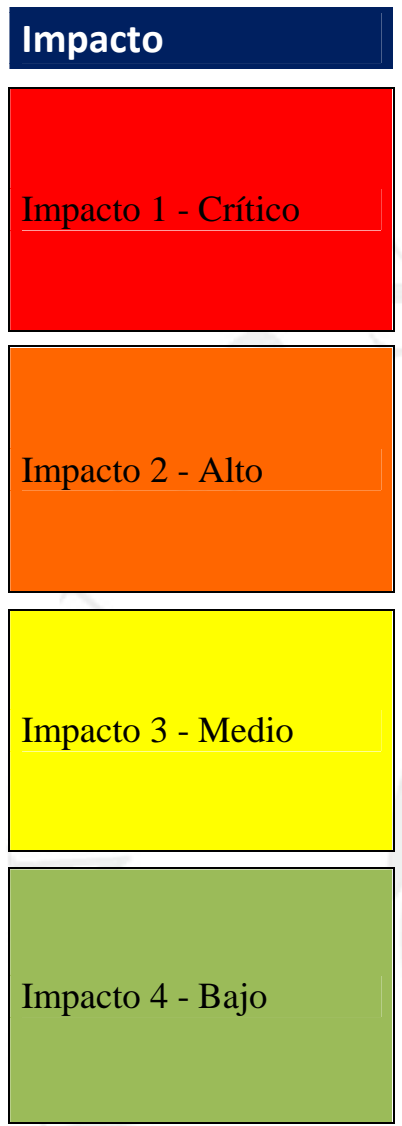

Fuente: Elaboración propia

\section{Descripción}

Incidente de alto impacto en las funciones críticas del negocio por indisponibilidad o degradación excesiva de desempeño de las aplicaciones y/o servicios, que requiere solución inmediata. No existe workaround.

Incidente de impacto significativo en alguna de las funciones del negocio por indisponibilidad o degradación de desempeño en las aplicaciones y/o servicios. El evento está controlado dado que existe un workaround, por lo tanto no requiere de una solución definitiva inmediata o los usuarios pueden esperar la restauración del servicio. La solución definitiva debe estar programada.

Incidente de impacto moderado en alguna de las funciones del negocio o por degradación leve de desempeño de las aplicaciones y/o servicios. El evento implica un número reducido de usuarios o clientes afectados y es de poca visibilidad. Existe un plan alternativo de solución y se puede esperar la solución definitiva. El riesgo inminente de que ocurra un incidente de impacto alto crítico también se debe considerar como severidad 3.

Incidente de bajo impacto en las funciones NO críticas del negocio y el usuario puede esperar a una fecha determinada para la solución definitiva. El usuario de negocio puede continuar con sus tareas críticas de la operación, se mantiene la funcionalidad y el desempeño de las aplicaciones y/o servicios. 
Definición de tiempos de respuesta y solución:

Tabla 5.6

Definición de tiempos de respuesta

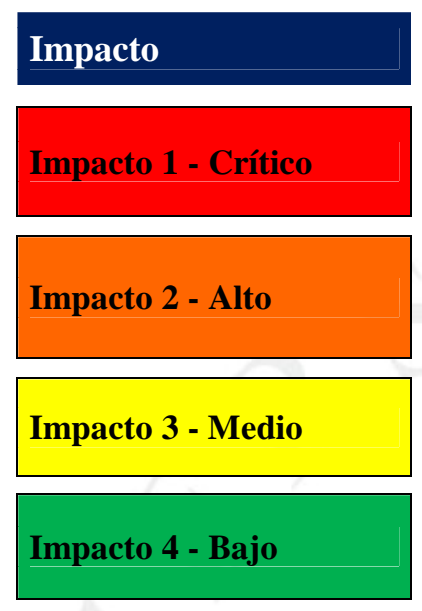

\section{Tiempo de Respuesta} $70 \%$ de incidentes dentro de 15
minutos

$\mathbf{7 0 \%}$ de incidentes dentro de 30 minutos

$70 \%$ de incidentes dentro de 8 horas

$70 \%$ de incidentes dentro de 1 día hábil

\section{Tiempo de Restauración}

95\% de incidentes dentro de 4 horas / $100 \%$ de incidentes dentro de 6 horas

95\% de incidentes dentro de 8 horas / $100 \%$ de incidentes dentro de 12 horas

$95 \%$ de incidentes dentro de 3 días hábiles

95\% de incidentes dentro de 5 días hábiles

Fuente: Elaboración propia

\subsubsection{Criterios de cambio entre niveles de impacto}

\section{Impacto - Downgrade son:}

De Impacto 1 a Impacto 2:

- No afecta aplicaciones críticas del negocio o el impacto es significativo en alguna de las funciones del negocio.

- Existe workaround o se puede esperar a la solución.

- El desempeño (performance) de la aplicación permite trabajar de manera limitada.

De Impacto 2 a Impacto 3:

- El impacto es moderado y se reduce solo para algunas funciones del negocio. 
De Impacto 3 a Impacto 4:

- El impacto es bajo en funciones no críticas del negocio.

\section{Impacto - Upgrade son:}

De Impacto 4 a Impacto 3:

- El incidente impacta moderadamente a un grupo de usuarios, o impacta alguna función del negocio.

De Impacto 3 a Impacto 2:

- El incidente impacta significativamente a varias funciones de negocio

- El incidente tiene visibilidad sobre clientes externos

De Impacto 2 a Impacto 1:

- No existe workaround

- Existe impacto alto en funciones críticas del negocio.

\subsection{Modelo Propuesto}

El modelo propuesto entrega un marco en detalle para la gestión de incidentes, con el propósito de adaptar las buenas prácticas de ITIL en la organización. El modelo se complementa con actividades de monitoreo que suplen algunas carencias ante la ausencia de procesos necesarios. (Ver figura 5.5). A continuación se describirán las actividades de monitoreo que servirán de soporte al modelo propuesto. 


\section{a) Monitoreo de Servicios de TI}

La Entidad Gubernamental como ente proveedor de servicios para las entidades del estado debe asumir un rol proactivo en la detección de incidentes, esto implica que se deban realizar actividades de monitoreo constantemente a los diversos equipos y sistemas.

Estas actividades deben ser realizadas por el equipo de Soporte de TI de la Entidad Gubernamental. El equipo de Soporte mantendrá informado al equipo de Mesa de ayuda y de esta manera se contribuirá a tener una eficiente atención de los incidentes.

Los procedimientos propuestos (Figuras 5.2, 5.3 y 5.4) serán documentados por el personal actual; adicionalmente se propuso que en los contratos del nuevo personal que ingrese se haga énfasis en el cumplimiento de los procedimientos preventivos del área de soporte para evitar que se realicen actividades distintas que puedan poner en riesgo la continuidad de los servicios.

A continuación se muestran algunos procedimientos propuestos debido a que involucran los componentes que afectan directamente a los servicios que ofrece la Entidad Gubernamental. Los demás procesos existentes deben de ser revisados para que se optimice la entrega de los servicios.

El responsable de soporte es el encargado de verificar que se ejecuten estas actividades.

Dentro de las actividades que se proponen monitorear tenemos: 
- Verificación de Servidores Físicos y Virtuales de la PIDE y otros Servicios, cuyo proceso propuesto se muestra en la figura 5.2

Figura 5.2

Flujo de Proceso propuesto para la verificación diaria de servidores

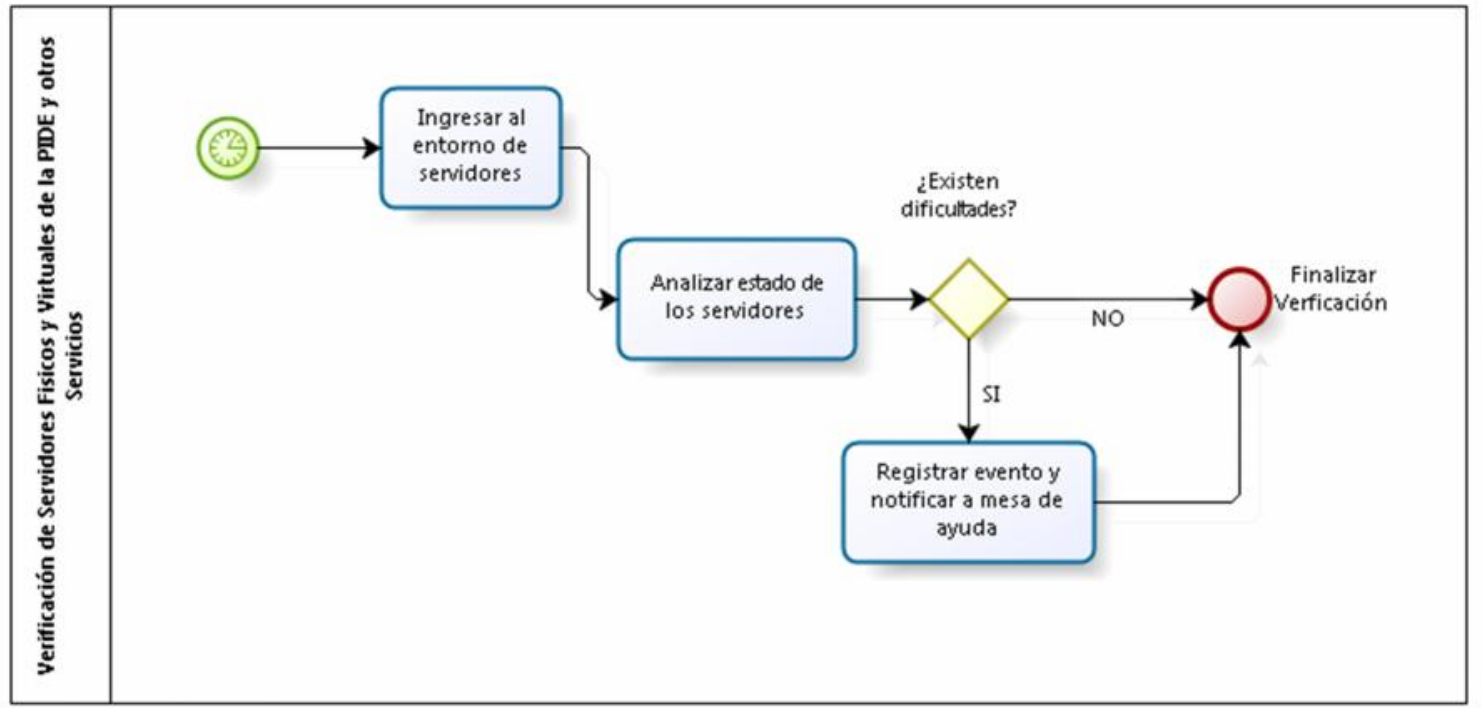

Fuente: Elaboración propia - Software Bizagi Process Modeler 
- Realización de pruebas de mensajería SMS se muestra en la figura 5.3, aquí se hace la verificación de la plataforma que hace el envío de los mensajes de acuerdo a la bolsa asignada a cada entidad.

Figura 5. 3

Flujo de Proceso propuesto para pruebas diarias de Servicios SMS

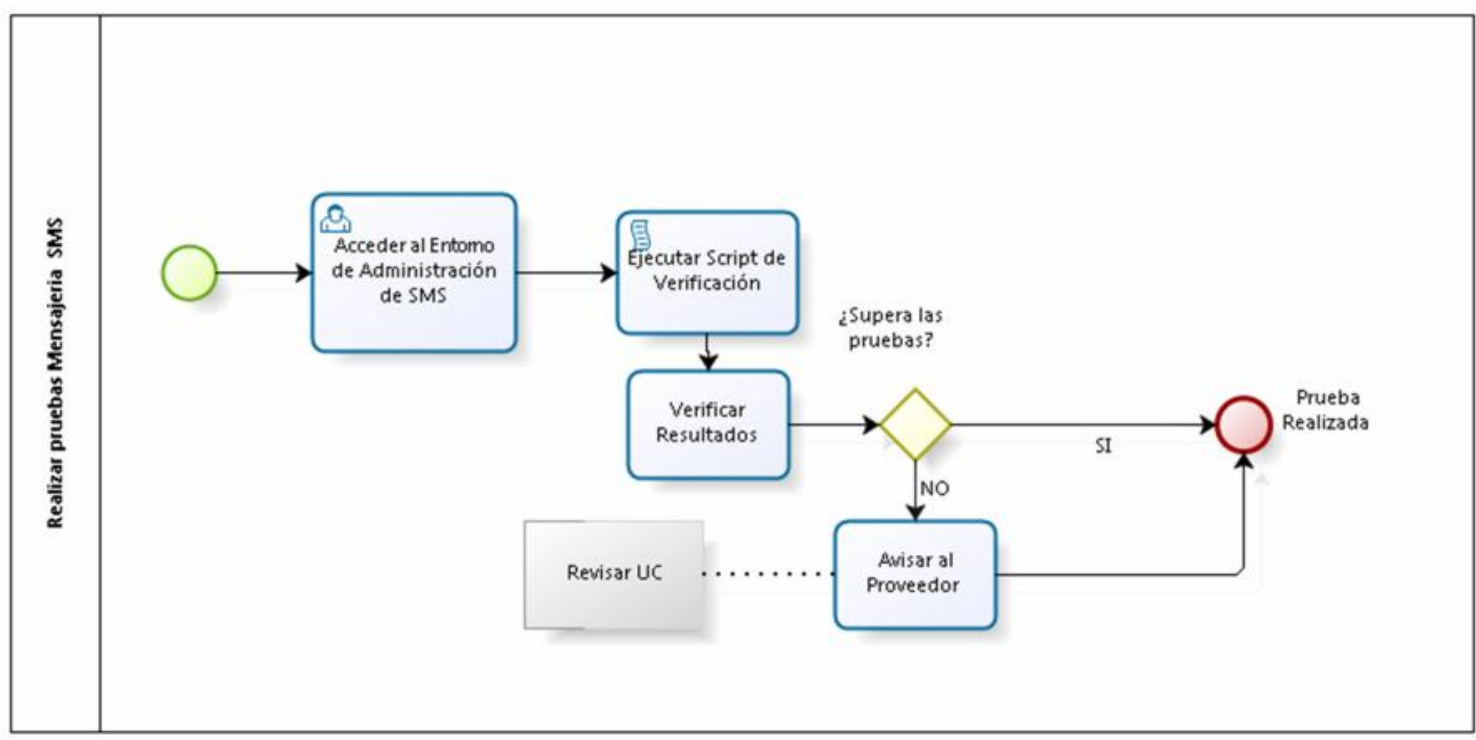

Fuente: Elaboración propia - Software Bizagi Process Modeler 
- Verificación diaria de usuarios bloqueados en el Directorio Activo se muestra en la figura 5.4. Aquí se hace la verificación de los usuarios bloqueados a todo nivel de acuerdo a los servicios que requieran accesos.

Figura 5. 4

Flujo de Proceso propuesto para la verificación de usuarios bloqueados

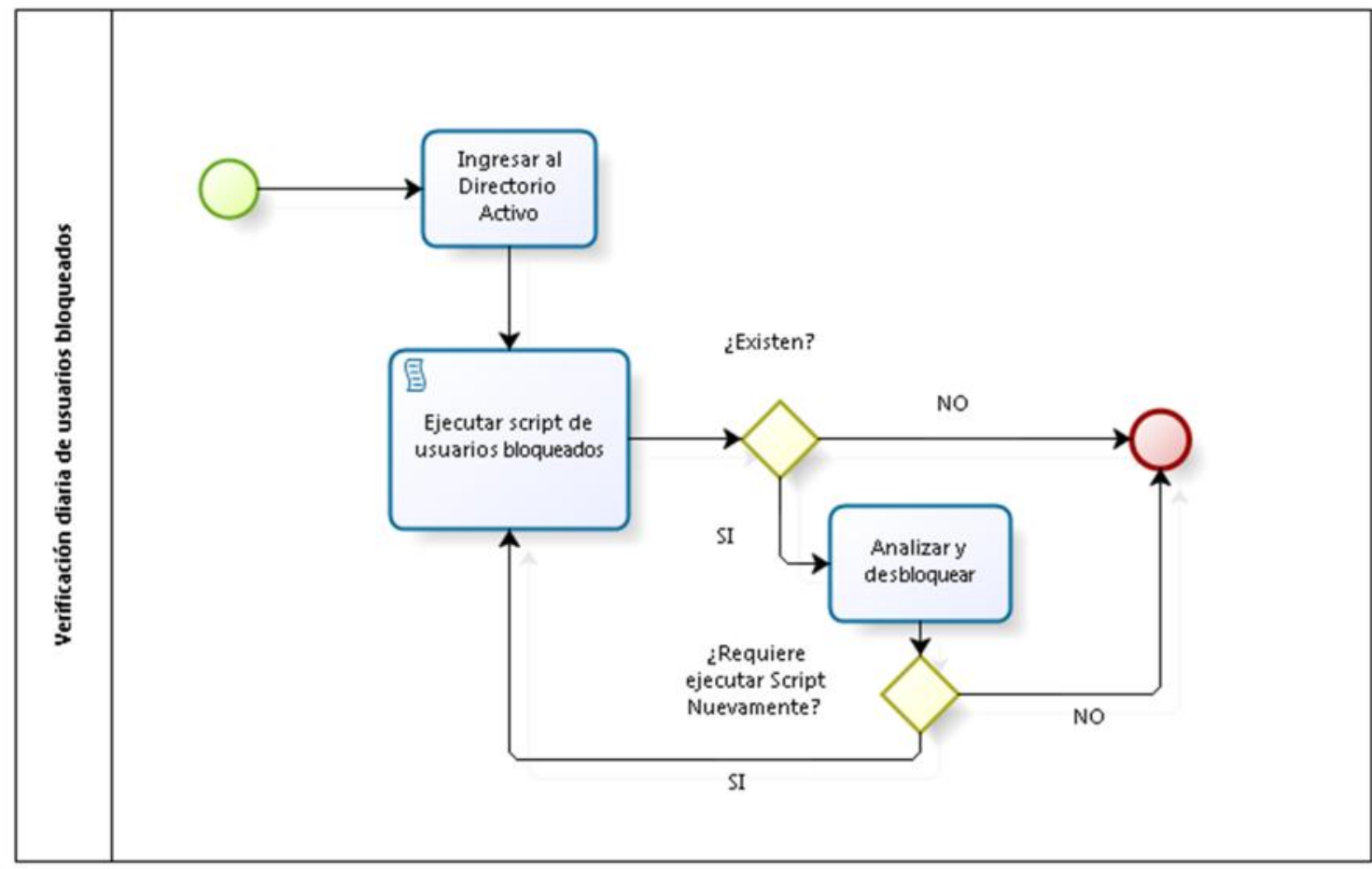

Fuente: Elaboración propia - Software Bizagi Process Modeler

Debido a la ausencia del proceso de gestión de eventos esta propuesta intenta dar las pautas iniciales para su posterior implementación, esto se conseguirá de acuerdo al nivel de madurez que la entidad vaya adquiriendo. El modelo propuesto busca que se incentive las acciones preventivas que permitan analizar las tendencias presentadas por alertas y eventos. Para cubrir la ausencia algunos procesos necesarios, se habilitará un módulo dentro la herramienta (ServiceTonic) exclusivo para el registro de eventos que será gestionado por el equipo de soporte. 
Figura 5. 5

Modelo para la Gestión de Incidentes en la Entidad Gubernamental

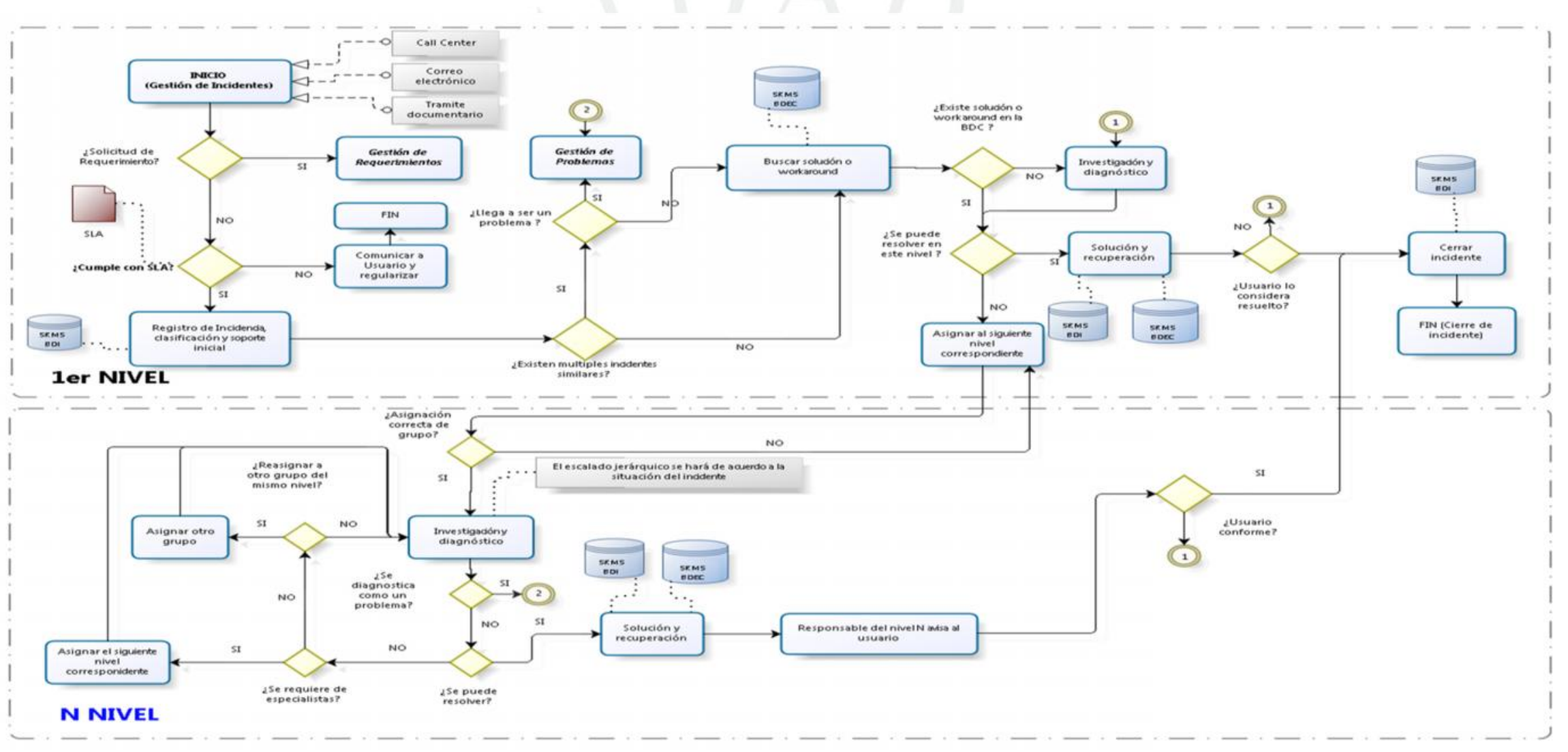

Leyenda

SKMS BDI : Base de Datos de Incidentes
SKMS BDEC : Base de Datos de Errores Conocidos

N Nivel Modelo Recursivo para el escalamiento de nivel, donde $N$ indica el nivel actual (2 6 3).

Fuente: Elaboración propia - Software Bizagi Process Modeler 


\section{b) Descripción del Proceso de atención de incidentes}

La Entidad Gubernamental muestra particularidades en cuanto a la atención de incidentes, siendo el caso puntual el que proviene a través de trámite documentario; el modelo propuesto ayuda a resolver esos inconvenientes generados por este tipo de entrada particular. El modelo cubre todas las actividades necesarias para la correcta gestión de incidentes en la Entidad Gubernamental.

\section{i. Identificación del Incidente}

El modelo presenta 3 formas de notificar un incidente:

- Call Center

- Correo Electrónico

- Trámite Documentario

Los incidentes que llegan a través de trámite documentario, estarán contemplados dentro del nuevo SLA (ver anexo 3), teniendo en cuenta que este tipo de notificación del usuario llega con retraso a la mesa de ayuda.

El siguiente paso es verificar si es una solicitud de requerimiento, si fuera el caso se deriva a los responsables de la Gestión de Requerimientos, caso contrario se continúa con el flujo.

Luego se verifica si cumple los niveles de acuerdo de servicio, si fuese el caso se pasa a la siguiente actividad de registro, caso contrario se le comunica al usuario que regularice la forma de ingresar el incidente de acuerdo al SLA. El soporte de primer nivel tendrá que evaluar varios detalles que permitan una correcta identificación de los incidentes. 


\section{ii. Registro, Clasificación y Soporte Inicial del Incidente}

Los incidentes serán registrados de acuerdo al siguiente formato propuesto:

- $\quad$ Tipo de Incidente

- Fecha

- Origen de Notificación (teléfono, correo, o tramite documentario)

- Entidad solicitante

- $\quad$ Nombre del usuario

- $\quad$ Prioridad

- $\quad$ Asignado a

- $\quad$ Estado

- Categoría

- Sub Categoría (anexo 4)

- Código de identificación

- Descripción

- Teléfono o celular del usuario

- $\quad$ Email del usuario.

- Indicador relacionado con otro incidente.

- $\quad$ Registro de Cambio de Impacto (Indicar el sentido).

- Indicador de Registro por Excepción del SLA 
Dentro de la Priorización de los Incidentes se debe considerar los siguientes parámetros:

- Impacto: Determinará la importancia del incidente dependiendo de cómo éste afecta a los procesos de negocio.

- Urgencia: Estará determinado por los tiempos acordados en el SLA (acuerdo de nivel de servicios).

Los incidentes de fácil resolución deberán ser atendidos inmediatamente. De acuerdo a lo identificado y acordado con las personas del área de TI se puede tomar como referencia el Anexo 4 para tener una referencia inicial, la cual puede ser ajustada de acuerdo a las necesidades de la entidad.

Hay que tener presente que la prioridad del incidente puede cambiar durante su ciclo de vida. 
Figura 5.6

Matriz Impacto-Urgencia

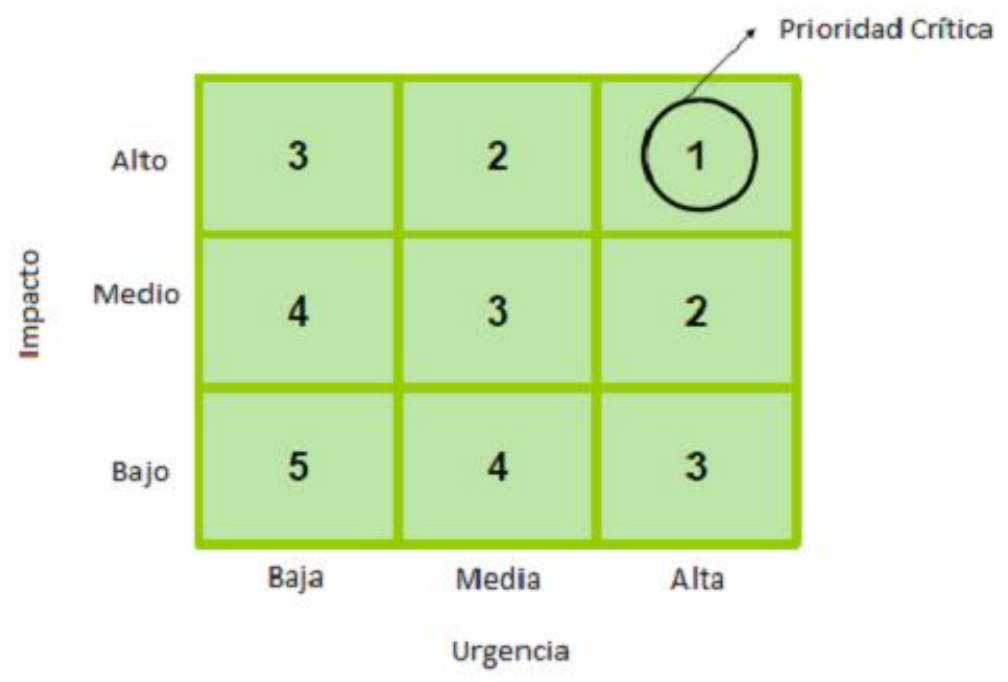

Fuente: OGC - ITIL v3, Service Operation, Pág. 51

Con los datos registrados se procederá a verificar si el incidente presenta casos similares, si no tuviera ninguna coincidencia se procederá a buscar una solución o workaround en la base de datos del conocimiento, caso contrario se verifica si el incidente llega a ser un problema (impacto crítico), si es el caso se deriva al proceso de Gestión de Problemas que se encargará de determinar detalladamente las causas que lo originan, de otra manera continuará con la búsqueda de la solución en la BDC (Base de Datos del Conocimiento).

Luego se verifica si existe una solución similar registrada en la base de datos del conocimiento, si existe la solución para el incidente se procede a verificar si puede ser resuelto en el presente nivel, si es el caso se pasa a la actividad de "Solución y Recuperación", de lo contrario se hará el escalamiento respectivo. 
En caso sea requerido un escalamiento jerárquico, se hará a partir del segundo nivel, esto como parte de la regla de negocio del área responsable.

\section{iii) Proceso de Investigación y Diagnóstico del Incidente}

A partir de la información recogida del soporte inicial, se buscará reponer el servicio tan rápido como sea posible, dependiendo del grado de severidad que presente el incidente.

En caso de que el incidente no sea resuelto en el primer nivel, se procederá a buscar una solución en el siguiente nivel técnico de soporte de la Entidad Gubernamental considerando a los grupos del mismo nivel involucrados en el incidente. Si en caso no puede ser resulto por los grupos del segundo nivel se procederá a escalar al tercer nivel donde estarían considerados los expertos y proveedores de servicios. Toda información registrada servirá para obtener indicadores referentes a los tiempos de investigación y diagnóstico.

\section{iv) Solución, Recuperación y Cierre del Incidente}

Cuando se haya solucionado el incidente, se procede a:

- Confirmar con los usuarios la solución satisfactoria del mismo.

- Incorporar el proceso de resolución al sistema de gestión de conocimiento del servicio.

- Reclasificar el incidente si fuera necesario.

- Actualizar la información en la base de datos de gestión de configuraciones (CMDB) sobre los elementos de configuración (CIs) implicados en el incidente.

- Medir el grado de satisfacción del usuario. En el caso que no sea satisfactoria la respuesta del usuario se procederá de nuevo con la 
actividad de Investigación y Diagnóstico hasta encontrar la solución definitiva para el incidente.

\section{Estados de Incidentes del Modelo de Gestión de Incidentes}

El modelo propuesto presenta los siguientes estados de incidentes, los cuales se muestran en la tabla 5.7:

\section{Tabla 5.7}

Estados de Incidentes del Modelo Propuesto

\begin{tabular}{|l|l|}
\hline \multicolumn{1}{|c|}{ Estado } & \multicolumn{1}{|c|}{ Descripción } \\
\hline Registrado & $\begin{array}{l}\text { Indica que el incidente fue registrado, categorizado y } \\
\text { clasificado. }\end{array}$ \\
\hline Suspendido & Este estado indica que la suspensión del incidente por \\
incumplimiento del SLA. \\
\hline Activo & El incidente está en proceso de atención en cualquiera de \\
& los 3 niveles de atención. \\
\hline Atendido & Estado que indica que el incidente fue resuelto. \\
\hline Cerrado & Incidente cerrado. \\
\hline
\end{tabular}

Fuente: Elaboración propia 


\subsubsection{Relación del Modelo propuesto con otros procesos y funciones}

Figura 5.7

Impacto del Modelo Propuesto con la función de mesa de servicios

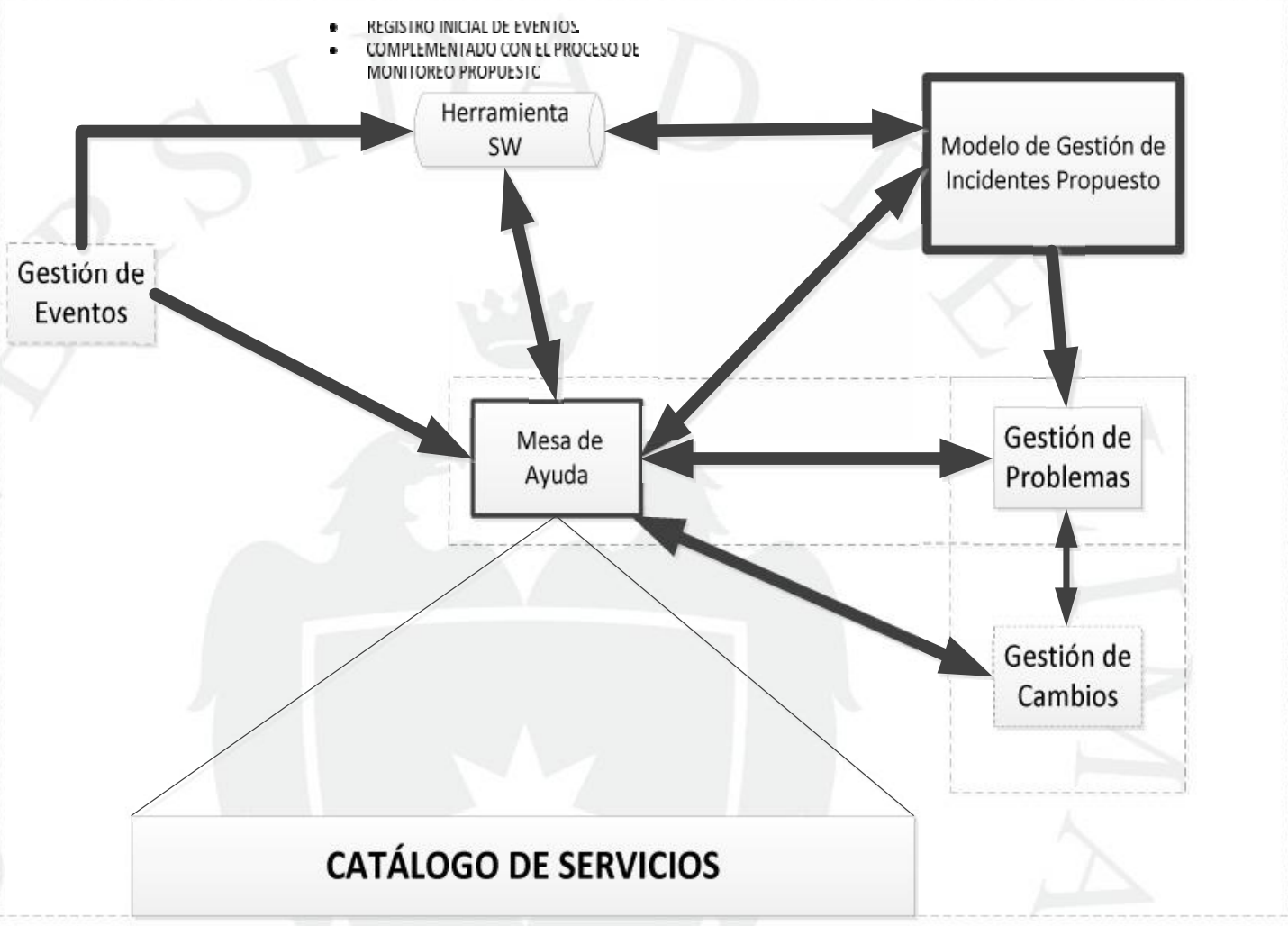

\section{MEJORA CONTINUA}

Fuente: Elaboración propia

Adicionalmente al modelo propuesto para la Gestión de Incidentes, se considera necesario dar las pautas para mejorar la mesa de servicios, para lo cual se propone implementar algunos procesos de ITIL.

Se puede observar en el gráfico que la función de mesa de ayuda ahora está respaldada por un modelo de gestión de incidentes mejorado. Así mismo se observa en el gráfico, en líneas discontinuas a la Gestión de Eventos como un proceso que no está implementado en la Entidad Gubernamental, pero que es 
importante para la detección temprana de incidentes, para lo cual dentro de la herramienta se activó un módulo básico para el registro de los mismos, a su vez esto se complementa con los procesos de monitoreo propuestos. Cabe indicar que bajo este registro y monitoreo inicial se busca detectar tendencias que permitan solucionar diversos incidentes y/o problemas según sea el caso.

El proceso de Gestión de Problemas precisa de ajustes y mejoras, esto no está contemplado dentro del alcance del presente trabajo de investigación pero es importante mencionarlo porque se ve impactado por el modelo propuesto. La gestión de problemas es importante para poder encontrar la causa raíz y su posterior solución. Cabe mencionar que de acuerdo a los recursos de la Entidad Gubernamental parte del equipo de mesa de ayuda se aboca a resolver parte de los problemas.

Dentro del esquema se puede observar también el proceso de Gestión de Cambios que es atendido por el mismo grupo de personas de Gestión de Problemas, en el modelo se puede ver que todo cambio será supervisado por la mesa de ayuda. Aunque formalmente el proceso de Gestión de Cambio no existe se busca tener un mejor control de los cambios que impacten en los servicios que se entregan.

El catálogo de servicios es el punto de partida para la mesa de ayuda, para lo cual se ha propuesto también la definición del SLA referente a la atención de incidentes que permitan una mejor gestión de los incidentes, pudiendo hacer los ajustes necesarios que permitan evidenciar mejoras.

El proceso de Mejora Continua envuelve a todos estos procesos y funciones involucrados, buscando que cada proceso y función sea monitoreado a partir de los resultados entregados por los indicadores. 


\subsubsection{Estrategias para mejorar la función de Mesa de Servicios}

La mesa de servicios tiene como principal objetivo entregar soporte a la provisión de servicios acordados, asegurando la accesibilidad y disponibilidad de la organización de TI, además de desarrollar actividades de soporte.

Cada Mesa de Servicios se estructura de acuerdo a las particularidades de cada entidad. El presente trabajo de investigación busca entregar las opciones para que se pueda estructurar adecuadamente la mesa de servicios. Dentro de las opciones principales se encuentran:

- Mesa de Servicios Local.

- Mesa de Servicios Centralizada.

- Mesa de Servicios Virtual.

- Mesa de Servicios 7x24 los 365 días de año "Follow the sun"

A continuación en la tabla 5.8 se describirán las características que pueden adecuarse a la Entidad Gubernamental. 
Tabla 5.8

Tipo de estructuras organizacionales para Mesa de Servicio

\begin{tabular}{|c|c|c|}
\hline $\begin{array}{c}\text { Tipo de Estructura } \\
\text { Organizacional }\end{array}$ & Características & Entidad Gubernamental \\
\hline Mesa de Servicios & $\begin{array}{l}\text { Está localizada dentro de su } \\
\text { comunidad y puede existir para } \\
\text { cada sede de una empresa o } \\
\text { entidad. }\end{array}$ & $\begin{array}{l}\text { Para la realidad de la entidad en } \\
\text { estudio no es adecuada, debido a } \\
\text { que generaría un incremento en el } \\
\text { costo innecesario. }\end{array}$ \\
\hline $\begin{array}{l}\text { Mesa de Servicios } \\
\text { Centralizada. }\end{array}$ & $\begin{array}{l}\text { Es una estructura centralizada que } \\
\text { usa una mesa de servicios en una } \\
\text { única localización. }\end{array}$ & $\begin{array}{l}\text { Esta estructura se adecua más a la } \\
\text { realidad de la Entidad } \\
\text { Gubernamental. }\end{array}$ \\
\hline $\begin{array}{l}\text { Mesa de Servicios } \\
\text { Virtual. }\end{array}$ & $\begin{array}{l}\text { Esta opción precisa del uso de } \\
\text { tecnología a través de internet y } \\
\text { podría cumplir una función } 24 \times 7 \text {. }\end{array}$ & $\begin{array}{l}\text { Para el nivel de madurez de la } \\
\text { organización no es recomendable } \\
\text { en este momento, mas podría } \\
\text { aplicarse posteriormente. }\end{array}$ \\
\hline Seguir al sol. & $\begin{array}{l}\text { Esta estructura puede tener } 2 \text { o más } \\
\text { mesas de servicios dispersas } \\
\text { geográficamente. Esto supone un } \\
\text { alto costo. }\end{array}$ & $\begin{array}{l}\text { No se aplicaría a la realidad de la } \\
\text { Entidad Gubernamental debido a } \\
\text { que la atención es a nivel nacional. }\end{array}$ \\
\hline
\end{tabular}

Fuente: Elaboración propia

La estructura que se propone para la Entidad Gubernamental es la de Mesa de Servicios Centralizada, que es la que se adecua de acuerdo a las características particulares de la entidad en estudio. En la figura 5.8 se muestra el esquema que se acopla mejor a la entidad en estudio. 
Figura 5.8

Estructura de Mesa de Servicio para la organización

\section{Mesa de Servicio \\ Centralizada}

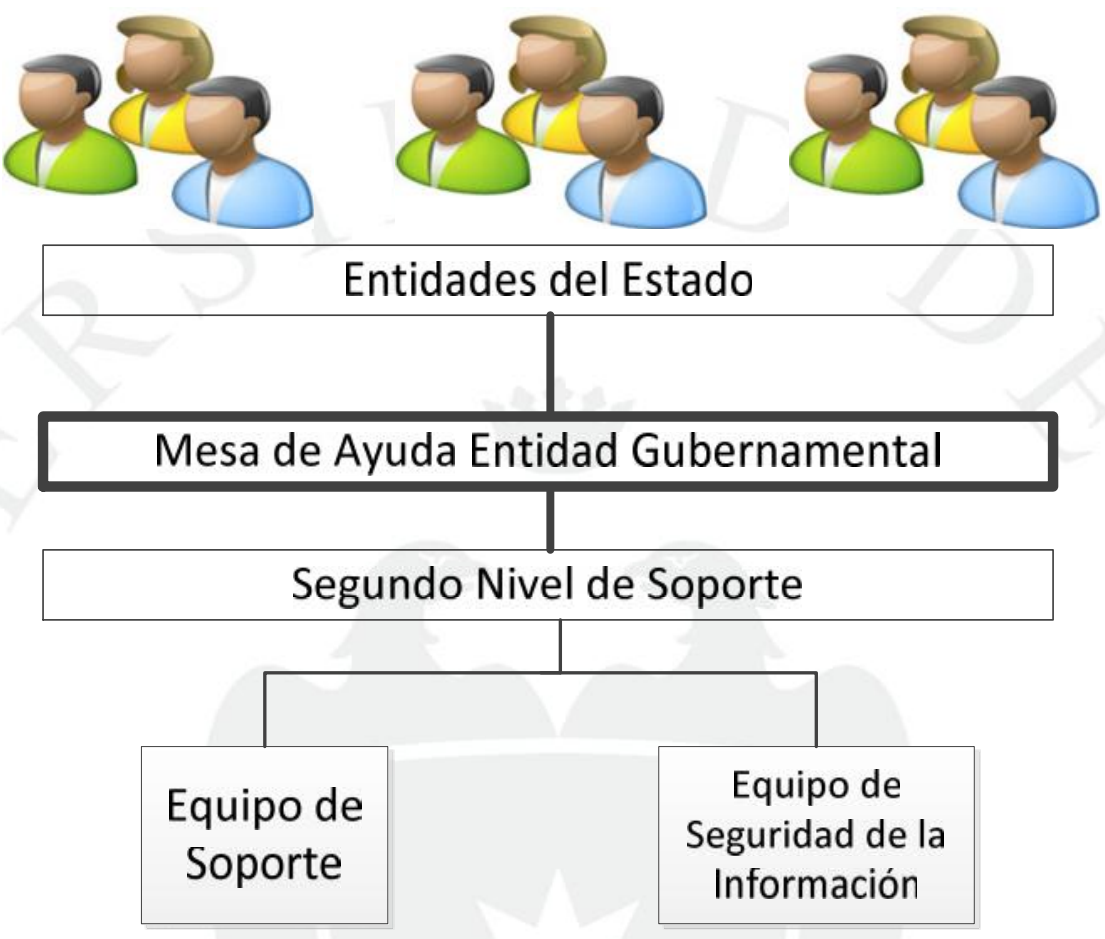

Fuente: Elaboración propia

Esta propuesta modifica la forma actual de trabajar de la entidad debido a que ahora el único punto de contacto con los usuarios de las entidades será el equipo de mesa de ayuda.

\subsection{Consideraciones sobre la Implementación del Modelo propuesto}

La aplicación del modelo propuesto implica superar varios factores que son determinantes para el diseño e implementación del modelo de Gestión de incidentes. Dentro de los factores se encuentra la cultura organizacional que en toda implementación es un factor determinante para el éxito, sabiendo que la implementación involucra comprometer a todas las personas que de TI que participan en la atención de los incidentes. 
La implementación también implica saber manejar y coordinar con los equipos de TI, evangelizar a cada equipo sobre las buenas prácticas del nuevo modelo. En muchos casos hay que educar y re-educar a los involucrados, en otros hay que hacer que desaprendan y vuelvan a aprender para romper con los paradigmas creados por el entorno de trabajo.

La implementación consiste en aplicar el diseño propuesto, considerando los factores mencionados en el párrafo anterior y también sabiendo que cada organización tiene sus propias particularidades y en el caso de la Entidad Gubernamental en estudio, muchas de las consideraciones mencionadas se tienen que aplicar. 


\section{CAPÍTULO VI: RESULTADOS DE LA INVESTIGACION}

\subsection{Consideraciones Preliminares}

Las pruebas al modelo contaron con el respaldo del director de la Entidad Gubernamental, permitiendo implementar el modelo propuesto en la herramienta adquirida (ServiceTonic) por la entidad, además de involucrar a las personas necesarias.

Las coordinaciones se hicieron con los responsables de cada equipo de trabajo, organizando y distribuyendo al personal de manera en la nueva distribución de trabajo.

Aprovechando el plan de capacitaciones programadas previamente por la Entidad Gubernamental se solicitó incluir las capacitaciones propuestas en el modelo.

Las capacitaciones se llevaron a cabo según se muestra en la tabla 6.1: 
Tabla 6. 1

Plan de Capacitaciones

\begin{tabular}{|c|c|c|}
\hline Curso & Duración & Lugar \\
\hline $\begin{array}{l}\text { ITIL Foundation v3.0. } \\
\text { Con el objetivo de nivelar al personal } \\
\text { que no recibió capacitación (6) en otras } \\
\text { gestiones. El costo por el examen de } \\
\text { certificación fue asumido por el propio } \\
\text { personal. }\end{array}$ & $\begin{array}{l}40 \text { horas, full Day, por orden del director. } \\
\text { * Programado con previamente por la Entidad } \\
\text { Gubernamental }\end{array}$ & $\begin{array}{l}\text { Entidad } \\
\text { Gubernamental }\end{array}$ \\
\hline $\begin{array}{l}\text { Nuevo Modelo de Gestión de } \\
\text { Incidentes. }\end{array}$ & $\begin{array}{l}8 \text { horas, esta capacitación se realizó para los } \\
\text { equipos: } \\
\text { Mesa de ayuda } \\
\text { Equipo de Soporte } \\
\text { Equipo Seguridad Informático } \\
\text { * Se solicitó al Director esta capacitación para } \\
\text { complementar las pruebas al modelo propuesto } \\
\text { y por disposición del director se llevó a cabo un } \\
\text { fin de semana. }\end{array}$ & $\begin{array}{l}\text { Entidad } \\
\text { Gubernamental }\end{array}$ \\
\hline $\begin{array}{l}\text { Técnicas para la atención adecuada de } \\
\text { usuarios en un entorno gubernamental }\end{array}$ & $\begin{array}{l}16 \text { Horas, exclusivo para el equipo de mesa de } \\
\text { ayuda. } \\
\text { * Esta capacitación fue sugerida como parte del } \\
\text { proceso de cambios que son requeridos, a los } \\
\text { cuales el director dio su autorización. La } \\
\text { capacitación se hizo luego del horario trabajo. }\end{array}$ & ENAP \\
\hline
\end{tabular}

Fuente: Elaboración propia

La capacitación para el personal de mesa de ayuda fue realizada por la ENAP (Escuela Nacional de Administración Pública - SERVIR) en convenio con la Entidad Gubernamental en estudio. Gracias a estos convenios, el personal de Mesa de Ayuda pudo adquirir algunas habilidades para una atención adecuada a las entidades del estado. 


\subsection{Resultados del modelo de Gestión de Incidentes}

Se consideran los datos de los meses Marzo, Abril y Mayo del 2015, posteriores a la implementación del modelo. Los resultados obtenidos provienen de la herramienta para la gestión de incidentes adquirida por la entidad.

\subsubsection{Total de Incidentes Registrados}

Figura 6. 1

Incidentes registrados

Total de Incidentes Registrados 2015

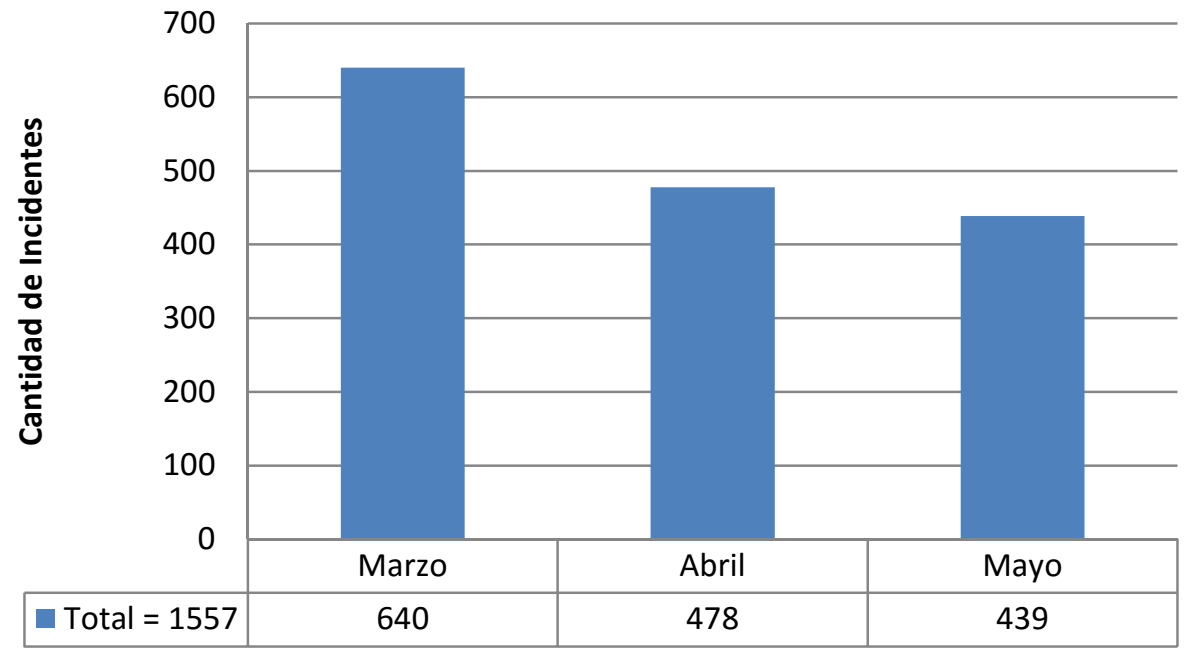

Fuente: Elaboración propia

Para validar esta información se pidió información de los meses de marzo, abril, mayo del 2014 para ver qué diferencias se pueden encontrar con las estadísticas mostradas en la Figura 6.1, los datos proporcionados fueron 811, 784, 723 respectivamente, entregando un total de 2318 incidentes registrados para esos meses.

Haciendo la comparación respectiva de los meses, se puede observar que la disminución fue de 32\%. Estas comparaciones iniciales muestran que existe mejora debido a que se tiene una mejor gestión de los incidentes. El resultado actual servirá para comparaciones posteriores que permitan medir la madurez del modelo. 


\subsubsection{Incidentes repetidos solucionados con métodos conocidos}

\section{Figura 6. 2}

Incidentes agrupados por algunos métodos utilizados

\section{Incidentes resueltos por Métodos conocidos}

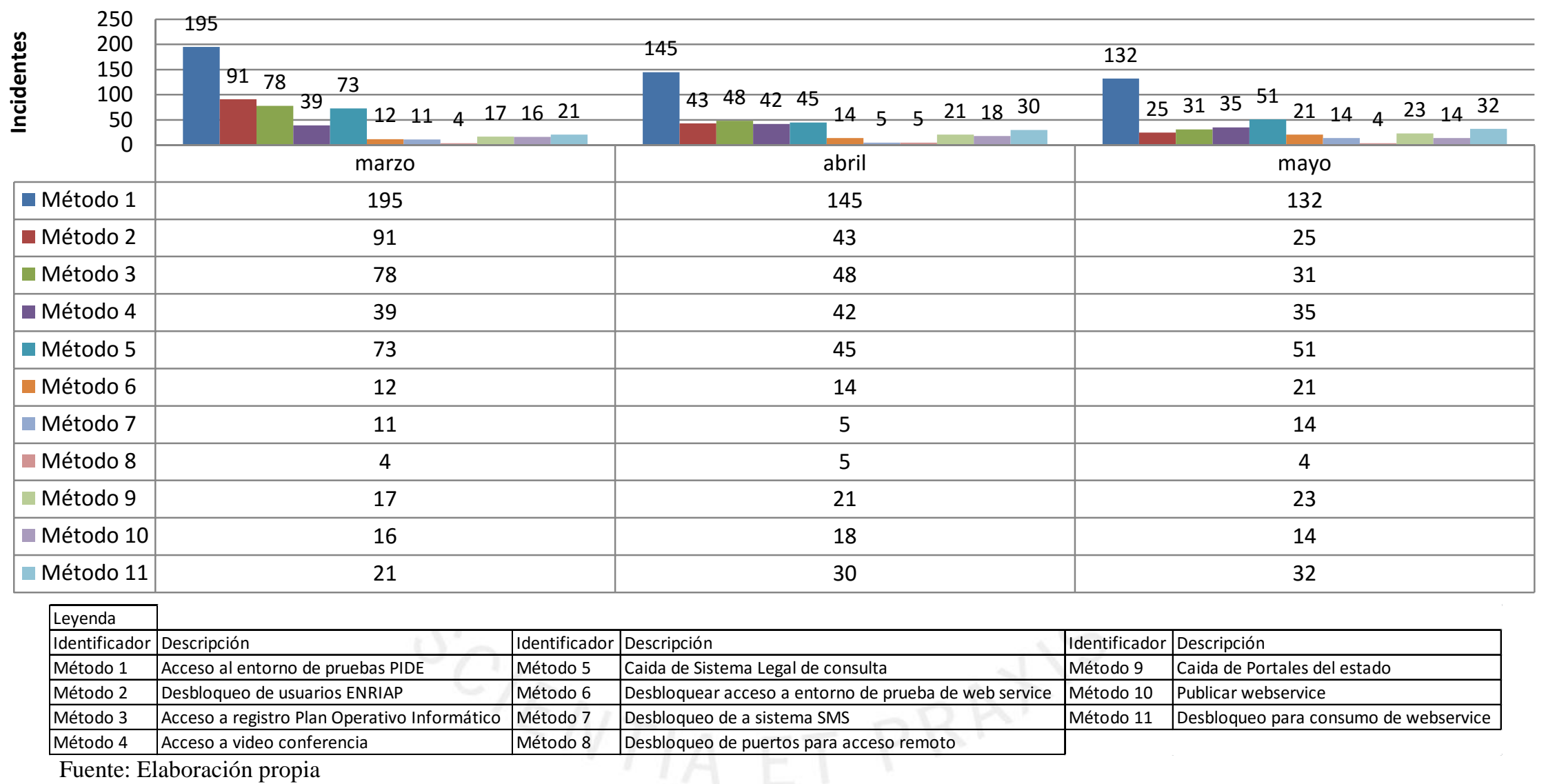


Se puede observar que el "método 1" referente al acceso de pruebas a la plataforma PIDE, fue el más común, existen más métodos documentados pero en esta oportunidad no fueron requeridas. Este indicador muestra que la gran mayoría de incidentes atendidos por mesa de ayuda fueron resueltos por métodos de resolución ya existentes.

\subsubsection{Tiempos mínimos y máximos para resolver un incidente}

Tabla 6.2

Tiempos obtenidos

\begin{tabular}{|l|l|l|l|}
\hline Incidentes & Tiempo Mínimo & \multicolumn{1}{|c|}{ Tiempo Máximo } & \multicolumn{1}{|c|}{$\begin{array}{c}\text { Promedio } \\
\text { Mensual }\end{array}$} \\
\hline Marzo & 8 minutos & 2 horas & 30 minutos \\
\hline Abril & 5 minutos & 3 horas 10 minutos & 45 minutos \\
\hline Mayo & 4 minutos & 2 horas 35 minutos & 20 minutos \\
\hline
\end{tabular}

Fuente: Herramienta de Gestión de Incidentes - Elaboración propia

Los datos obtenidos muestran que el tiempo mínimo que tomó resolver un incidente se registró en el mes de mayo teniendo una duración de 4 minutos. El mes de abril registró el mayor tiempo de atención con 3 horas y 10 minutos. Estas métricas servirán como línea base para futuras comparaciones que permitan hacer los ajustes necesarios. 


\subsubsection{Número de Incidentes agrupados por tipo de prioridad}

Figura 6.3

Incidentes agrupados por tipo de prioridad

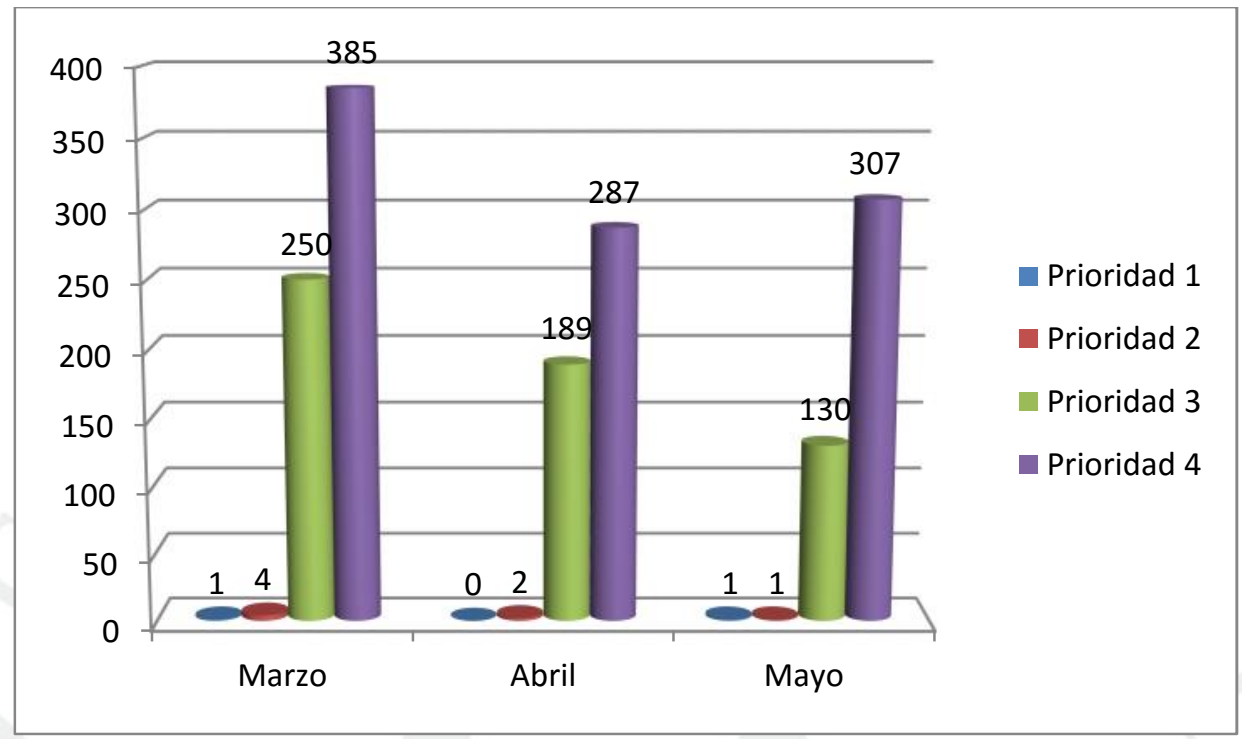

Fuente: Elaboración propia

El gráfico muestra que los incidentes de prioridad 4 son los de mayor frecuencia. 


\subsubsection{Incidentes por mes de acuerdo a equipos de trabajo y prioridad}

A continuación se muestra los resultados obtenidos por cada mes:

\section{$\underline{\text { Marzo 2015 }}$}

Figura 6.4

Incidentes para el mes de marzo

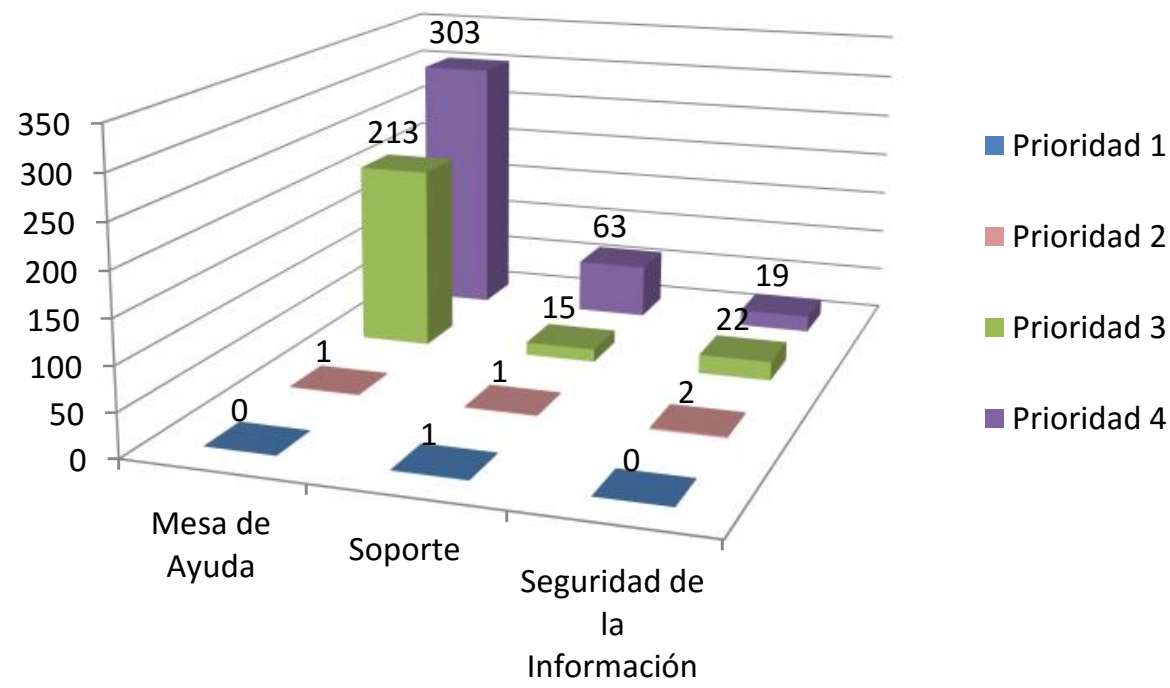

Fuente: Elaboración Propia

En el mes de marzo se puede observar que la mayor cantidad de incidentes registrados tienen prioridad 4. Se puede observar que el equipo de Mesa de ayuda es el que atiende más incidentes, seguido del equipo de Soporte. 


\section{$\underline{\text { Abril } 2015}$}

Figura 6. 5

Incidentes para el mes de abril

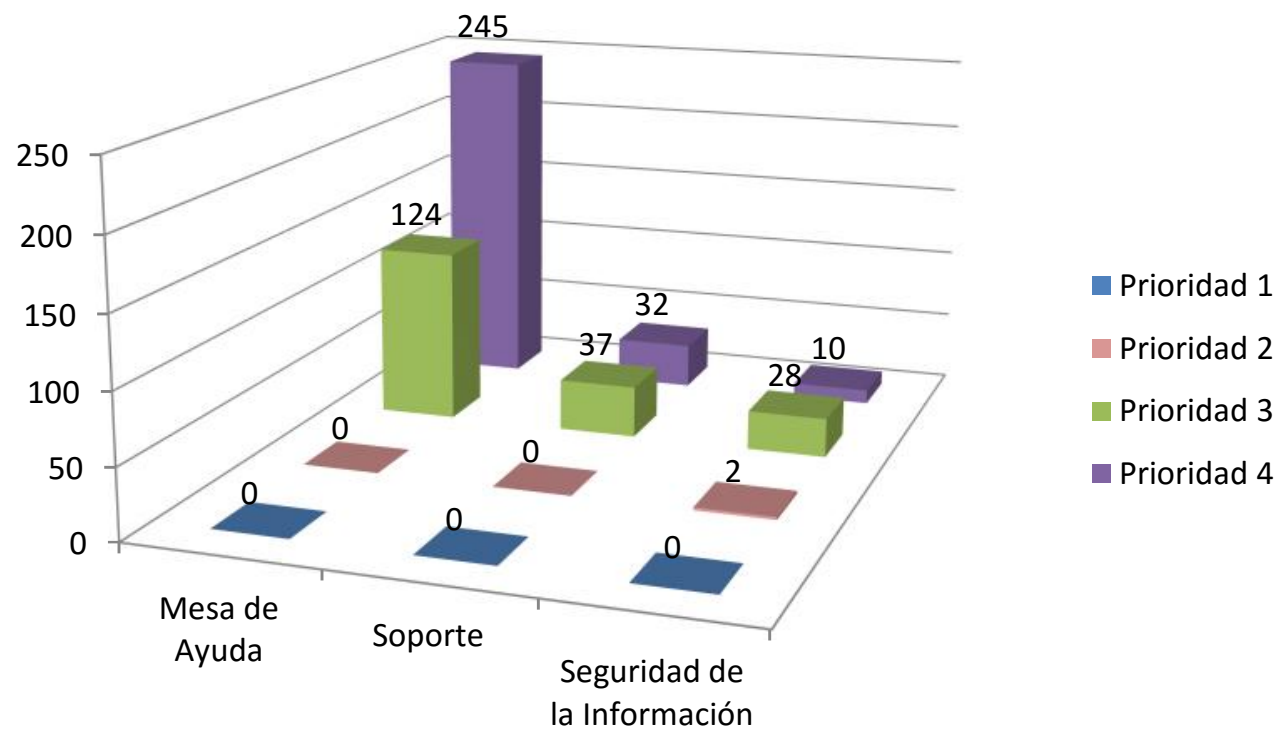

Fuente: Elaboración propia

Se puede observar que mesa de ayuda es el equipo que más incidentes tiene asignados. 


\section{Mayo 2015}

Figura 6.6

Incidentes para el mes de mayo

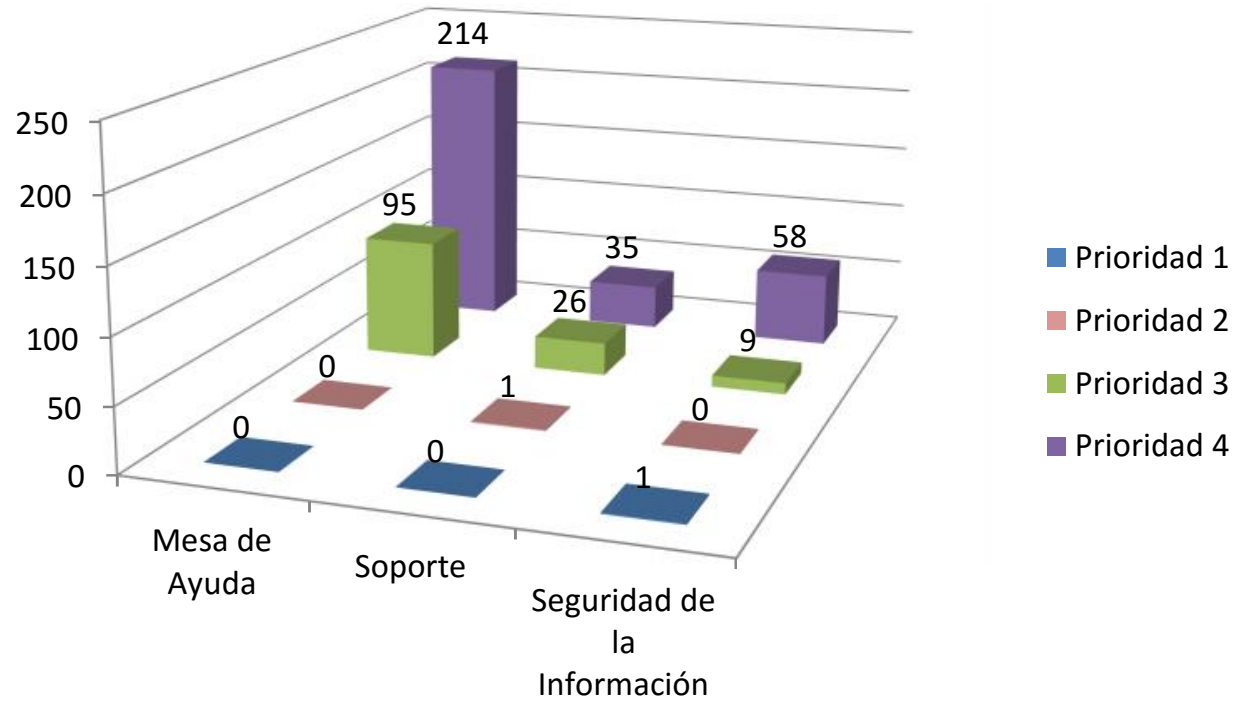

Fuente: Elaboración propia

En este mes la tendencia a asignar más incidentes es para el equipo de mesa de ayuda, siendo los de prioridad 4 el más atendido. 


\subsubsection{Cantidad de Incidentes agrupados por Categoría}

Figura 6.7

Incidentes agrupados por categoría

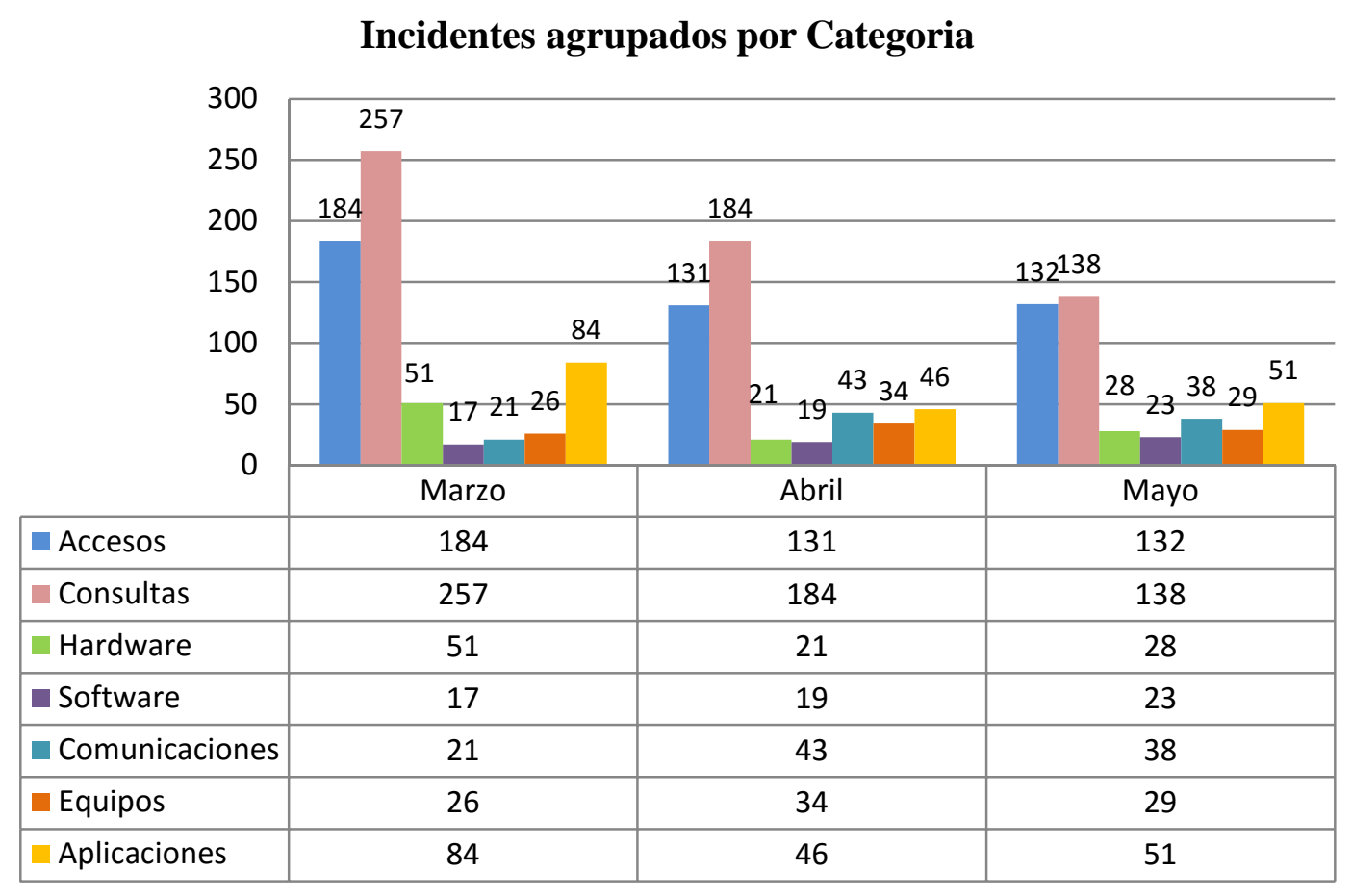

Fuente: Elaboración propia

La categoría que mayor requerimiento tiene es la de Consultas, seguido por la de Accesos. La herramienta permite una serie de indicadores que permitirán ir evaluando el nivel de madurez del modelo propuesto. 


\subsubsection{Número de incidentes que desembocaron en problemas}

Figura 6.8

Incidentes que desembocaron en problemas

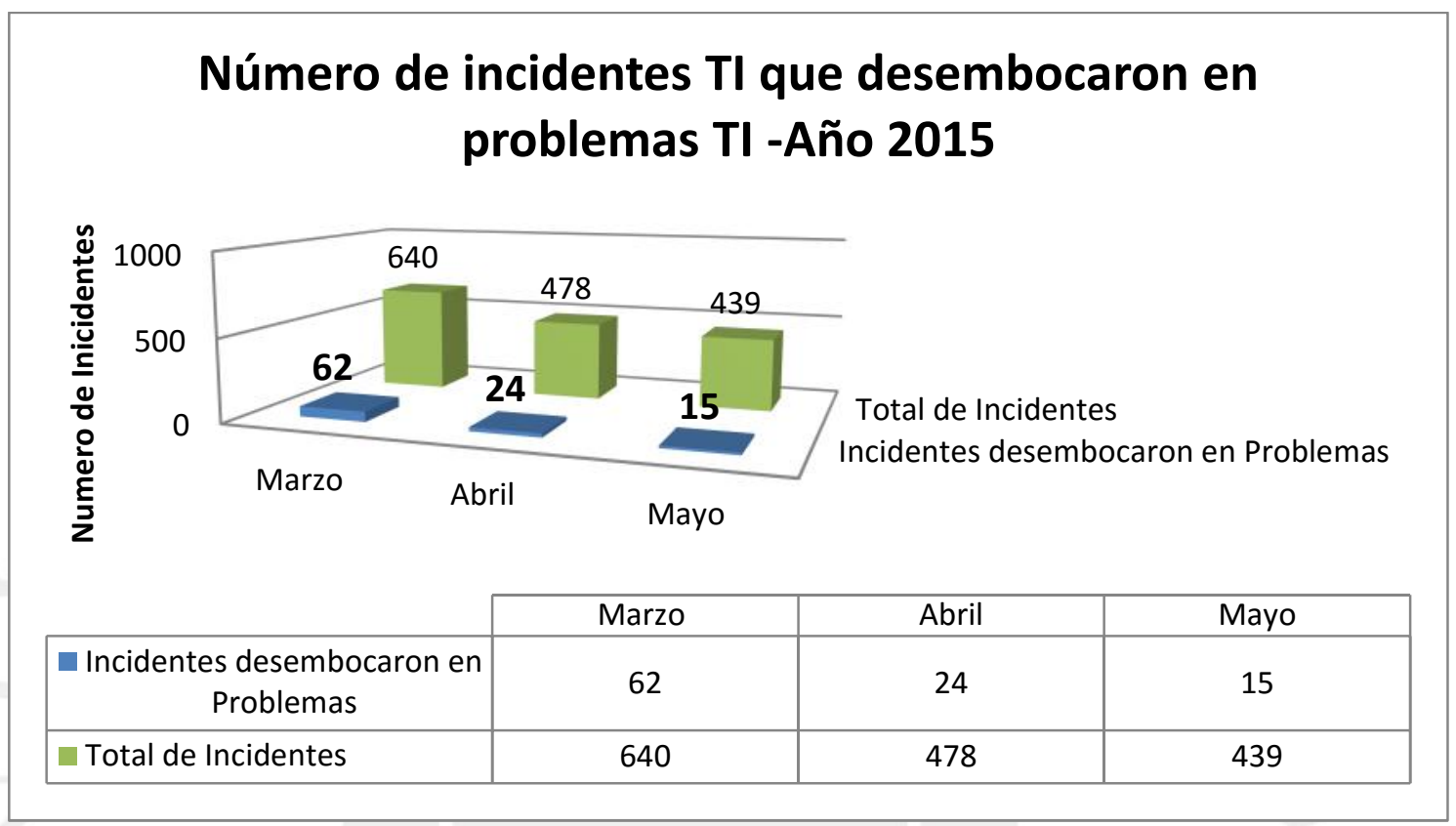

Fuente: Elaboración propia

Bajo el concepto de ITIL, un incidente de TI que se vuelve recurrente y no puede ser resuelto rápidamente por algún método conocido pasa a convertirse en un problema que debe ser resuelto por la Gestión de problemas.

Los porcentajes $9.7 \%, 5 \%, 3.4 \%$ corresponden a lo meses de marzo, abril y mayo respectivamente, aquí se puede observar que el nivel problemas es manejable por parte del equipo de mesa de ayuda. Se observa que más del $90 \%$ son incidentes resueltos por el equipo de mesa de ayuda.

Validando esta información, se pudo observar que no todos los incidentes que desembocaron como problemas lo eran realmente, esto se debe a que aún el personal está adaptándose a los cambios, también se puede observar que con el transcurso de los meses las derivaciones a problemas de TI han mejorado debido a las observaciones y ajustes realizados durante esta fase de pruebas al modelo. 


\subsection{Encuesta de Satisfacción}

Es necesario medir el impacto y nivel de satisfacción por parte de las entidades usuarias, también es importante determinar si los equipos de trabajo están aplicando lo aprendido en las capacitaciones recibidas. La muestra de usuarios encuestados fue de 120 (Anexo 6), siendo estas las que más usan los servicios de TI de Entidad Gubernamental. A continuación se muestra el formato utilizado para la encuesta.

Tabla 6.3

Cuestionario de preguntas

\begin{tabular}{|l|l|l|l|}
\hline Preguntas & \multicolumn{1}{|c|}{ Objetivo Pregunta } \\
\hline Grupo 1: & $\begin{array}{l}\text { Comprobar si los procedimientos } \\
\text { fueron explicados de manera adecuada } \\
\text { por el personal de la Entidad } \\
\text { Gubernamental }\end{array}$ & $\begin{array}{l}\text { P1 ¿Cómo califica las instrucciones que le dio } \\
\text { la persona de soporte para solucionar el } \\
\text { incidente? }\end{array}$ \\
\hline Grupo 2 & $\begin{array}{l}\text { Revisar tiempos de solución del } \\
\text { incidente }\end{array}$ & $\begin{array}{l}\text { P2 ¿Cómo califica el tiempo total utilizado } \\
\text { para la solución del incidente? }\end{array}$ \\
\hline Grupo 3 & $\begin{array}{l}\text { Comprobar la relación entre los } \\
\text { equipos de trabajo de Entidad } \\
\text { Gubernamental y los usuarios de las } \\
\text { entidades gubernamentales. }\end{array}$ & $\begin{array}{l}\text { P3 Cómo fue la calidad en la atención que } \\
\text { recibió del personal de mesa de ayuda? } \\
\text { P4 ¿Cómo califica la nueva forma de atención } \\
\text { de los incidentes? }\end{array}$ \\
\hline Calificación: Excelente (5), Muy Bueno (4), Bueno (3), Regular (2) y Deficiente (1).
\end{tabular}

Fuente: Elaboración propia

Según la figura $\mathrm{N}^{\circ} 6.9$, se entregan los resultados de los meses de marzo, abril y mayo del 2015. De acuerdo a los resultados se puede ver que el promedio de aprobación es de $72 \%$ (resultado del cálculo de la división entre el promedio de la puntuación y el puntaje máximo de aceptación).

El nivel de aprobación está por encima del $70 \%$, lo que indica que se ha percibido cierto nivel de mejora pero que aún precisa mejorar. El modelo puesto a prueba entrega resultados favorables que indican que se ha procedido de manera correcta. Cabe resaltar que es la primera vez que se realiza una encuesta de satisfacción en la Entidad Gubernamental. 
Figura 6. 9

Resultado de la encuesta realizada a los usuarios

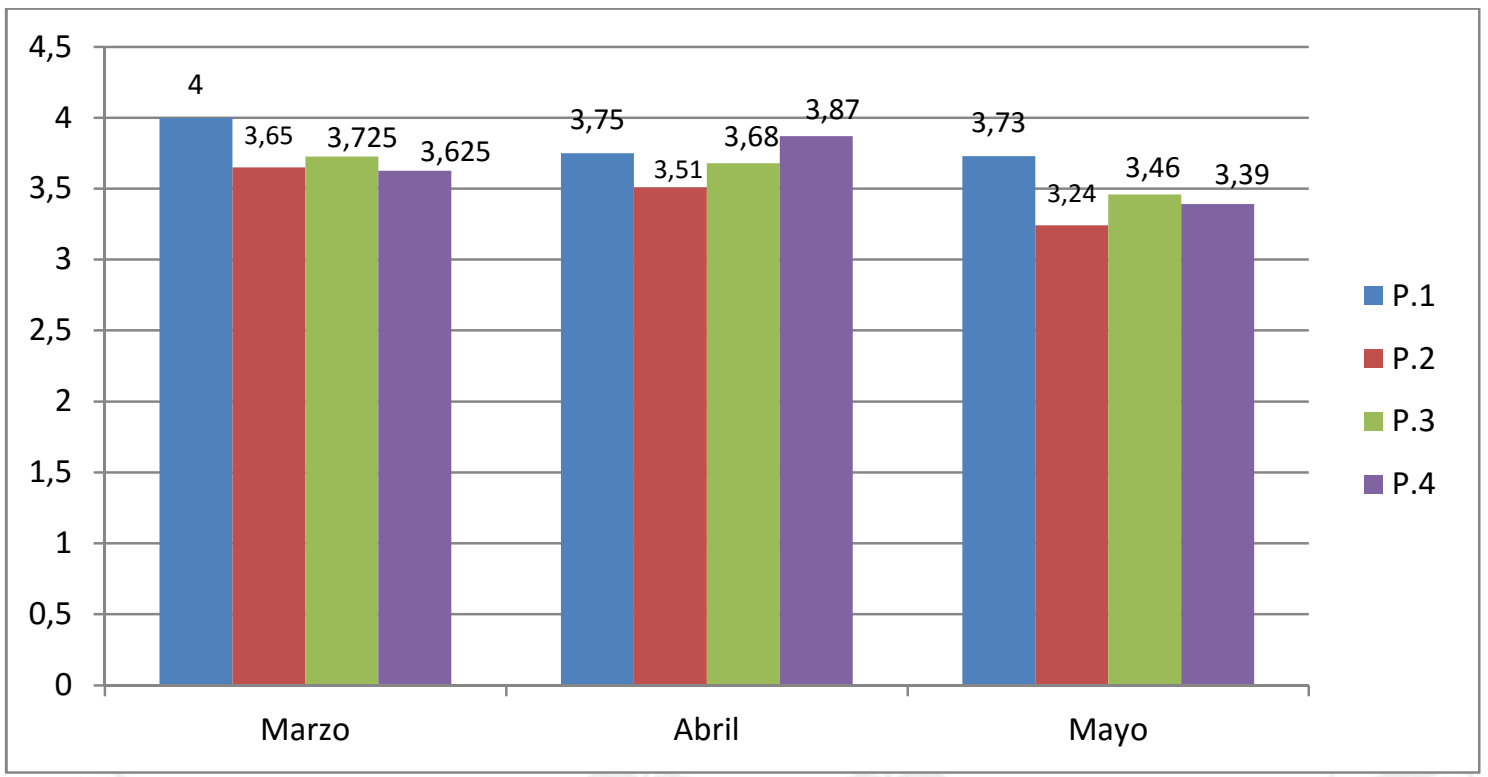

Fuente: Elaboración propia

\subsection{Comentarios finales}

El trabajo de investigación permitió al bachiller coordinar con los responsables de cada equipo de trabajo. Comenzando por el responsable del área de TI con el que se pudo coordinar sobre los beneficios de la implementación.

El nuevo equipo de trabajo (Equipo de Control) asumió la función de coordinar con los otros equipos de trabajo, permitiendo crear un entorno de coordinación adecuado para la gestión de los servicios 
Los puntos favorables de la implementación fueron los siguientes:

- Las buenas prácticas para la atención y registro de incidentes fueron bien recibidas.

- El equipo de mesa de ayuda es el único punto de contacto además ser el primer nivel de resolución de los incidentes.

- Los procesos propuestos para el monitoreo de los servicios más críticos fue aceptado de la mejora manera y se comenzó a registrar eventos en la herramienta (ServiceTonic). La idea de hacer este registro es la de ver tendencias y generar la costumbre en la detección temprana de incidentes y problemas.

- Las entidades usuarias percibieron las mejoras, pero aun sienten que hay temas por mejorar de acuerdo a la encuesta de satisfacción.

- A nivel gerencial fue bien recibido el hecho de tener una línea base de indicadores que permitan hacer los ajustes necesarios para la mejora continua.

También se encontraron algunos inconvenientes:

- Si bien a nivel gerencial y de jefatura el cambio fue bien recibido, por parte del nivel operativo algunas personas se mostraron reacias al cambio, a pesar de que en un principio estuvieron de acuerdo con la propuesta.

- Algunas entidades del estado siguieron con la forma tradicional de notificación de los incidentes, por ser esta una etapa piloto fueron aceptadas, pero dejándoles en claro cómo debía ser la forma de notificación la próxima vez. 


\section{CONCLUSIONES}

- El presente trabajo permitió ordenar y clasificar mejor los incidentes, evitando la duplicidad de registros y el re trabajo. Esto se puede ver reflejado en los primeros indicadores mostrados (Total de Incidentes Registrados). Luego de la implementación se observó una disminución de más del 50\% de incidentes.

- La aplicación del modelo propuesto involucró cambios tecnológicos, y de organización en la Entidad Gubernamental, lo que implicó que se tenga que cambiar los hábitos de trabajo para la atención de incidentes, teniendo un solo punto de contacto además de un nuevo nivel de coordinación entre equipos de trabajo. Si bien el modelo muestra mejoras, no fue aceptado del todo por algunas personas que se mostraron reacias al cambio.

- El monitoreo temprano permitió disminuir la carga de trabajo del equipo de mesa de ayuda debido a que se pudieron detectar tempranamente alertas y eventos comunes como es el caso de bloqueo de usuarios en el sistema de mensajes SMS. Si bien el proceso de Gestión de Eventos no está implementado, estos procesos preventivos propuestos nos muestran que es necesario su implementación.

- Se logró establecer una línea base de indicadores que permitirán el monitoreo de la gestión de incidentes y hacer los ajustes necesarios. 


\section{RECOMENDACIONES}

- Se recomienda optimizar la gestión de problemas, con el fin de documentar mejor los problemas resueltos y entregar mejores servicios.

- Formalizar el proceso de gestión de eventos, para la detección temprana de incidentes y problemas que puedan presentarse.

- Se recomienda crear un plan de continuidad para el personal técnico de la Entidad Gubernamental, con el fin de evitar la pérdida de talento humano. Se propone crear contratos de mediano y largo plazo para que el personal pueda tener continuidad y evitar salidas bruscas ante cambios de políticos de turno.

- Es importante continuar con las capacitaciones a los equipos de trabajo de la Entidad Gubernamental, con el fin de buscar un nivel de especialización mayor en ITIL que permitan generar un ambiente en el cual se sigan las buenas prácticas. Y que de esta manera se obtenga un nivel de madurez que permita atender mejor las necesidades de los usuarios. 


\section{GLOSARIO DE TÉRMINOS}

Acuerdo de Nivel de Servicio - ANS (Service Level Agreement - SLA): Acuerdo entre un proveedor de servicio de TI y un cliente.

Acuerdo de Nivel Operativo (Operational Level Agreement - OLA): Acuerdo entre el área de TI y otra área de la Organización.

Alerta: Advertencia de que se ha superado un umbral, algo ha cambiado o hubo un fallo.

Arquitectura: Estructura de un servicio o sistema de TI.

Base de datos de conocimiento (Knowledge Data Base "KDB"): Es un almacén de información que conforma un repositorio central de soluciones que puede ser consultado desde una aplicación de software que implemente la Mesa de Servicios para brindar respuestas a casos asociados a problemas usuales. Así una KDB constituye una primera línea de soporte ágil y eficaz para la resolución rápida de problemas frecuentes.

Base de Datos de Errores Conocidos [Known Error Database] (KEDB) (Operación del Servicio): Base de datos que contiene todos los Registros de Errores Conocidos. Esta base de datos es creada por la Gestión del Problema y utilizada por Gestión del Incidente y Gestión del Problema. La Base de Datos de Errores Conocidos es parte del Sistema de Gestión del Conocimiento del Servicio.

Calidad en TI: Característica de un servicio, producto o proceso para proporcionar valor.

CI (Configuration Item): Es un elemento de configuración, un componente de la infraestructura de TI que está bajo su control. Los CI's pueden presentar grandes variaciones en complejidad, tamaño y tipo, desde un sistema completo hasta un solo módulo, o componente de hardware menor.

CMDB (Configuration Management Data Base): Representa una base de datos que tiene registros de todos los elementos de configuración que se asocian con la infraestructura de TI incluyendo versiones, ubicación, documentación, componentes y relaciones de ellos. 
CMMI: Las empresas que buscan mejorar todos sus procesos utilizan modelos de madurez para disciplinas como ingeniería de software entre otras mediante la integración de diferentes modelos en un solo marco de trabajo.

CobiT: Está orientado a ser utilizado para organizaciones que deseen garantizar una adecuada estructura de Gobierno, es decir busca definir una estructura que comprenda, implante y evalúe capacidades, rendimiento y riesgos de TI para fundamentalmente cumplir los requisitos del negocio.

Contrato de Soporte (Underpinning Contract - UC): Contrato entre un proveedor de servicio y un tercero.

\section{Encuesta Nacional de Recursos Informáticos en la Administración Pública}

(ENRIAP): Es una herramienta que se encarga de medir la evolución en cuanto a recursos informáticos que se disponen en las entidades públicas del Poder Ejecutivo, Poder Judicial, Poder Legislativo, de los Organismos Autónomos, Gobiernos Regionales y Gobiernos Locales.

Evento de TI: Un cambio de estado significativo en un elemento de configuración (CI) o un servicio de TI.

Fallo de TI: Pérdida de la capacidad de operar de acuerdo a las especificaciones o de proporcionar el resultado requerido.

Gestión de Incidentes: Tiene como objetivo resolver, de la manera más rápida y eficaz posible, cualquier incidente que cause una interrupción en el servicio.

Gestión del Cambio: Permite obtener información de programación de cambios y la valoración de los cambios asociada al impacto en la prestación de los servicios.

Incidente de TI: Puede determinarse como la interrupción no planificada de un servicio de TI o reducción en su calidad.

Interesados (Stakeholders): Son todas aquellas personas u organizaciones que afectan o son afectadas por el proyecto, ya sea de forma positiva o negativa. 
ITIL: Puede describirse como aquella gestión capaz proporcionar las mejores prácticas para la Gestión de Servicios de TI y con ello entrega una serie de procesos integrados para brindar con alta calidad la provisión y el soporte de los servicios de TI, lo pueden adoptar las organizaciones que quieran normalizar los procesos de Gestión de Servicios de TI de acuerdo a un marco de mejores prácticas mundialmente reconocido.

ITSM: IT Service Management, disciplina basada en procesos, enfocada en alinear los servicios de TI proporcionados con las necesidades de las empresas, poniendo énfasis en los beneficios que puede percibir el cliente final.

\section{Línea Base [Baseline] (Mejora Continua del Servicio)}

Una Referencia que se usa como punto de marca. Por ejemplo:

- Una Línea Base de ITSM se puede usar como punto de partida para medir el resultado de un Plan de Mejora del Servicio.

- Una Línea Base de Rendimiento se puede usar para medir cambios en el Rendimiento de un Servicio TI en un periodo de tiempo.

- Una Línea Base de la Gestión de la Configuración puede servir para restablecer la Infraestructura TI en una Configuración conocida en caso de un fallo de un Cambio o de un Entregable.

Mesa de Ayuda: La mesa de ayuda o help desk es un conjunto de servicios destinados a la gestión y solución de todas las posibles incidencias relacionadas con las tecnologías de la información y comunicación.

Mesa de Servicios: El service desk o mesa de servicios nos permite tener un mayor control en el área de TI, y definir con mayor precisión las actividades realizadas por cada área de servicio asignando roles a los responsables de dichas actividades. Es decir una mesa de servicios puede hacer todo lo que una Mesa de Ayuda, pero además te permite planear, estructurar y proveer la entrega de una gran variedad de servicios IT. En lugar de reaccionar a los problemas mientras van surgiendo, te permite un acercamiento más estratégico a la Gestión de Servicios de TI, y actúa como un punto único de contacto (SPOC) para todas las actividades de TI. 
Orientación a Procesos: Gestionar recursos y actividades con un enfoque BPM, permitirá la automatización de los procesos claves, con resultados de impacto en la satisfacción de los clientes, a través de ventajas como la disminución de costos, tiempos de espera y papel, y un mejor aprovechamiento de la información.

Plan Operativo Informático (POI): Guía para la elaboración, formulación y evaluación del plan operativo informático, de las entidades de la administración pública. Es cumplimiento obligatorio para conocer el nivel de planificación en temas informáticos.

Prioridad de TI: Categoría empleada para identificar la importancia relativa de un incidente, problema o cambio, está dada entre el impacto y la urgencia.

Problema de TI: Causa desconocida de uno o más incidentes.

Punto Único de Contacto [Single Point of Contact] (SPOC): Proporcionar un único y consistente modo de comunicarse con una Organización o Unidad de Negocio. Por ejemplo, Un SPOC para un Proveedor de Servicios de TI se denomina normalmente Centro de Servicio al Usuario.

Riesgo de TI: Evento que puede causar daño o pérdidas o deteriorar la habilidad para ejecutar ciertas acciones.

Sistema Bitácora: Software desarrollado a medida para la entidad gubernamental en estudio por un empresa externa, para el registro de incidentes y problemas de TI que soportaba la fase inicial de los servicios gestionados.

Six Sigma: Proceso de calidad que busca detectar permanentemente oportunidades de mejora basándose en el rendimiento de sus procesos. Brinda a las empresas herramientas para realizar medidas estadísticas que contribuyan a aumentar la capacidad de los procesos de negocio y de TI reduciendo el número de defectos y minimizando la diferencia entre los procesos.

SLA (Service Level Agreement): Es un contrato escrito entre un proveedor de servicio y su cliente con objeto de fijar el nivel acordado para la calidad de dicho servicio. El SLA es una herramienta que ayuda a ambas partes a llegar a un consenso en términos del nivel de 
calidad del servicio, en aspectos tales como tiempo de respuesta, disponibilidad horaria, documentación disponible, personal asignado al servicio, etc.

Solución temporal (workaround): Reducción o eliminación del impacto de un incidente o problema para el que la solución definitiva aún no se encuentra disponible.

Tiempo de Caída (Downtime): Tiempo en que un servicio o elemento de configuración no se encuentre disponible.

Urgencia de TI: Una medida del tiempo en que un incidente, problema o cambio tendrá un impacto significativo para el Negocio. 


\section{BIBLIOGRAFÍA}

Bon, J. v., Jong, A. d., Axel, K., \& Mike, P. (2008). Estrategia del Servicio Basada en ITIL

V3. Londres: Van Haren Publishing.

Entidad Gubernamental. (2014). Manual de Gestión. Lima.

Hunnebeck, L. (2011). ITIL Service Design 2011 Edition, the Stationery Office (2a ed.).

Jan Van Bon, A. d. (2010). Estrategia del Servicio basada en ITILV3 - Guia de Gestion(1a ed.). Van Haren Publishing.

OGC. (2008). ITIL v3, Continual Service Improvement, TSO (2 ed.). Londres: TSO.

OGC. (2011). ITIL, Mejora Continua del Servicio. En ITIL, Mejora Continua del Servicio (págs. 3-11). Londres: TSO.

OGC. (2011). ITIL Service Operation. En OGC, ITIL Service Operation (págs. 7-10).

Londres: TSO.

OGC. (2011). ITIL Service Transition. En OGC, ITIL Service Transition (págs. 1-11).

Londres: TSO.

OGC. (2011). ITIL v3, Service Strategy. Londres: TSO.

OGC, O. o. (2007). ITIL v3, Service Transition, TSO (1 a ed.).

OGC, O. o. (2007). ITL v3, Service Design, TSO (1 a ed.). 


\section{REFERENCIAS}

Chávarry Sandoval, C. J. (2012). Propuesta de Modelo Ajustado a la Gestión de TI/SI Orientado a los servicios basado en el marco de trabajo ITIL. Caso de estudio aplicado al Departamento de TI/SI de la Universidad de Lambayeque-Perú. Chiclayo: Universidad Católica Santo Toribio de Mogrovejo.

Ariza, S. P., \& Ramirez Cuero, H. (2012). Plan de acción para la implementación de una mesa de servicio para la administración de incidentes y solicitudes de cambios soportado en el modelo de ITIL caso aplicado a la empresa soluciones y servicios informáticos empresariales S.A.S. Bogotá: Universidad EAN.

Barletta, F., Pereira, M., Robert, V., \& Yoguel, G. (2013). Argentina: dinámica reciente del sector de software y servicios informáticos. Revista de la CEPAL(110), 137-155. Obtenido de http://www.cepal.org/publicaciones/xml/1/50511/RVE110Yoqueletal.pdf

Choy, M. \&. (2014). Medidas macroprudenciales aplicadas en el Perú. Lima: Banco Central de Reserva del Perú. Obtenido de http://www.bcrp.gob.pe/docs/Publicaciones/Documentos-deTrabajo/2014/documento-de-trabajo-07-2014.pdf

De la Cruz Ramirez, A. \&. (2012). Implementación de un Sistema Service Desk basado en ITIL. Ciudad de México: Universidad Nacional Autónoma de México.

Decreto supremo 066-2033-PCM. (2003). Obtenido de https://www.inei.gob.pe/media/archivos/24_Agosto_1.pdf

Decreto supremo 067-2003-PCM. (s.f.). Obtenido de http://www.ongei.gob.pe/normas/0/NORMA_0_DECRETO\%20SUPREMO\%20N\% C2\%BA\%20067-2003-PCM.pdf

Guía Técnica Sobre Evaluación De Software Para La Administración Pública. Resolución Ministerial $N^{\circ}$ 139-2004-PCM. (s.f.). Obtenido de http://www.EntidadGubernamental.gob.pe/bancos/banco_normas/archivos/guiaevaluacion-sw.pdf

ITSM Community - Resources. (s.f.). Obtenido de http://www.itsmcommunity.org/Resources/ Jan Van Bon, A. d. (2010). Estrategia del Servicio basada en ITILV3 - Guia de Gestion(1a ed.). Van Haren Publishing. 
Metricas ITIL- KPIs ITIL.Operacion de Servicio. (s.f.). Obtenido de http://wiki.es.itprocessmaps.com/index.php/ITIL_gestion_de_Incidentes osiatis.es. (03 de 08 de 2013). OSIATIS. Obtenido de http://www.osiatis.es/ Service Desk Software (revision). (s.f.). Obtenido de http://www.ca.com/us/intellicenter/caservice-desk-manager.aspx

Service Level Agreement and SLA Guide. The SLA Toolkit. (s.f.). Obtenido de http://www.service-level-agreement.net/

WIKI. (03 de 08 de 2013). Obtenido de http://wiki.es.itprocessmaps.com/index.php/ITIL_Operaci\%C3\%B3n_del_Servicio 
ANEXOS 


\section{Anexo 1: Acuerdo de Servicios para la Atención de Incidentes}

\begin{tabular}{|l|l|l|}
\hline ID & SLA-INC-001 & Versión v1.2 \\
\hline
\end{tabular}

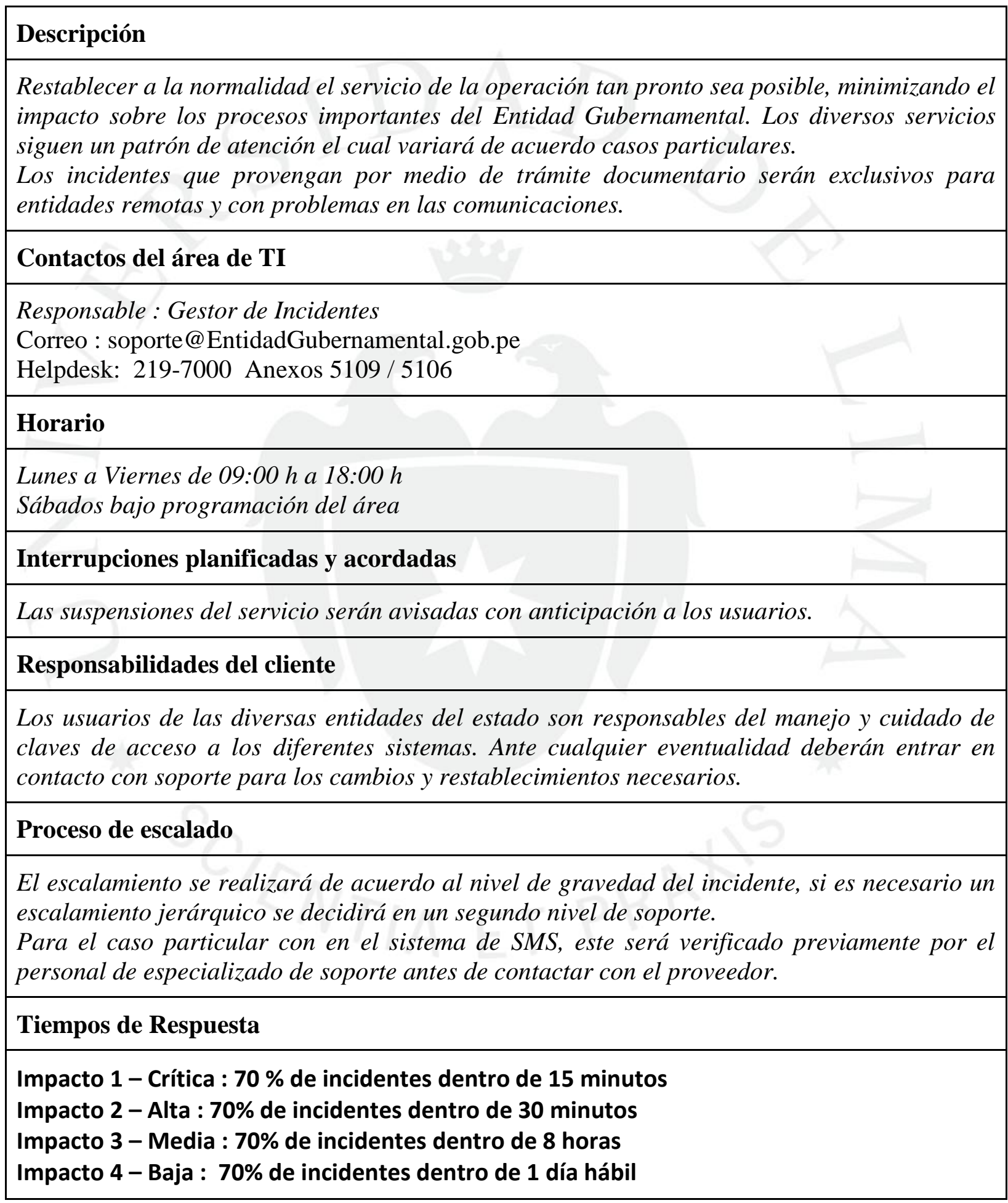


Acciones a llevar a cabo en caso de interrupción del servicio

Impacto 1 - Crítica : 95\% de incidentes dentro de 4 horas / 100\% de incidentes dentro de 6 horas

Impacto 2 - Alta : 95\% de incidentes dentro de 8 horas / $100 \%$ de incidentes dentro de 12 horas

Impacto 3 - Media : 95\% de incidentes dentro de 3 días hábiles

Impacto 4-Baja : 95\% de incidentes dentro de 5 días hábiles

\section{Excepciones}

Ante algún incidente de alto impacto (Impacto 2 o 3) que provenga por trámite documentario, no siendo este el conducto regular, se procederá a atender el incidente, dejando registrado esta excepción y comunicando a la entidad que en lo sucesivo deben contactarse por los medios regulares establecidos( Correo o Teléfono).

Para los casos particulares de cumplimiento normativo como ENRIAP o POI, estos deberán ser tener en cuenta que no pueden ser utilizados por excusa para el incumplimiento normativo, teniendo que cumplir con el registro hasta 60 días antes de la fecha límite de corte, la atención de los incidentes generados por estos servicios estarán sujetos a disponibilidad del área de mesa de ayuda.

\begin{tabular}{|l|l|l|}
\hline \multicolumn{2}{|l|}{ Firmas } & \multirow{2}{*}{ Fecha de Revisión } \\
\hline Responsable de TI & Usuario Responsable de la entidad & \\
\hline & & \\
\hline & & \\
\hline
\end{tabular}




\section{Anexo 2: Formato de Modelo en Excel}

\begin{tabular}{|c|c|c|c|c|c|c|c|c|c|c|c|c|c|c|c|c|}
\hline FECHA & NUIERACION & TURINO & $\begin{array}{l}\text { TPPO DE } \\
\text { SOLCLTUD }\end{array}$ & INSTITUCION & $\begin{array}{c}\text { NOMBRE DEL } \\
\text { TFESPONSABL }\end{array}$ & CAREO & $\begin{array}{l}\text { PORTAL } \\
\text { DE } \\
\text { SOPOR T }\end{array}$ & DESCRPCOON DEL CASO & RESUNEN & TELEFONO & EVAAL & ESTADO DE ATENCION & ASIGNADOA A & ACCOON & $\begin{array}{l}\text { FECHA DE } \\
\text { SOLUCIÓN }\end{array}$ & PAGE CORREO \\
\hline 03022014 & 43 & TARDE & CORREO & Zona Registal NXX-Sedel Cusco & $\begin{array}{l}\text { Vargas Belotia Vadimir } \\
\text { Serguei }\end{array}$ & $\begin{array}{l}\text { Unidadde Tecnologiasde } \\
\text { la hiomacion }\end{array}$ & ERRAP & 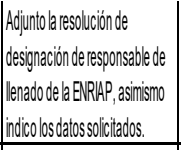 & Acceso & 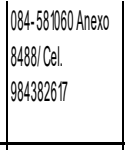 & $\begin{array}{l}\text { Nadiminaragas@esunaprog } \\
\text { ob.pe }\end{array}$ & ATEVDOO & Cecilia Layza & Seleenvioelussuarioyla dave. & 03022014 & \\
\hline 04022014 & 75 & MANIANA & TEEEFONO & Zona Registal NXX-Sedel Cusco & $\begin{array}{l}\text { Varasas Belotal Vadodini } \\
\text { Servuel }\end{array}$ & $\begin{array}{l}\text { Unidadade Tenonogiasse } \\
\text { ahnommacion }\end{array}$ & ENRAP & Solician Nanuadelde suario & Consulta & $\begin{array}{l}\text { O84-581000 Anexo } \\
\text { 8488CCel. } \\
\text { 9843826617 }\end{array}$ & \begin{tabular}{|l} 
vadiminaragas@sunarp.g \\
ob.pe
\end{tabular} & ATEDDDO & Cecilia Layza & Selesenvioellananal & 04022004 & \\
\hline 07022014 & 185 & MANÄANA & CORREO & |Univesidada Nacional Hemilio Vadizan- WWHE/ALL & $\begin{array}{l}\text { Econ.Goria E García } \\
\text { Berri }\end{array}$ & UsuarioAdministrador & $\begin{array}{l}\text { Potalde } \\
\text { Transparenci } \\
a \\
\\
\end{array}$ & 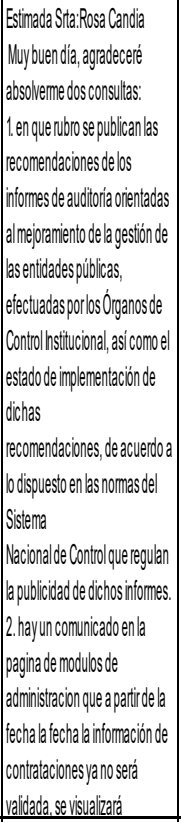 & Consulta & 002-591000/2013 & $\begin{array}{l}\text { transparenci@@unheval. } \\
\text { edu.pe }\end{array}$ & ATENDDO & Rosa Candia & 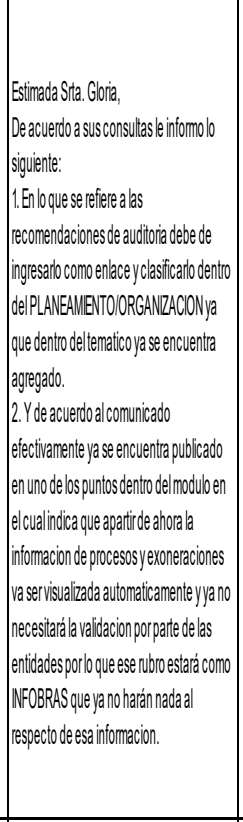 & 07022014 & \\
\hline
\end{tabular}




\section{Anexo 3: Modelo de Catálogo de Servicios}

\begin{tabular}{|c|c|}
\hline Elemento & Descripción \\
\hline Nombre del Servicio & Nombre que identifica al servicio \\
\hline Objetivo & Objetivo al cual apunta este servicio \\
\hline Documento a presentar & $\begin{array}{l}\text { Indica si es necesario algun formato y/o ficha para su solicitud, como por } \\
\text { ejemplo formato de consumo PIDE o formato de publicación del mismo. }\end{array}$ \\
\hline Descripción & Breve descripción del servicio \\
\hline Calificación & $\begin{array}{l}\text { Indicar si las reglas de negocio referente a : Silencio Negativo, Silencio } \\
\text { positivo etc.; indicando los tiempos que son requeridos para el servicio } \\
\text { solicitado (Ley de Silencio administrativo Nro 29060). }\end{array}$ \\
\hline Inicio de Requerimiento & $\begin{array}{l}\text { Se indica dónde comienza el trámite del servicio, por ejemplo si es mesa de } \\
\text { partes, vía web o directamente. }\end{array}$ \\
\hline Unidad que evalúa el requerimiento & Indicar el área responsable. \\
\hline Teléfono de contacto & Número telefónico con anexo o celular de atención. \\
\hline E-mail de contacto & Indicar correo electrónico al cual los usuarios pueden contactarse. \\
\hline Red Social asociada o página web & $\begin{array}{l}\text { Indicar si existe cuenta de Facebook, Twitter o alguna otra red } \\
\text { asociada.También se puede indicar la página web respectiva. }\end{array}$ \\
\hline Horario del Servicio & Indicar el horario de atención. \\
\hline Responsable del servicio & Indicar el o los responsables del servicio. \\
\hline $\begin{array}{l}\text { Prioridad del SLA(Acuerdo de Nivel de } \\
\text { Servicio). }\end{array}$ & Describir los alcances y compromisos con respecto al servicio. \\
\hline $\begin{array}{l}\text { Informe sobre el estado del servicio } \\
\text { solicitado }\end{array}$ & $\begin{array}{l}\text { Indicar la forma de visualizar el estado del servicio solicitado (vía web, } \\
\text { telefónicamente, dirección del local o email). }\end{array}$ \\
\hline Base Legal & Indicar la base legal que respalda al servicio. \\
\hline Versión & Versión del servicio indicado por la nomenclatura v.Nro, ejemplo: v.1 \\
\hline Observaciones & Indicar si existe alguna particularidad o requerimiento adicional. \\
\hline
\end{tabular}


Plataforma de Interoperabilidad del Estado (PIDE).

\begin{tabular}{|c|c|}
\hline Elemento & Descripción \\
\hline Nombre del Servicio & Plataforma de Interoperabilidad del Estado (PIDE). \\
\hline Objetivo & $\begin{array}{l}\text { Publicar y Entregar servicios a las entidades del estado que utilizan } \\
\text { diferentes servicios. Por ejemplo consulta DNI, RUC etc. }\end{array}$ \\
\hline Documento a presentar & 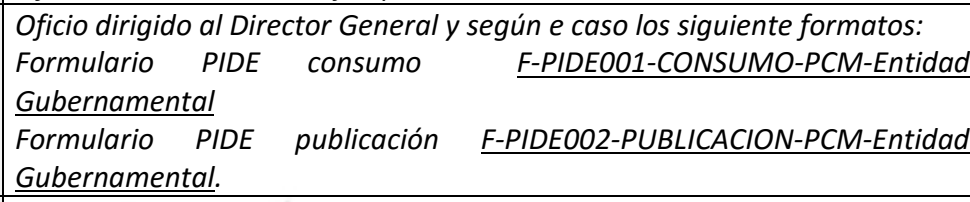 \\
\hline Descripción & $\begin{array}{l}\text { La plataforma PIDE permite el intercambio electrónico de datos entre las } \\
\text { entidades públicas, mejorando su gestión y permitiendo la implementación } \\
\text { intensiva de servicios públicos en línea con alto impacto en los ciudadanos, } \\
\text { al reducir tiempos y costos en su desarrollo, implementación y uso. }\end{array}$ \\
\hline Calificación & $\begin{array}{l}\text { DS } N^{\circ} 083-2011-P C M \text { Articulo } 7 \text { Procedimiento } \\
\text { La Entidad Gubernamental deberá comunicar al entidade solicitante la } \\
\text { recepción del requerimiento en un plazo que no excederá los siete (7) días } \\
\text { hábiles. }\end{array}$ \\
\hline Inicio de Requerimiento & Mesa de partes \\
\hline Unidad que evalúa el requerimiento & Gestión de Proyectos \\
\hline Teléfono de contacto & \begin{tabular}{|l|}
$219-7000$ Anexo $5103 / 5101$ \\
$634-6000$ Anexo $103 / 101$
\end{tabular} \\
\hline E-mail de contacto & pide@pcm.gob.pe \\
\hline Red Social asociada & https://www.facebook.com/GobiernoElectronico \\
\hline Horario del Servicio & Solicitudes de Servicio de Lunes a Viernes de 9 a.m. a 5 p.m. \\
\hline Prioridad del SLA & Detalles se encuetran en el documento SLA-INC-001 \\
\hline $\begin{array}{l}\text { Informe sobre el estado del servicio } \\
\text { solicitado }\end{array}$ & E-mail, Telefonicamente \\
\hline Base Legal & $\begin{array}{l}\text { Resolución Ministerial № 381-2008-PCM } \\
\text { Decreto Supremo № 083-2011-PCM }\end{array}$ \\
\hline Versión & $v .2$ \\
\hline Observaciones & $\begin{array}{l}\text { La entidad solicitante se encargará de desarrollar su propio software para } \\
\text { el consumo. } \\
\text { La entidad debe proporcinar la documentación técnica del software } \\
\text { ( código e indicar particularidades). } \\
\text { Para el caso de mensajeria se tiene que enviar un oficio formal. }\end{array}$ \\
\hline
\end{tabular}




\section{Coordinadora de Emergencias de Redes Teleinformáticas de Perú - PeCERT}

\begin{tabular}{|c|c|}
\hline Ítems & Descripción \\
\hline Nombre del Servicio & Pe-Cert \\
\hline Objetivo & $\begin{array}{l}\text { Tiene como finalidad apoyar en elevar los niveles de seguridad de la } \\
\text { información en el sector público y servir como repositorio de la información } \\
\text { referente a eventos o hechos en los cuales esté involucrada la seguridad en } \\
\text { las redes. }\end{array}$ \\
\hline Documento a presentar & Oficio dirigido al Director General \\
\hline Descripción & $\begin{array}{l}\text { PeCERT es un sistema de coordinación ante incidentes informáticos, a } \\
\text { manera de un CSIRT Nacional (Computer Security Incident Response Team - } \\
\text { Equipo de Respuesta ante Incidentes de Seguridad Computacional), cuya } \\
\text { comunidad objeto es la Administración Pública, y que tiene como finalidad } \\
\text { apoyar en elevar los niveles de seguridad de la información en el sector } \\
\text { público y servir como repositorio de la información referente a eventos o } \\
\text { hechos en los cuales esté involucrada la seguridad en las redes; mediante } \\
\text { la investigación, desarrollo, actualización de la información y difusión. }\end{array}$ \\
\hline Calificación & $\begin{array}{l}\text { La Entidad Gubernamental deberá comunicar al entidad solicitante la } \\
\text { recepción del requerimiento en un plazo que no excederá los siete (7) días } \\
\text { hábiles. }\end{array}$ \\
\hline Inicio de Requerimiento & Mesa de partes o via e-mail : pecert@pcm.gob.pe \\
\hline Unidad que evalúa el requerimiento & Seguridad de la Información \\
\hline Teléfono de contacto & $\begin{array}{l}\text { 219-7000 Anexo } 5116 \\
634-6000 \text { Anexo } 116,111\end{array}$ \\
\hline E-mail de contacto & pecert@pcm.gob.pe \\
\hline Horario del Servicio & Atención de solicitudes de Servicio de Lunes a Viernes de 9 a.m. a 5 p.m. \\
\hline Prioridad del SLA & Detalles se encuetran en el documento SLA-INC-001 \\
\hline $\begin{array}{l}\text { Informe sobre el estado del servicio } \\
\text { solicitado }\end{array}$ & $\begin{array}{l}\text { E-mail } \\
\text { Telefónicamente }\end{array}$ \\
\hline Base Legal & $\begin{array}{l}\text { Norma RM 129-2012-PCM } \\
\text { Implementación incremental de NTP-ISO/IEC 27001:2008 } \\
\text { NTP ISO IEC 27001:2008 EDI Tecnología de Información. Técnicas de } \\
\text { Seguridad. Sistemas de gestión de seguridad de la Información. }\end{array}$ \\
\hline Versión & v.2 \\
\hline Observaciones & $\begin{array}{l}\text { *Para el caso de monitoreo de los sistemas de las entidades es necesario el } \\
\text { pedido formal a traves de un oficio dirigido a nuestras oficinas. } \\
\text { *Para el caso de Ethical Hacking, tienen que enviar la autorizacion } \\
\text { permitiendo los accesos necesarios al oficial de seguridad TI.Este tramite } \\
\text { tiene que venir con el documento firmado por parte del responsable del } \\
\text { área de su entidad } \\
\text { *Actualizar la informacion del jefe de seguridad por parte de la entidad } \\
\text { solicitante. }\end{array}$ \\
\hline
\end{tabular}




\section{Anexo 4: Prioridades para la atención de Incidentes}

\begin{tabular}{|c|c|c|}
\hline Categoría & Subcategoría & Prioridad \\
\hline Accesos & Todos los sistemas & 4 \\
\hline \multirow[t]{2}{*}{ Consulta } & PIDE & 4 \\
\hline & Otros sistemas & 3 \\
\hline \multirow[t]{3}{*}{ Hardware } & Servidores & 1 \\
\hline & Desktop & 2 \\
\hline & Video-Conferencia & 1 \\
\hline 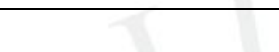 & Anexos & 2 \\
\hline 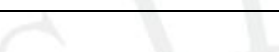 & Seguridad UTM & 1 \\
\hline+2 & Backup & 1 \\
\hline 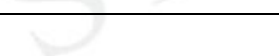 & Redes & 1 \\
\hline \multirow{4}{*}{ Software } & End User Computing & 2 \\
\hline & Sistema Legal & 3 \\
\hline & Escritorio Remoto & 3 \\
\hline & Base de datos & 1 \\
\hline \multirow[t]{5}{*}{ Comunicaciones } & Streaming & 1 \\
\hline & UTM & 1 \\
\hline & Modems & 1 \\
\hline & VPN & 1 \\
\hline & Soporte Portales & 2 \\
\hline \multirow[t]{4}{*}{ Aplicaciones } & Testing SOA WS & 2 \\
\hline & SMS & 3 \\
\hline & Proyectos IDEP & 2 \\
\hline & Legal & 4 \\
\hline
\end{tabular}




\title{
Anexo 5: Formato para la creación Acuerdos de Nivel Operativo
} (OLA)

\begin{tabular}{|l|l|l|}
\hline ID & OLA-INC-001 & Versión v1.0 \\
\hline
\end{tabular}

\begin{abstract}
Servicio a Proveer
Dos sectores internos uno el destinatario del servicio (Sector A) y otro el proveedor del mismo (Sector B). Indicar cuál es el servicio.

Este "Operating Level Agreement" (OLA) describe el servicio de soporte de TI provisto por $\langle$ Sector B $\rangle,\langle$ Servicio a proveer $\rangle$. El principal objetivo de este acuerdo es documentar los servicios a prestar y los procesos asociados al mismo para asegurar que éstos se presten en el tiempo y la forma previstos.
\end{abstract}

\section{Partes}

Describir exhaustivamente los elementos en este acuerdo. Recordar que la omisión de un elemento indica que está excluido del acuerdo:

Las partes afectadas en este acuerdo son

- $\quad<$ Oficina A del $<$ Sector A>>

- $\quad<$ Departamento $X$ del $<$ Sector $A>>$

- $\quad\langle$ Sucursales $K, Y$, y $Z$ del $<$ Sector $A>>$

No terminar la lista con " $y$ otros", "etc." No deje lugar a ambigüedades.

\section{Contexto}

Describir el entorno operativo dentro del cual se desarrollara el <Servicio a prestar > indicar todo lo que sea relevante para definir el ambiente sobre el cual está basado el acuerdo.

\section{Referentes}

Listar las personas o cargos que intervienen en la definición y el establecimiento del acuerdo con todos sus datos

$<$ Sector $A>$

\begin{tabular}{|l|l|}
\hline$\langle$ Nombre $\rangle$ & $\langle$ Nombre $\rangle$ \\
$\langle$ Cargo $\rangle$ & $\langle$ Cargo $\rangle$ \\
$\langle$ E-mail $\rangle$ & $\langle$ E-mail $\rangle$ \\
$\langle$ Teléfono $\rangle$ & $\langle$ Teléfono $\rangle$ \\
\hline
\end{tabular}

$\langle$ Sector $B>$

\begin{tabular}{|l|l|}
\hline $\begin{array}{l}\langle\text { Nombre }> \\
\langle\text { Cargo }>\end{array}$ & $\begin{array}{l}\langle\text { Nombre }> \\
\langle\text { Cargo }>\end{array}$ \\
\hline
\end{tabular}




\begin{tabular}{|c|c|c|}
\hline & $\begin{array}{l}\langle\text { E-mail }\rangle \\
\langle\text { Teléfono }\rangle\end{array}$ & \\
\hline \multicolumn{3}{|l|}{ Vigencia } \\
\hline \multicolumn{3}{|c|}{$\begin{array}{l}\text { Indicar la fecha de inicio y fecha límite del acuerdo y las condiciones para su revisión o } \\
\text { sustitución. }\end{array}$} \\
\hline \multicolumn{3}{|c|}{ Revisiones } \\
\hline \multicolumn{3}{|c|}{ Establecer la frecuencia de revisión y las excepciones que se consideren necesarias. } \\
\hline \multicolumn{3}{|c|}{ Horarios } \\
\hline \multicolumn{3}{|c|}{ Indicar los horarios de cobertura } \\
\hline \multicolumn{3}{|c|}{ Nivel de Servicio } \\
\hline \multicolumn{3}{|c|}{ Indicar los tiempos de respuesta del sector proveedor } \\
\hline \multicolumn{3}{|c|}{ Servicios Soportados } \\
\hline \multicolumn{3}{|c|}{$\begin{array}{l}\text { Especificar todos los servicios comprendidos en el acuerdo, por ejemplo: } \\
\text { Detalle del hardware comprendido. } \\
\text { - } \quad \text { Detalle de los servicios centralizados. } \\
\text { - Servicios del ambiente desktop (por ejemplo instalación, actualizaciones, mudanzas) } \\
\text { La sintaxis del ítem puede ser la siguiente: } \\
\text { El <Sector B> acuerda proveer el <Servicio a proveer }>\text { al <Sector } B>\text { con el siguiente detalle de } \\
\text { actividades y alcances de las mismas } \\
\text { Nota : Incluir el detalle completo de las actividades y sectores usuarios comprendidos }\end{array}$} \\
\hline \multicolumn{3}{|c|}{ Responsabilidades de las partes } \\
\hline \multicolumn{3}{|c|}{ Describir las responsabilidades de cada Sector } \\
\hline \multicolumn{3}{|c|}{ Medición y Reportes } \\
\hline \multicolumn{3}{|c|}{$\begin{array}{l}\text { Detallar la manera en que el servicio va a ser monitoreado, cómo se van a obtener los valores } \\
\text { de los indicadores establecidos, con qué frecuencia, cuál será el método de cálculo para } \\
\text { comparar con la meta establecida, cuál será la herramienta utilizada para dicha medición. }\end{array}$} \\
\hline \multicolumn{3}{|l|}{ Firmas } \\
\hline Sector A & Sector B & \\
\hline
\end{tabular}




\section{Anexo 6: Datos de la encuesta}

\begin{tabular}{|c|c|c|c|c|c|}
\hline Usuario & P. 1 & P. 2 & P. 3 & P. 4 & Mes \\
\hline 1 & 4 & \begin{tabular}{|l}
3 \\
\end{tabular} & 4 & 3 & Marzo \\
\hline 2 & 3 & 4 & 4 & 3 & Marzo \\
\hline 3 & 4 & 3 & 3 & 4 & Marzo \\
\hline 4 & 3 & 4 & 4 & 2 & Marzo \\
\hline 5 & 5 & 4 & 4 & 4 & Marzo \\
\hline 6 & 4 & 4 & 4 & 3 & Marzo \\
\hline 7 & 5 & 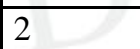 & 2 & 2 & Marzo \\
\hline 8 & 3 & 4 & 4 & 4 & Marzo \\
\hline 9 & 5 & 4 & 4 & 4 & Marzo \\
\hline 10 & 4 & 2 & 2 & 2 & Marzo \\
\hline 11 & 4 & 5 & 5 & 5 & Marzo \\
\hline 12 & 3 & 4 & 4 & 4 & Marzo \\
\hline 13 & 4 & 3 & 4 & 3 & Marzo \\
\hline 14 & 1 & 1 & 1 & 1 & Marzo \\
\hline 15 & 3 & 3 & 4 & 2 & Marzo \\
\hline 16 & 4 & 5 & 5 & 5 & Marzo \\
\hline 17 & 3 & 5 & 5 & 5 & Marzo \\
\hline 18 & 5 & 5 & 5 & 5 & Marzo \\
\hline 19 & 5 & 4 & 4 & 4 & Marzo \\
\hline 20 & 4 & 3 & 3 & 4 & Marzo \\
\hline 21 & 5 & 2 & 2 & 2 & Marzo \\
\hline 22 & 5 & 5 & 5 & 5 & Marzo \\
\hline 23 & 4 & 5 & 5 & 5 & Marzo \\
\hline 24 & 5 & 5 & 5 & 5 & Marzo \\
\hline 25 & 4 & 3 & 3 & 2 & Marzo \\
\hline 26 & 5 & 5 & 5 & 5 & Marzo \\
\hline 27 & 4 & 4 & 4 & 4 & Marzo \\
\hline 28 & 4 & 4 & 4 & 4 & Marzo \\
\hline 29 & 4 & 5 & 5 & 5 & Marzo \\
\hline 30 & 5 & 5 & 5 & 5 & Marzo \\
\hline 31 & 4 & 4 & 4 & 4 & Marzo \\
\hline 32 & 3 & 3 & 3 & 3 & Marzo \\
\hline 33 & 4 & 4 & 4 & 5 & Marzo \\
\hline 34 & 4 & 1 & 1 & 1 & Marzo \\
\hline 35 & 4 & 2 & 2 & 2 & Marzo \\
\hline 36 & 5 & 2 & 2 & 2 & Marzo \\
\hline 37 & 4 & 5 & 5 & 5 & Marzo \\
\hline 38 & 4 & 4 & 4 & 5 & Marzo \\
\hline 39 & 4 & 3 & 3 & 3 & Marzo \\
\hline 40 & 3 & 3 & 3 & 4 & Marzo \\
\hline 41 & 3 & 3 & 3 & 4 & Abril \\
\hline 42 & 4 & 4 & 3 & 4 & Abril \\
\hline 43 & 3 & 3 & 3 & 3 & Abril \\
\hline 44 & 3 & 3 & 3 & 3 & Abril \\
\hline 45 & 2 & 2 & 2 & 2 & Abril \\
\hline 46 & 4 & 5 & 5 & 4 & Abril \\
\hline 47 & 4 & 4 & 5 & 5 & Abril \\
\hline
\end{tabular}




\begin{tabular}{|c|c|c|c|c|c|}
\hline Usuario & P. 1 & P. 2 & P. 3 & P. 4 & Mes \\
\hline 48 & 2 & 2 & 2 & 2 & Abril \\
\hline 49 & 5 & 5 & 5 & 5 & Abril \\
\hline 50 & 4 & 5 & 5 & 5 & Abril \\
\hline 51 & 3 & 3 & 3 & 3 & Abril \\
\hline 52 & 5 & 5 & 5 & 5 & Abril \\
\hline 53 & 4 & 4 & 4 & 4 & Abril \\
\hline 54 & 5 & 5 & 5 & 5 & Abril \\
\hline 55 & 5 & 5 & 5 & 5 & Abril \\
\hline 56 & 5 & 5 & 5 & 5 & Abril \\
\hline 57 & 4 & 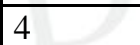 & 3 & 4 & Abril \\
\hline 58 & 4 & 3 & 3 & 4 & Abril \\
\hline 59 & 2 & 2 & 2 & 2 & Abril \\
\hline 60 & 5 & 5 & 5 & 5 & Abril \\
\hline 61 & 5 & 5 & 5 & 5 & Abril \\
\hline 62 & 5 & 3 & 5 & 5 & Abril \\
\hline 63 & 5 & 2 & 2 & 5 & Abril \\
\hline 64 & 3 & 5 & 5 & 5 & Abril \\
\hline 65 & 4 & 4 & 5 & 5 & Abril \\
\hline 66 & 4 & 4 & 4 & 4 & Abril \\
\hline 67 & 3 & 1 & 3 & 2 & Abril \\
\hline 68 & 5 & 5 & 5 & 5 & Abril \\
\hline 69 & 4 & 3 & 4 & 4 & Abril \\
\hline 70 & 3 & 3 & 3 & 3 & Abril \\
\hline 71 & 3 & 3 & 1 & 5 & Abril \\
\hline 72 & 2 & 1 & 2 & 1 & Abril \\
\hline 73 & 2 & 2 & 3 & 2 & Abril \\
\hline 74 & 2 & 2 & 2 & 2 & Abril \\
\hline 75 & 5 & 4 & 4 & 4 & Abril \\
\hline 76 & 5 & 3 & 5 & 5 & Abril \\
\hline 77 & 3 & 4 & 4 & 4 & Abril \\
\hline 78 & 3 & 3 & 3 & 3 & Abril \\
\hline 79 & 4 & 4 & 4 & 3 & Abril \\
\hline 80 & 4 & 3 & 3 & 4 & Abril \\
\hline 81 & 3 & 3 & 3 & 3 & Mayo \\
\hline 82 & 3 & 3 & 3 & 3 & Mayo \\
\hline 83 & 2 & 2 & 2 & 2 & Mayo \\
\hline 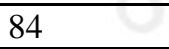 & 5 & 5 & 4 & 5 & Mayo \\
\hline 85 & \begin{tabular}{|l|l|}
5 \\
\end{tabular} & 3 & 2 & 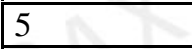 & Mayo \\
\hline 86 & 2 & 2 & 2 & 3 & Mayo \\
\hline 87 & 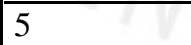 & ( & 5 & 4 & Mayo \\
\hline 88 & 5 & 5 & 5 & 4 & Mayo \\
\hline 89 & 3 & 3 & 3 & 3 & Mayo \\
\hline 90 & 5 & 5 & 5 & 4 & Mayo \\
\hline 91 & 4 & 4 & 4 & 5 & Mayo \\
\hline 92 & 5 & 5 & 5 & 5 & Mayo \\
\hline 93 & 5 & 5 & 5 & 5 & Mayo \\
\hline 94 & 5 & 5 & 5 & 5 & Mayo \\
\hline 95 & 4 & 4 & 3 & 4 & Mayo \\
\hline 96 & 2 & 4 & 3 & 4 & Mayo \\
\hline 97 & 2 & 2 & 2 & 1 & Mayo \\
\hline
\end{tabular}




\begin{tabular}{|l|l|l|l|l|l|}
\hline Usuario & P. & P. 2 & P. 3 & P. 4 & Mes \\
\hline 98 & 5 & 5 & 5 & 5 & Mayo \\
\hline 99 & 5 & 3 & 3 & 3 & Mayo \\
\hline 100 & 5 & 3 & 5 & 3 & Mayo \\
\hline 101 & 4 & 3 & 4 & 2 & Mayo \\
\hline 102 & 5 & 4 & 4 & 4 & Mayo \\
\hline 103 & 3 & 2 & 4 & 3 & Mayo \\
\hline 104 & 4 & 2 & 4 & 2 & Mayo \\
\hline 105 & 4 & 5 & 4 & 5 & Mayo \\
\hline 106 & 5 & 3 & 4 & 2 & Mayo \\
\hline 107 & 3 & 4 & 4 & 4 & Mayo \\
\hline 108 & 3 & 3 & 3 & 4 & Mayo \\
\hline 109 & 4 & 4 & 4 & 3 & Mayo \\
\hline 110 & 3 & 1 & 2 & 1 & Mayo \\
\hline 111 & 2 & 2 & 3 & 3 & Mayo \\
\hline 112 & 2 & 2 & 2 & 2 & Mayo \\
\hline 113 & 5 & 5 & 4 & 3 & Mayo \\
\hline 114 & 5 & 2 & 4 & 4 & Mayo \\
\hline 115 & 3 & 3 & 1 & 5 & Mayo \\
\hline 116 & 2 & 1 & 2 & 1 & Mayo \\
\hline 117 & 2 & 2 & 3 & 2 & Mayo \\
\hline 118 & 2 & 2 & 2 & 2 & Mayo \\
\hline 119 & 5 & 4 & 4 & 4 & Mayo \\
\hline 120 & 3 & 2 & 3 & 3 & Mayo \\
\hline
\end{tabular}

